Portland State University

PDXScholar

\title{
A method for analyzing census data from small populations : developed, tested and applied to a 1958 census of Suba barrio, Paoay, llocos Norte, the Philippines
}

\author{
Stephen Aulick Million
}

Portland State University

Follow this and additional works at: https://pdxscholar.library.pdx.edu/open_access_etds

Part of the Social and Cultural Anthropology Commons, and the South and Southeast Asian Languages and Societies Commons Let us know how access to this document benefits you.

\section{Recommended Citation}

Million, Stephen Aulick, "A method for analyzing census data from small populations : developed, tested and applied to a 1958 census of Suba barrio, Paoay, llocos Norte, the Philippines" (1979). Dissertations and Theses. Paper 2912.

https://doi.org/10.15760/etd.2909

This Thesis is brought to you for free and open access. It has been accepted for inclusion in Dissertations and Theses by an authorized administrator of PDXScholar. Please contact us if we can make this document more accessible: pdxscholar@pdx.edu. 
AN ABSTRACT OF THE THESIS OF Stephen Aulick Million for the Master of Arts in Anthropology, presented August 13, 1974.

Title: A Method for Analyzing Census Data from Smal1 Populations: Developed, Tested and Applied to a 1958 Census of Suba Barrio, Paoay, Ilocos Norte, The Philippines

APPROVED BY MEMBERS OF THE THESIS COMMITTEE:
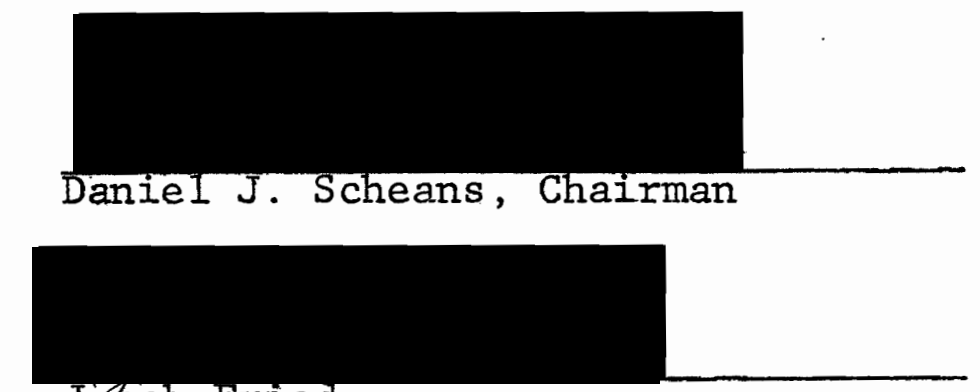

Jakob Fried

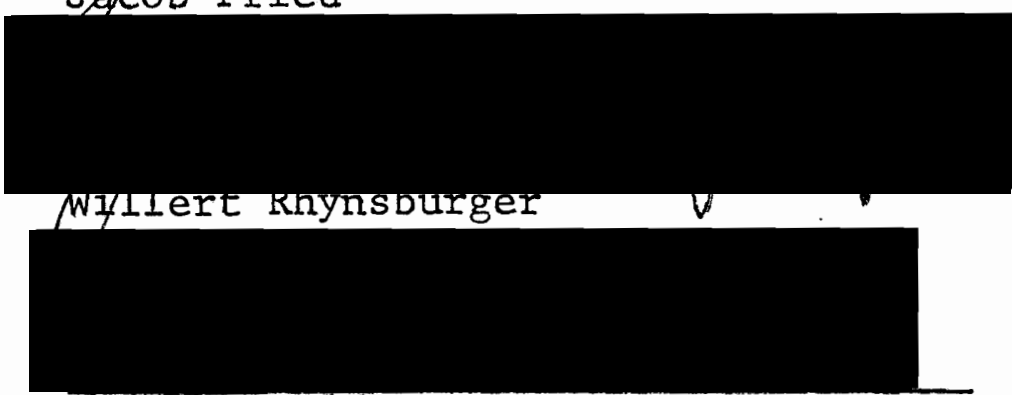

Marc R. Feldesman

As part of his anthropological fieldwork, in January 1958 Daniel J. Scheans took a census of Suba, an Ilokano barrio in Paoay, Ilocos Norte, the Philippines. The purpose of the thesis was. to use the Suban data to develop, describe and test a method for analyzing census data for 
smal1 populations (1000 or fewer persons).

The method was to be complete, to generate as much information as possible based on the data collected, to expose weaknesses and gaps in the data collected and in the data collection procedures, to aid future census-takers in structuring the content of and procedures for taking a census, to be computerized for speed and ease of analysis and adjustment, and to furnish data sufficiently free from methodological variations to allow meaningful comparisions of different populations.

The method developed appears to fulfill these purposes, in part illustrated by certain unexpected findings concerning the Suban population of 511. The barrio had an exceptionally high sex ratio, in a province with the second lowest sex ratio in the country. In keeping with provincial trends, Suba had much lower fertility than in the nation as a whole. The method supported an inference that the pattern of migration in and out of Suba may be changing. The involvement of Suban households in multiple economic avenues, highlighting the general economic strategy of diversification, was also revealed. The analysis also confirmed Scheans' impression that for the most part Subans did not give accurate economic information.

Based on this test of the method and the substantive findings concerning Suba, it is recommended that (a) standard census-taking procedures and forms for small 
populations be developed, (b) a center with a trained staff familiar with the method, computer programming and censustaking in small populations be established, (c) a new census of Suba be taken to refine the method and to correct errors in the analysis of the Suban population, and (d) further social, economic and geographic studies of Suba and its population be undertaken. 
A METHOD FOR ANALYZING CENSUS DATA FROM SMALL POPULATIONS: DEVELOPED, TESTED AND APPLIED TO A 1958 CENSUS OF SUBA BARRIO, PAOAY, ILOCOS NORTE

THE PHILIPPINES

by

STEPHEN AULICK MILIION

A thesis submitted in partial fulfillment of the requirements for the degree of

MASTER OF ARTS

ANTHROPOLOGY

Portland State University

1979 
TO THE OFFICE OF GRADUATE STUDIES AND RESEARCH:

The members of the Committee approve the thesis of Stephen Aulick Million presented August 13, 1974.

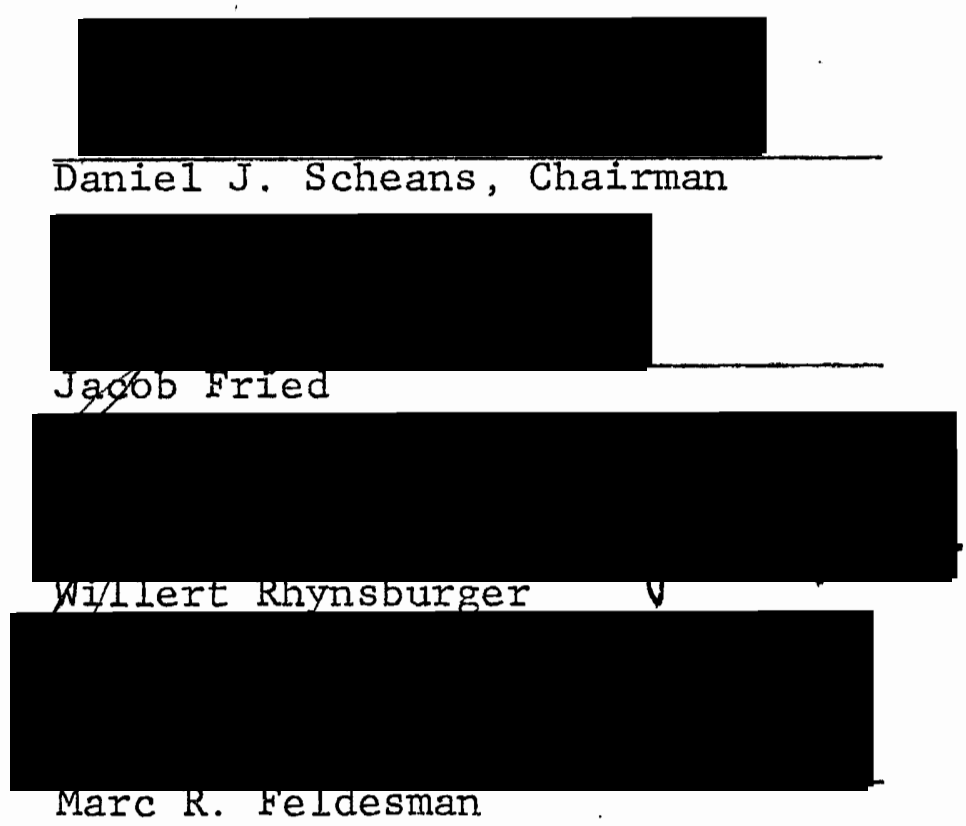

APPROVED:

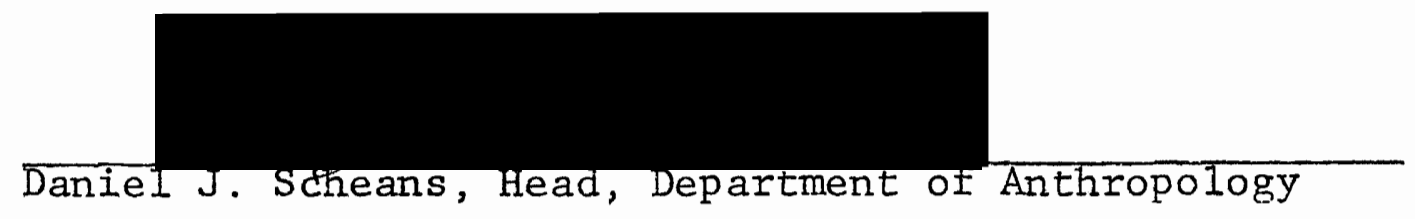

Stanley E. Rauch, Dean of Graduate Studies and Research 
TABLE OF CONTENTS

PAGE

LIST OF TABLES . . . . . . . . . . . . . . . . . . . V V

LIST OF FIGURES . . . . . . . . . . . . . . . . . . $\mathrm{x}$

CHAPTER

I. INTRODUCTION . . . . . . . . . . . . . . . . 1

II METHODS AND PROCEDURE . . . . . . . . . 5

The Suban Data . . . . . . . . . 5

Collection of Census Data

Format of Census Data

Coding the Census Data . . . . . . . 7

Development of Codes

Explanation of Codes

Adjusting the Coding System

Computer Programming . . . . . . . . . 19

General Features and Format

Common Variables

The Programs

Adjusting the Computer Programs

III SUBSTANTIVE EINDINGS . . . . . . . . . . 37

Population Structure . . . . . . . . 37

Age and Sex Distribution

Religion

Sitio Residence

Vital Statistics and Marriage Data . . 45

Fertility

Mortality

Marriage 
CHAPTER

PAGE

Migration .. . . . . . . . . . . 62

Immigration

Emigration

Household and Economic Data . . . . . 78

Economic Strategies Within Suba

IV EVALUATION AND CONCLUSION . . . . . . . . . . 113

Census-Taking . . . . . . . . . . . . . 113

Computer Analysis . . . . . . . . . 115

The Suba Pattern . . . . . . . . 116

Recommendations . . . . . . . . . 121

SOURCES CONSULTED . . . . . . . . . . . . . . . . . 125

APPENDIX A FORM OF CENSUS DATA SHEETS . . . . . . . 133

APPENDIX B CODING SYSTEM FOR CENSUS DATA CARDS • • 136

APPENDIX C INFORMATION CODED FOR INDIVIDUALS . . . 149

APPENDIX D INFORMATION CODED FOR HOUSEHOLDS . . . . 163 
LIST OF TABLES

TABLE

PAGE

I Average Value in Pesos of Animals Owned by Suban Households .... . . . .

II Estimates of the Yearly Rice Consumption Requirements of a Family of Five in Cavans of Palay . . . . .

III Scale Used to Determine the Reliability of Economic Information Given by Suban Households . . . . . . . .

IV Population Profile Program Output and Computer Variables . . . . . . . .

V Marriage and Fertility Program Output and Computer Variables for Living Residents . . . . . . . . . 28

VI Marriage and Fertility Program Output and Computer Variables for Dead Spouses of Househeads . . . . . .

VII Mortality Program Output and Computer Variables . . . . . . . . . .

VIII Workplace Mobility Program Output and Computer Variables . . . . . . .

IX Occupations Program Output and Computer Variables . . . . . . . . . . 
X Migration Program Output and Computer Variables . . . . . . . . .

XI Households and Economic Strategies

Program Output and Computer

Variables . . . . . . . . . 34

XII Sex Ratio and Age Distribution of the

Suba Population, January 1958 . . .

XIII Total Number of Children per Ever-

Married Female by Age of Females.

XIV Number of Living Children per Ever-

Married Female by Age of Females.

XV Age at First Birth by Age Group of Females . . . . . . . . . .

XVI Age at Most Recent Birth by Age Group of Females . . . . . . . . . . . . 49

XVII Causes of Death by Age Died . . . . . 54

XVIII Gauses: of. Death by Sex and Age at Death

XIX Estimated Age-Specific Death Rates in

Suba . . . . . . . . . . . . 56

XX Marital Status of Suba Residents . . . 59

XXI Marital Status by Sex... . . . . . 60

XXII Place of Origin of Spouses at Marriage

by Sitio . . . . . . . . . . 61

-XXIII Status of Persons at Time of Immigra-

tion to Suba . . . . . . . . . . 
XXIV Status of Persons at Time of Immigration to Suba by Sex... . . . . . 64

XXV Piace of Origin of Suba Residents . . . 66

XXVI Place of Origin of Suba Residents by

Sex... . . . . . . . . . .

XXVII Past and Present Location of Outside

Employment by Age and Sex . . . . 70

XXVIII Permanency of Separation and Location

of Suban Emigrants . . . . . . . 73

XXIX Permanency of Separation and Location

of Suban Emigrants by Sex . . . . . 74

XXX Occupations of Emigrants from Suba . . 76

XXXI Occupations of Emigrants from Suba by

Sex . . . . . . . . . . . 77

XXXII Size Distribution of Suba Households . 80

XXXIII Family Structure of Suba Households . . 80

XXXIV House Size and Construction in Suba . . 81

XXXV House Ownership Among Suba Households . 83

XXXVI Landholding Status of Households by

$$
\text { Sitio... . . . . . . . . . } 85
$$

XXXVII Household Distribution of Value of

Landholdings in Pesos . . . . . .

XXXVIII Number of Fields Owned by Suban Households... . . . . . . . . . 
XXXIX Distribution of the Number of Animals

Owned by Suban Households . . . . .

XI Distribution of Value in Pesos of

Animals Owned by Suban Households .

XII Animal Tenancy Among Suban Households.

XLII Household Distribution of the Value of

Fishing Gear Owned in Pesos . . . .

XLIII Household Distribution of Income from

Fishing in Pesos per Month . . . . 94

XIIV Mobility of the Suban Labor Force . . .

XIV Jobs Held by Members of the 1958 Suban

Labor Force by Place of Work and Age . . . . . . . . . . . .

XLVI Jobs Held by Male Members of the Suban

Labor Force by Place of Work and $\because$ Age . . . . . . . . . . . .

XIVII Jobs Held by Female Members of the Suban

Labor Force by Place of Work and Age . . . . . . . . . . . . . 101

XLVIII Diversity of Economic Activity Among

Suban Households . . . . . . . . . 104

XIIX Rice Income per Year in Cavans of Palay for Suban Households . . . . . . 106

L Amount of Income Derived from Barter by Suban Households . . . . . . . 106 
LI Monetary Income in Pesos per Month for Suban Households . . . . . . . . 107

LII Economic Strategies of Suban Households 110

LIII Reliability of Economic Information for Suban Households . . . . . . . 110 


\section{LIST OF FIGURES}

FIGURE

PAGE

1. Population pyramid for Suba, 1958 . . . . 38 


\section{CHAPTER I}

\section{INTRODUCTION}

The primary purpose of this thesis is to develop a method for analyzing census data from small populations. ${ }^{1}$ The method is tested by using census data from Suba, an Ilokano barrio of Paoay, Ilocos Norte, the Philippines. The secondary purpose of this thesis is to present the results of an analysis of the suban data. The results include a demographic profile of Suba, an interpretation of household economic strategies and suggestions for additional useful data. I also make an attempt to compare the results of the analysis of the Suban data to information available on the Philippine population as a whole.

Daniel J. Scheans took the census of Suba in January, 1958, by household survey using a translator-field assistant. Scheans was new to the Suban area; the major part of his professional training had been in non-demographically oriented areas of sociology and anthropology. For these reasons he did not collect all. of the information on the Suban population which an analyst would want. For example, the dates of events such as births, marriages and deaths

$1_{\mathrm{A}}$ small population is tentatively defined as one with fewer than 1000 persons. The method can be expanded to accommodate larger populations, however. 
were not collected, although with accurate age estimates for living Subans, the year of birth could be derived. In some respects this thesis represents an attempt to salvage the Suban census, i.e., to learn as much as possible from the information which was actually collected. This information includes the age, sex, marital status, religion and occupation of individuals and the size, composition, income and economic resources of households.

A method for analyzing census data from small populations is useful for several reasons. The method becomes a guide to the kind of information a field worker should collect. If the field worker so desires, he can code the data while in the field. If preliminary results can be conveyed to the researcher while he is still in the field, he has an opportunity to direct further investigations suggested by these results. The method can illuminate the completeness and accuracy of the data. For example, the results of the analysis of the Suban census confirmed Scheans' impression that the information on household incomes and resources is not very reliable. The method also directs the field worker's attention to areas in which knowledge of the population is deficient, as well as highlighting relevant information about the population. ${ }^{2}$ The method facilitates

2 Relevant is used in the sense that the information forms the basis for useful ethnographic, economic or demographic insights into the structure of the population. 
comparisons among populations by eliminating variations in the results of census analysis which the use of different methods might induce. Although the method presented in this thesis is primarily suited to analyzing populations similar in economic structure to the Suban population, the method can be adapted to suit the emphasis which the field worker desires. These purposes demonstrate the necessity for, and utility of, a useful and thorough census method. The analysis of the Suban data shows the extent to which the method presented fulfills these purposes.

The utility of a method can be judged in three ways. The method should reflect the reliability and completeness of the raw data. The method should enable the researcher to analyze the data as thoroughly, accurately and completely as possible. Finally, the method should support the most detailed comparisons among populations which the different sets of data can justify.

Standard demographic analysis underlies the method proposed in this thesis (Barclay 1958; Weiss 1973). I assume that demographic analysis provides a meaningful framework for analyzing a population. I also assume that census-taking and demographic analysis can reveal information of real or potential ethnographic significance. The ethnographic theory which underlies this thesis is Eggan's (1954) theory and method of controlled comparison. This theory rests on the assumption that limiting the scope of an 
investigation demonstrates more clearly the nature and extent of the differences and similarities between the things being compared. The proposed method allows the scope of the investigation to be varied. Here, it is limited to demographic and economic analysis. The researcher may limit it further to populations of roughly equal size or ones dependent on similar economic activities. The method may be limited to the same population over a period of time. These limitations on the scope of the inquiry should reveal information and provide conclusions which a broader scope would not reveal or could not justify.

This thesis is presented in three basic parts. Chapter II discusses the method developed for this thesis. It explains how the data were recorded on census sheets and how they were coded onto computer cards. The remainder of the Chapter explains the computer programs, and it illustrates how these programs can be adapted for analyzing other populations. Chapter III presents and discusses the results of the analysis of the Suban census. In Chapter III, I also analyze the "reliability of economic information."3 In Chapter IV I interpret and judge the method developed. The appendices present a sample census data sheet, the master sheet for coding the data and a copy of the coded data.

3 Reliability is basically intended to measure how truthful informants were when they provided economic information. 
CHAPTER II

METHODS AND PROCEDURE

I. THE SUBAN DATA

Collection of Census Data

Using a translator-field assistant Scheans interviewed informants from each household in Suba. For some households Scheans obtained extensive information, including a list of all household possessions. Nevertheless, I focused the analysis on information generally available from all households. Scheans collected the relevant demographic data on each of the individual members of the Suban population; however, he did not record the dates of marriages, births or deaths. This omission makes it more difficult to estimate the rates of change or occurrence of these events. It also makes the estimates more speculative.

It is Scheans' impression (personal communication) that the data are accurate, with the exception of the information on household economics. Despite some apparent age errors, I assume the data are accurate. Scheans did not attempt to crosscheck the information he obtained to confirm his impression of its accuracy. No records were available to do this, and Scheans had other interests he wished to pursue in the limited time he was engaged in field work in 
Suba.

Format of Census Data

I obtained the census data in the form of a loose-leaf notebook containing census data sheets. The data from each household were summarized on a two-page form, a sample of which is included as Appendix A. The data were presented in a standardized format, facilitating coding onto computer cards.

Any method changes the format in which information is presented. Often, the method presented here merely accumulates information and summarizes it in a table. For example the size of each household was recorded, and all of this information was collected and is presented in a table showing the distribution of household sizes. Output which involved any arithmetical computation is often based on estimates. It must be viewed with caution based on an awareness of the computation procedures and an awareness of the accuracy, completeness and quantity of the information on which it is based. For example, estimates of the birth rate are based on the number of children born during a defined period to a defined group of females. The estimates require knowledge of when and how many living and deceased children the defined females bore. It assumes that the group of females is accurately defined and known. Incomplete or inaccurate information in any of these areas produces some error in the birth rate estimate. I do not discuss the actual computa- 
tions when the output variables are standard demographic measures, since I assume a familiarity with these measures. Otherwise, I discuss the computations involved. This discussion gives the reader an idea of the kinds of errors in the raw data which affect the accuracy of the variable, and it emphasizes the changes which the raw data undergo in the process of reaching the results as presented.

\section{CODING THE CENSUS DATA}

Development of Codes

I devised a series of codes based on the data available from the census data sheets. There had been an attempt in 1965 to code the data, but that code was largely discarded. Each code category deals with a specific piece of information. Alternative responses to each specific piece of information were assigned a number. For some of the categories the alternatives were readily apparent. For example, every person in Suba lives in one of four sitios, or hamlets, each of which was assigned a different number. I assigned each category a specific place on the field of a computer card. The proper number was recorded in the appropriate place on IBM FORTRAN coding sheets for each individual. Once I had coded information on approximately one-third of the individuals and households, I revised the coding system. Two codes were eliminated; one was added. I revised the scales for assigning numbers to the alternatives for several 
of the economic codes, $\underline{i . e .}$, ones dealing with fishing, animals, land and income. I added alternatives to many of the other codes. At this point I recoded the information on the previously coded individuals and households using the new coding system. The final code system is included as Appendix B. Then I completed the task of coding information onto the coding sheets for the remainder of the individuals and households .

At this point I spent several hours in the computer center punching the numerically coded data onto computer cards. A computer program was written ${ }^{1}$ which yielded a printout of the information on the cards to enable me to check the accuracy of the coding. Once the errors were eliminated, the pack of data cards was duplicated with the assistance of another computer program. Appendix $C$ is a printout of the coded information on individuals, which includes information coded. in columns one through fifty-two: Appendix $D$ is a printout of columns fifty-three through seventy-seven, information about each household.

\section{Explanation of Codes}

Most of the codes are self-explanatory; nevertheless, several of them require some comment. The substantive meaning of many code categories is explained in the next chapter

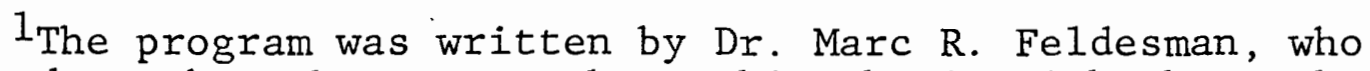
assisted me throughout my work on this thesis with the problems I had with the computer. 
where the results are presented. I gave each household (columns 1 and 2) and each individual (columns 3, 4 and 5) a code number, although these numbers are never used in the computer analysis. However, they aided me in coding the data and provided considerable assistance in sorting or analyzing the cards by hand. For larger populations, where five columns would be insufficient to record both and household and individual numbers, it is recommended that only an individual code number is used.

Year Born. Only three columns (12, 13 and 14) are used to code the year born, since adding the fourth column would be repetitious. Even after the year 2000, only three columns will be needed until census data cover a 1000-year span. The computer can be instructed to distinguish between the individuals born in the respective milleniums.

Whereabouts. The code for column 19 was solely designed to indicate whether the individual was in Suba at the time of the census. Residency is reflected in column 45 .

Migration. The alternatives for the category of when new Subans immigrated is coded in column 23 as follows. A "O" is assigned to anyone who was a child when he immigrated, invariably with his family. Young adults move into Suba for a variety of reasons. Frequently, the purpose is to marry a Suban. These people are assigned "2". Young immigrants who enter for other reasons are assigned "1". Adults who immigrate with their families are assigned "3". Older persons 
whose children and spouse have died sometimes emigrate to join relatives in another barrio. Those entering Suba for this reason are assigned "4".

Fertility. The information coded in columns 28 through 34 pertains only to females who have attained child-bearing age. There is no category for the total number of children a female has borne. One category records the number of living children (column 28) with "0" assigned to all women with ten or more living children. There is an identical category to record the number of deceased children (column 29). A1though large families are not uncommon, only one female had over nine living children. She had eleven. ${ }^{2}$

Status in House. It is desirable to have some means of distinguishing among the members of a household by their relationship to one another and to the household: The category in column 45 attempts to achieve this purpose. The househead and the resident members of his family are coded "0". If one of these persons was absent at the time of the census, although normally a resident of the household, he is coded "1". Members of the household who are not relatives of the househead are coded "2". Codes "3" and "4" concern deceased members of the household, "3" for a deceased spouse of the househead and "4" for a deceased child of a female in the household. Codes "5" and "6" apply to relatives who are

2 Household "45", individual "288" on p. 155 of Appendix C. 
not members of the household. If the relative is expected to contribute to the household income, he is assigned " 5 ". Most of these people can be expected to return to the household eventually. Alternative, "6" codes emigrated children of female members of the household.

Family Size and Type. The total number of persons living in the household is only coded in column 47. "A "0" designates a household of ten or more members. Four households are coded "0". Two had ten members each, and the other two had eleven members each. This information is only coded on the card of the househead.

The category for domestic family type is unnecessarily complex (columns 48 and 49). A "0" codes a nuclear family. These families often have relatives, or occasionally nonrelatives, living with them. Codes "01" through "08" distinguish among the relationships of the additional individual(s) to the family. Codes. "14" through "19"' indicate at least two extra persons living with. the nuclear family. The two types of joint families are coded by "09" and "10". The remaining households, represented by "11" through "13", are headed by an unmarried person. As for household size, family type is only coded on the card of the househead.

Tenancy. A Suban household's relationship to the land can be quite complex. A household can work its own land, work land as tenants and/or be landlords (column 53). Ones which are not involved in any of these activities are coded 
"0". Households which own and tenant land are coded "I", while those which only tenant are coded "3", and those which only work their own land are coded "7". Households which work some of their own land and are landlords for the rest are coded "4", while if the household is only a landlord, the code is "5". Households which work land to which they have an ownership claim, e.g., an expected inheritance, but to which they do not yet have full claim are "part owners," code " 6 ". Households which tenant land and are landlords for other land are coded "2".

Fishing. If a household which owned fishing gear attempted to make any income from fishing, it is coded "2" in column 56. Owning some gear, code "1", implies that the household fishes for home consumption only. Both the monthly income from fishing and the value of the gear are recorded on the census data sheets for only a few households (columns 57, 582. From the households for which both are known, I determined that the value of the fishing gear a household owns is roughly five times the expected monthly income. Since most households which fish for income indicated either the value of their gear or their monthly income, the other figure could be derived easily.

Animals. Frequently a household informant would give the animal holdings without assigning any particular value to each animal or to the entire group. Several households did assign values to the various animals they owned. There 
were enough of these households to provide the basis for developing estimates of the average value of each kind of animal which are shown in Table $I$.

\section{TABLE I.}

AVERAGE VALUE IN PESOS OF ANIMALS OWNED BY SUBAN HOUSEHOLDS

Anima1

Nuang (carabao or water buffalo)

Bul1

Cow

Calf

Baca (Cattle)

$\mathrm{Bul1}$

Cow

Calf

Baboy (Pig)

Adult

Young

Calding (Goat)

Manok (Chicken)

Adult

Chicks (5)

Aso (Dog)
Value

\250

150

75

200

100

50

30

10

15

2

1

4

Animal tenancy is common in Suba (column 69). The tenant household which raises the animal may own most of the 
animals it raises (code "l"), or it may raise more animals for others than it owns for itself (code "2"). Similarly, the owners of the animals may let other people raise most of the animals they own, code "4", or they may raise most of the animals themselves, code "3".

Economic Indices. The diversity of economic activity is the number of kinds of animals, trees and crops a household raises (columns 71,72 ). Income in the numbers of cavans (columns 73,74 ) is the reported or estimated yearly rice income in cavans of palay. 3

Reliability of Economic Information. The "reliability of economic information" is a category which I developed to measure the accuracy of the economic data. Scheans questions the accuracy of this data, especially as it relates to landholdings and rice income. To measure accuracy, the total yearly income of the household is compared to the yearly income neçessary to survive at minimum subsistence levels. The reported income and the necessary minimum income have to be to the same scale if they are to be compared. The scale used is rice consumption in cavans of palay per person per year.

Several authorities have estimated the necessary minimum income in unhusked rice for a family of five for one year. Some of these estimates appear in Table II.

${ }^{3} \mathrm{~A}$ cavan of palay, or unhusked rice, is 75 liters and weighs about 100 pounds. 
TABLE II

ESTIMATES OF THE YEARLY RICE CONSUMPTION REQUIREMENTS

OF A FAMILY OF FIVE IN CAVANS OF PALAY

Source.

Hanks (1972)

Lava (1938)

$$
\begin{aligned}
& \text { text at page } 61 \\
& \text { text at page } 74
\end{aligned}
$$

Nydegger and Nydegger (1966)

Scheans (1965)

Takahashi (1970)
Estimate

18.5 cavans

15

30

33

19

24

It is apparent from the Table that Lava contradicts his own estimates. Fortünately, "he also provides consumption figures for twelve families of five in Ilocos Norte and Ilocos Sur for periods ranging from forty-five to "sixty-one days. Lava's figures indicate that a family of three" adults and EWo children with a diet

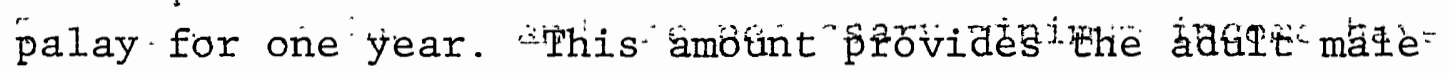
worker with 1400 calories a day. The caloriè consumption figure includes aIl other food sources. The figure of 6.9 cavans is much lower than all of the estimates in Table II. Since the calories provided by this level of consumption are so low, I assume that the consumption figures are from families living at minimum subsistence levels. Lava confirms this impression. Adjusting slightly for other food sources, I assume that a family of five requires a total income 
equivalent of 7.5 cavans of palay per year to survive at minimum subsistence levels, or 1.5 cavans of palay per person per year.

Income in Suba comes in four basic forms: rice, other foods, money and barter. Since: barter rarely provides food for the household, it is ignored for the purposes of determining reported income. Since rice income is reported in cavans of palay per year, no conversion is necessary.

Monetary income is converted to a scale of rice income by determining how much rice the money could buy. The Philippines Free Press indicated in February, 1958 that a ganta ${ }^{4}$ of husked rice was selling for between $\not 11.20$ and $\not 1.60$ in Manila. The paper said that the price was probably higher in the provinces. Using the city prices, a cavan of husked rice cost between $\$ 30$ and $\$ 50$. Since it takes just over two cavans of palay to produce one cavan of husked rice, a cavan of palay would cost between $\not 15$ and $\not 25$. I used an intermediate figure of $\$ 20$ for a cavan of palay to convert monetary income into rice income. Multiplying the reported monthly monetary income by twelve and dividing by twenty yields an estimate for the number of cavans of palay the household could have purchased outside of the barrio during one year. Dividing by the number of persons in the household yields a monetary income equivalent in cavans of palay per person per cavan.

${ }^{4} \mathrm{~A}$ ganta is three liters, or one twenty-fifth of a 
year. This figure is added to the reported rice income. The most important diet supplement in Suba is camotes, or sweet potatoes. The poorer households eat them regularly. I guessed that each field of camotes a household reported is equivalent to 0.2 cavans of palay per person per year. This figure should be supplanted by one based on accurate data: Since many households raise camotes solely for their animals the additional income equivalent may artificially raise their reported income. Also, since camotes are very cheap (Scheans reports a bucket of them cost $\$ 0.50$ in 1958.), poorer families may buy them in lieu of rice. They are also purchased for animals.

The total income in palay, money and camotes is compared with a scale based on minimum subsistence income to determine the reliability of economic information. The scale is presented in Table III.

\section{TABLE IIT}

SCALE USED TO DETERMINE THE RELIABILITY OF ECONOMIC INFORMATION GIVEN BY SUBAN HOUSEHOLDS

Assessmt. of Reliability Indicated Consumptn. Code No. Unreliable $0.0-0.4$ cavans per person 0
per year

Relatively Unreliable

$0.5-0.9$

Relatively Reliable

$1.0-1.4$

Reliable

$1.5+$

Unknown 
The scale is very generous when it is compared to the minimum subsistence income of 1.5 cavans of palay per person per year. Theoretically, any household reporting less than this amount could not avoid starvation.

\section{Adjusting the Coding System}

It might be useful to split the information on individuals and households onto separate computer data cards. I coded economic information on the card of the househead. If the economic data are coded on a separate card, the code indicating that an individual is a househead should be retained on the individual data cards if the household code in columns 1 and 2 is eliminated. Retention of this code would allow the computer to be programmed to count the number of households. However, as the categories of information are increased, additional data cards would become necessary in any event.

Several additional categories might be desirable and useful. The method can accommodate any category which can have its alternatives numerically coded. Some additional categories of information which would be desirable include information on education and literacy, age at marriage, age and reasion for emigration and immigration, political affiliations, native language and ability to speak other languages, personal physical and genetic traits and important social statuses, e.g., possession of special knowledge or powers or membership in clans or lineages. 
Other information which is not as amenable to coding might also be useful to a demographic analyst. Such information includes the knowledge and use of birth control methods, size of the breeding unit (area from which spouses are drawn), altitude, size of the village, a map of the village, size and yield of the fields, second cropping, irrigation, absentee ownership and household data such as energy sources, water supply, toilet facilities and health care resources. These suggestions are not exhaustive, but they will hopefully stimulate the census-taker and guide him to the kinds of information which he should collect.

\section{COMPUTER PROGRAMMING}

\section{General Features and Format}

The following discussion is intended to give the careful reader with a knowledge of FORTRAN IV the information necessary to adapt the computer programs to his own. needs. It is not intended to give the reader a working familiarity with FORTRAN IV. Any demographer or field worker who wishes to use the programs must take the time to learn FORTRAN IV or engage the help of someone with knowledge of FOR'RAir. Since the programs are basically simple in design and operation, an extensive computer background is not necessary. However, if the field worker does not have access to a computer with a FORTRAN compiler identical to the one used by me, the programs 
will have to be adapted for use on the computer to which the worker has access. The adaptations will probably require the assistance of an experienced programmer.

The core of the method is a series of seven computer programs written in FORTRAN IV and originally designed for use on the IBM 1130 computer. Due to changes in computers at Portland State University, updated programs are unavailable for publication with this thesis. I wrote each program on FORTRAN coding sheets and then punched it onto computer cards. Each program was first compiled without data cards to find any errors. Once the program was debugged, I submitted it to the computer operator along with the first fourteen data cards to see if the computer program yielded the information as desired. Any errors were eliminated. At this point each computer program was ready. for submission with the complete set of data cards.

The general format is the same for all of the programs. The computer is given the dimension of all of the major variables. This process tells the computer how much storage space to reserve for a particular variable. For all but the last program analyzing household data, age brackets are needed in the printout. For that reason, for all of the other programs, a single card containing the following information is placed at the top of the data pack: $0-45-910-1415-1920-2425-2930-3435-3940-4445-4950-5455-5960-$ 6465-6970-7475 +. After the variables are dimensioned, the 
computer reads this card and stores the values for use in the printout.

Since a computer must be told what the value of a variable is before it can manipulate it properly, the next step in the programs is to have the computer read the initial value of each variable as zero. On the IBM 1130 a final preliminary step of the programs had been to have the computer read the categories which the program uses off of the data cards and to store those values on a disk. However, disk storage has been eliminated in subsequent revisions.

The actual operation of a program consists of telling the computer which variable or variables to read while summing the appropriate totals. For example, if the number of resident married females is desired, the computer is instructed to look at residents only, then see if they are females, and, if so, whether they are married or not. If the resident female is married, the computer adds one to the relevant variable and proceeds to read the data from the next card. After information from all of the cards is read, the computer has the desired total. This figure can then be used for computations, such as determining the percentage of resident females who are married.

The third basic part of each program sets up the format of the printout. All of the output is presented in tables which are labeled. The computer is told what the labels are. If the output is by age group, the format for 
output of the totals for the population is also stored in the computer.

A computer access card is necessary, the format for which the computer operator must tell whoever is having the programs run. A job card is also necessary, but this was provided by the computer center at Portland State. The program is followed by an // XEQ card, the age data card where appropriate, and the pack of data cards.

Common Variables

IARRA $(X)$, IARRA $(I, X)$. The variable IARRA is the one used to read information off of the data cards. The number of variables the program uses is " $\mathrm{X}$ ". The number of data cards is "I".

AGE(32). The variable which reads the age data card is AGE(32). The cards which accomplish this task look like the following.

\footnotetext{
$\operatorname{READ}(2,1)(\operatorname{AGE}(\mathrm{J}), \mathrm{J}=1,32)$

1 FORMAT (2(A2,A1), 13(A3,A2), 2A2).
}

The AGE(32) variable is given in " $\mathrm{A}$ " or alphanumeric format so that the computer will print the variable exactly as it is given to the computer. These variables are not used in computations. Since alphanumeric variables can be a maximum of four digits (A4), the age brackets are each broken into two parts. This severance also allows computer manipulation of the. age brackets so that fewer than sixteen may be used, such as in the marriage and fertility program where only six 
age groups are used in some tables. The first program uses the variable IAGE(32) rather than AGE(32).

DATA Cards. With a data card information is stored as a constant between two slashes. Alphanumeric constants are coded within apostrophies. I used two data cards when they proved necessary.

DATA M/' '
DATA MM/,

The first card assigns the variable $M$ the alphanumeric value of a blank. The second card gives MM the value of a double blank. The purpose of these DATA cards is to provide a means for distinguishing between blanks and zeros on the coded data cards. The computer will read a blank as zero unless it is instructed otherwise. When reading the data the computer is told to reread the relevant variables as alphanumeric ones. During the course of the program, the alphanumeric value of the variable is compared to either $M$ or $M$ M. If they are not the same, the computer knows that the space is not blank and it reads the integer variable for use in the program.

\section{The Programs}

Population Profile Program. This program is the first one I wrote. The information is printed out all at once after compilation for all age groups rather than as compiled for each age group. In the other programs, where the data are printed out by age group, the computer is instructed to add the totals for the group to the population totals before 
beginning again with the next age group, so that information for each age group is not stored. Since this program retains all of this information, it uses more storage space. The program yields totals for several separate categories of information. These categories could be separated into separate programs at the researcher's convenience. Although not all of the separately coded categories are utilized in this program, the format card for this program reads all forty-seven of the coded pieces of information. The other programs only read the categories which are actually needed for that program. This program requires the use of an age data card preceding the actual census data cards.

The information which the program yields and the computer variables used to compute this information are listed in Table IV.

It would be possible to convert marital status to a two-dimensional array, such as the ones for sitio residence and religion. The variable could be $M S(X, W)$ where $W$ is two times the number of possible marital statuses coded in column 26. Alternatively, two arrays could be used, one for each sex, such as $\operatorname{MSM}(X, V)$ and $\operatorname{MSF}(X, V)$, where $V$ is the number of possible marital statuses in column 26 . With either kind of array system, appropriate markers for the total number of males and females of each marital status would be needed, such as those used for Table IV for sitio 
POPULATION PROFILE PROGRAM OUTPUT

AND COMPUTER VARIABLES

\begin{tabular}{|c|c|c|c|}
\hline Variable: & By Age Group* & Total & \\
\hline Number of persons & $\operatorname{NUMB}(X)$ & NUMBT & \\
\hline Number in each sitio & $\operatorname{NSITE}(X, Y)$ & $\begin{array}{l}\text { NSITL, } \\
\text { NSITS, }\end{array}$ & $\begin{array}{l}\text { NSITT } \\
\text { NSITC }\end{array}$ \\
\hline $\begin{array}{l}\text { Number adhering to } \\
\text { each religion }\end{array}$ & $\operatorname{NREL}(\mathrm{X}, \mathrm{Z})$ & $\begin{array}{l}\text { NRLAG, } \\
\text { NRLCA, } \\
\text { NRLNE }\end{array}$ & $\begin{array}{l}\text { NRLPR } \\
\text { NRLOT }\end{array}$ \\
\hline Number of Males & $\mathrm{NM}(\mathrm{X})$ & NMT & \\
\hline Number of Females & $N F(X)$ & NFT & \\
\hline Sex Ratio & $\operatorname{SEXRA}(X)$ & SEXR & \\
\hline Males in Home & $\operatorname{NMIN}(\mathrm{X})$ & NINM & \\
\hline Females in Home & $\operatorname{NFIN}(X)$ & NINF & \\
\hline Males out of Home & $\operatorname{NMOUT}(\mathrm{X})$ & NOUTM & \\
\hline Females out of Home & $\operatorname{NFOUT}(X)$ & NOUTF & \\
\hline Total in Home & & IN & \\
\hline Total out of Home & & OUT & \\
\hline Percent of all Males & $\operatorname{PCM}(X)$ & & \\
\hline Percent of all Females & $\operatorname{PCF}(X)$ & & \\
\hline Percent of Population & $\mathrm{PC}(\mathrm{X})$ & & \\
\hline Dependency Ratio & & $\mathrm{DR}$ & \\
\hline \multicolumn{4}{|l|}{ Marital Status: } \\
\hline $\begin{array}{l}\text { Single Males } \\
\text { Married Males } \\
\text { Widowers } \\
\text { Divorced Males } \\
\text { Unknown Males }\end{array}$ & $\begin{array}{l}\operatorname{NSM}(X) \\
\operatorname{NMM}(X) \\
\operatorname{NWM}(X) \\
\operatorname{NDM}(X) \\
\operatorname{NNM}(X)\end{array}$ & $\begin{array}{l}\text { NMS } \\
\text { MM } \\
\text { NMW } \\
\text { NMD } \\
\text { MUN }\end{array}$ & \\
\hline
\end{tabular}


TABLE IV

(Continued)

Output Variable: By Age Group* Total

Marital Status:

$\begin{array}{lll}\text { Single Females } & \text { NSF (X) } & \text { NFS } \\ \text { Married Females } & \ddots \text { NMF (X) } & \text { NFM } \\ \text { Widows } & \text { NWF (X) } & \text { NFW } \\ \text { Divorced Females } & \text { NDF (X) } & \text { NFD } \\ \text { Unknown Females } & \text { NNF (X) } & \text { NUNF }\end{array}$

$* X$ is the number of age groups. $Y$ is the number of alternatives in column 16 . $Z$ is the number of alternatives in column 11 .

residence and religion. Alternatively, the numbers could be totaled by using an array variable, e.g., MST(W).

Marriage and Fertility Program. The output of marriage and fertility data breaks into three separate parts, with the output for each part completed before the computer begins the next part. Within each part the data for each age group is calculated and printed and the total is added to the appropriate variable before the computer proceeds to the next age group. The totals for the age group are not separately stored.

The first part of the output basically presents the total number of children and the number of living children which each female in Suba has borne. The second part concerns age at first and latest child, generation time, and the number of times a person has been married. The third part presents results analogous to the second part for deceased females and males who were spouses of persons 
classified as a househead in 1958. For the second and third parts the output is generated in age groups of fifteen years rather than the five-year breakdown which otherwise appears in the programs.

The information which this program yields and the variables used to compute this information are listed in Tables $\mathrm{V}$ and VI.

Mortality Program. There was very little information available on deceased Subans, so the mortality program was written with the knowledge that it would not yield very complete or accurate information. The output comes from three loops of the program -- one for all deceased Subans, one for males, and one for females. The information which this program yields and the variables used to compute this information are listed in Table VII.

In order to adapt this program for a different census, certain adjustments to the program are necessary to reflect the year in which the census was taken. These adjustments are discussed at the end of this chapter.

Workplace Mobility. This program is designed to compile information regarding the Suban workers who were temporarily out of Suba at the time of the census, who leave the barrio seasonally to find work elsewhere, or who have emigrated. The program does not compile information with.respect to the jobs held by these individuals; the following program provides that data. This program is very 
MARRIAGE AND FERTILITY PROGRAM OUTPUT AND COMPUTER VARIABLES FOR: LIVING RESIDENTS

Output Variable: By Age Group*

Total*

Distribution of Females by:

Number of Living Children

Total Number of Children Borne

Age at First Child

Age at Most Recent Child

Number of Females

Number of Children

(By Age Group of Mother)

Number of Females with Children

Number of Twin Births

Percentage of Twin Births

Number of Females 15-49

Number of Children Under 5

Total Population

Fertility Ratio

Birth Rate

Average Number of:

Children Borne per Female 15 or over

Living Children per Female 15 or over

Deceased Children per. Female 15 or over
KNO (Y)

KTN (W)

$\operatorname{KAGF}(\mathrm{Z})$

$\operatorname{KAGL}(Z)$

$\operatorname{NAGE}(\mathrm{X})$

$\mathrm{KNC}$

$\mathrm{KN}(\mathrm{Y})$

$\mathrm{KT}(\mathrm{W})$

NAG

NKT

ITOTL

NTW

TWINS

NG

NU5

NTN

FR

BR

AVKPF

AVLK

AVDK

Number of Times Married:

All Females (Living and Dead)

All Males (Living and Dead)

Average for all Females

Average for all Males

Estimate of Generation Time
NT

$\mathrm{MT}$

TM

TMM

GEN 


\section{TABLE V}

(continued)

$* X$ is the number of age groups. $Y$ is the number of alternatives for column $28 . \mathrm{W}$ is the number of alternatives for column 28 plus those for column 29. $Z$ is the number of age groups used for data on the childbearing of females.

\section{TABLE VI}

MARRIAGE AND FERTILITY PROGRAM OUTPUT AND COMPUTER VARIABLES FOR DEAD SPOUSES OF HOUSEHEADS

Output

Number of Females

Number of Males

Data for Females:

Number of Living Children

Average Number of Living Children

Total Number of Children Borne

Average Total Number of Children Borne

Age at First Child

Average Age at First Child

Age at Last Child

Average Age at Last Child

Average Number of Times Married:

Males

Females

Percentage of Twin Births

Generation Time

${ }^{*} \mathrm{~T}$ is the number of age groups used for data on deceased persons.
$\mathrm{KL}$

$\mathrm{AL}$

$\mathrm{KZ}$

AK

NAF

$\mathrm{AF}$

NAL

AL

$\mathrm{TM}$

TN

TWRT

GT
Total

NDAG

MAG 
TABLE VII

MORTALITY PROGRAM OUTPUT

AND COMPUTER VARIABLES

\section{Output}

Cause of Death

Number Born Within a 5-Year Span

Number in NAGE(X) Who Have Died

Percentage of NAGE(X) Now Dead

Age at Death

Year of Death

Death Rate:

\author{
Variable:

\section{By} \\ Age \\ $\operatorname{NCOD}(\mathrm{X}, \mathrm{Y})$
}

Grout

Total* $\operatorname{NOS}(\mathrm{Y})$

$\operatorname{NAGE}(X)$

NAG

$\mathrm{NCOH}(\mathrm{X})$

$\mathrm{NCH}$

$\operatorname{PCD}(\mathrm{X})$

$\operatorname{IYR}(X, Z)$

NYR (Z)

IY

$\begin{array}{lll}\text { Over Past } 5 \text { Years } & \text { DR }(X) & \text { DRT } \\ \text { Five to } 10 \text { Years Ago } & \text { DRE (X) } & \text { DRTE }\end{array}$

$* X$ is the number of age groups. $Y$ is the number of alternatives for columns 40 and $41 . \quad Z$ is the number of cohorts for which death rate estimates are being computed.

simple in operation and design and need not be utilized for a population where an insignificant number of members work outside of the census area. The information which the workplace mobility program yields and the variables used to compute this information are listed in Table VIII.

Occupations. The fifth program compiles the information on the occupations which Subans pursue. Originally, the program was designed so that it had to be run six times with substitution of a few cards each time to produce the new data required. To minimize the possibilities of error, the need for substitution was eliminated and the program is 
TABLE VIII

WORKPLACE MOBILITY PROGRAM OUTPUT

AND COMPUTER VARIABLES

Output

Number of Workers

Location of Work
Variable:
Total*

NAG

INI, IOUT, ISOUT

Place of Work in Past:

Males Currently in Suba

Females Currently in Suba

Place of Work if Out of Suba:

Males

Females
$\operatorname{NWHRP}(X, W)$

$\operatorname{MWHRP}(X, W)$
$\operatorname{NTRR}(W)$

$\operatorname{MTRP}(W)$

$* X$ is the number of age groups. $Y$ is the number of alternatives for colum 20. $Z$ is the number of alternatives for column 21. $W$ is the number of alternatives for column 22. (ivote that $W=Z+1$.)

modified to yield information on the jobs held by Subans in and out of the barrio and analyzed by sex. The coding of the cards makes it possible for the census taker to list two occupations for any given individual, and the output of the program reflects this ability. The information provided by this program and the variables used to compute this information are listed in Table IX.

Migration. The migration program compiles information with respect to emigration and immigration. Like the previous program, this program was originally designed to run several times (three), requiring the substitution of cards. The program now requires no substitution. Basically 
TABLE IX

OCCUPATIONS PROGRAM OUTPUT AND

COMPUTER VARIABLES

Output

Variable: By Age Group* Total*

Number of Persons:

ITAGE $(X)$

Persons with one Occupation

NAG

Persons with two Occupations

Number Engaged in an Occupation

$\operatorname{JOBS}(\mathrm{Y})$

JBT $(Y)$

$* X$ is the number of age groups. $Y$ is the number of alternatives for columns 50 and 51 .

the program concerns the origin and time of entering Suba for immigrants, and the occupation, location, and permanence of separation from Suba for emigrants. The information compiled by the migration program and the variables used to compute this information are listed in Table X. Households and Economic Strategies. The final program compiles information with respect to the family structure of households and the economic activities of these households. This program does not require an age data card. The program basically tallies the number of households under each alternative of code and the output simply prints the totals. For this reason Table XI does not show the dimension of the variables as do the previous tables. For every variable except the number of fields owned (columns 63-64) and the number of animals owned (columns 67-68) the dimension of the variable is simply the number of alternatives which can be coded in the corresponding 
TABLE $\mathrm{X}$

MIGRATION PROGRAM OUTPUT AND COMPUTER VARIABLES

Output

iNumber of Persons

Origin of Immigrants

Time of Immigration

Number of Persons not in Suba

Number Engaged in an Occupation

while out of Suba

Location of Emigrants
Variable: By Age Group* Total*

$\operatorname{MAGE}(\mathrm{X})$

NORIG $(Z)$

$\operatorname{NORT}\left(Z_{1}\right)$

$\operatorname{INBEC}(W)$

$\operatorname{NBT}(W)$

$\operatorname{JAGE}(X)$

$\operatorname{JOBS}(\mathrm{Y})$

JBT $(Y)$

NTHR (T)
$\operatorname{NWT}(\mathrm{T})$

$* X$ is the number of age groups. $Y$ is the number of alternatives for columns 24 and $25 . \quad Z$ is the number of alternatives for columns 17 and $18 . \mathrm{W}$ is the number of alternatives for column 23. $T$ is the number of alternatives for column 21 .

column or columns. Most output tables use the code number for the alternatives rather than using separate labels. A few tables show the information using the scale taken from the code alternatives or one programmed into the computer; it is obvious from the printout when these scales are used. The information provided by this program and the variables used to compute this information are listed in Table XI.

\section{Adjusting the Computer Programs}

In order to adapt the programs for use on information from another population certain changes are required, and others will be desirable. Each of the programs must be changed to reflect the number of individuals for whom the 


\section{TABLE XI}

HOUSEHOLDS AND ECONOMIC STRATEGIES PROGRAM

OUTPUT AND COMPUTER VARIABLES

Output

Number of Households

Number of People

Sizes of Househdids

Family Types

Tenancy

House Structures

Ownership of Fishing Gear

Fishing Income

Fishing Lot Membership

Investment in Land

Claim to House

Number of Fields Uwned

Investment in Animals

Number of Animals Owned

Animal Tenancy

Diversity of Economic Activity

Income in Cavans of Palay

Income from Barter

Monetary Income

Reliability of Information

Household Strategies
Variable Average

NCNT

INTOT

INT

AIN

IFAMT

JTEN

JHSTR

KFSG

KFSI

LOTM

LNDI

LNHSN

LNDFD

NANVL

NAN

NANTC

MDIV

$A D$

NCAV

AC

MBAPT

MONIN

NRLAB

AR

NSTRT

AS 
census-taker has information. Wherever the number "667" (the number of Subans on whom I had coded information) appears in cards such as DO J=1, 667, the 667 must be replaced with the number of cards in the researcher's census. Similarly, in the mortality program wherever the number "958" appears, the year of the census, omitting the first digit, should be substituted. Wherever the number "957" appears in that program the last three digits of the year before the census should be substituted. For example, for a census taken in 1978 the former number should be "978" and the latter, "977".

If any adjustments in the age groups are desired, the AGE or IAGE variable must be changed and the age data card changed. Generally, unless the researcher has special requirements for a more extensive breakdown, the five-year age groups now programmed, with the highest group 75 or over, should be sufficient.

If the researcher wishes to add or delete alternatives to the existing codes he may do so provided the cards dimensioning the variables accomodate the number of alternatives desired and provided the programs are changed to reflect a greater or lesser number of alternatives in the analysis. If the additional alternatives require the use of an extra column on the data cards, the format statement reading the variables will have to be altered to reflect 
the change in the coding system.

If additional variables are required or useful, the researcher will have to go through all of the processes described earlier in this chapter in developing a code, coding the cards, and developing a program to read and analyze the code.

Finally, to obtain the output in its most readable and comprehensible format, the WRITE statements must be changed to reflect the actual residence areas, religions, economic activity, etc., of the population being analyzed. If the spacing of the labels is changed, the corresponding format statements for writing the variables must be changed to reflect the new spacing.

If the researcher expands several codes and adds new ones he may find it more convenient to code information about individuals on one card and information about households and economics on a separate card. Then the cards used for the final program would be the only ones used for that program and they would be used for no other program. This procedure would require changes in all of the format statements reading information off of the data cards. However, unless the program is used for a population very similar in its economic structure to Suba, the program will essentially have to be rewritten anyway. 
CHAPTER III

SUBSTANTIVE FINDINGS

I. POPULATION STRUCTURE

Age and Sex Distribution

Figure one presents a profile of the Suba population as of January 1958. Table XII presents a numerical summary of the same data. There were 504 Suba residents present at the time of the census. An additional seven persons listed as Suba residents were absent during the census period. This figure corrects the erroneous figure of 446 given by Scheans (1963).

The two most important demographic measures used in the analysis of the age and sex structure of a population are the sex ratio and the dependency ratio. The sex ratio (males per 100 females) in the Philippines is 106, an unusally high figure since males have higher mortality in younger ages than females (Concepcion 1966b; Lorimer 1966): Lorimer (1966) has said this may indicate an unusually high sex ratio at birth for Filipinos. In fact, the indicated sex ratio at birth is so high that the reported national sex ratio is probably more likely due to a systematic bias of some kind (e.g. migration) than to an abnormally high. sex ratio at birth. Hunt et al. (1963), in commenting on 
AGE

$75+$

$70-74$

$65-69$

$60-64$

55-59

$50-54$

45-49

$40-44$

$35-39$

$30-34$

$25-29$

$20-24$

15-19

$10-14$

5-9

$0-4$

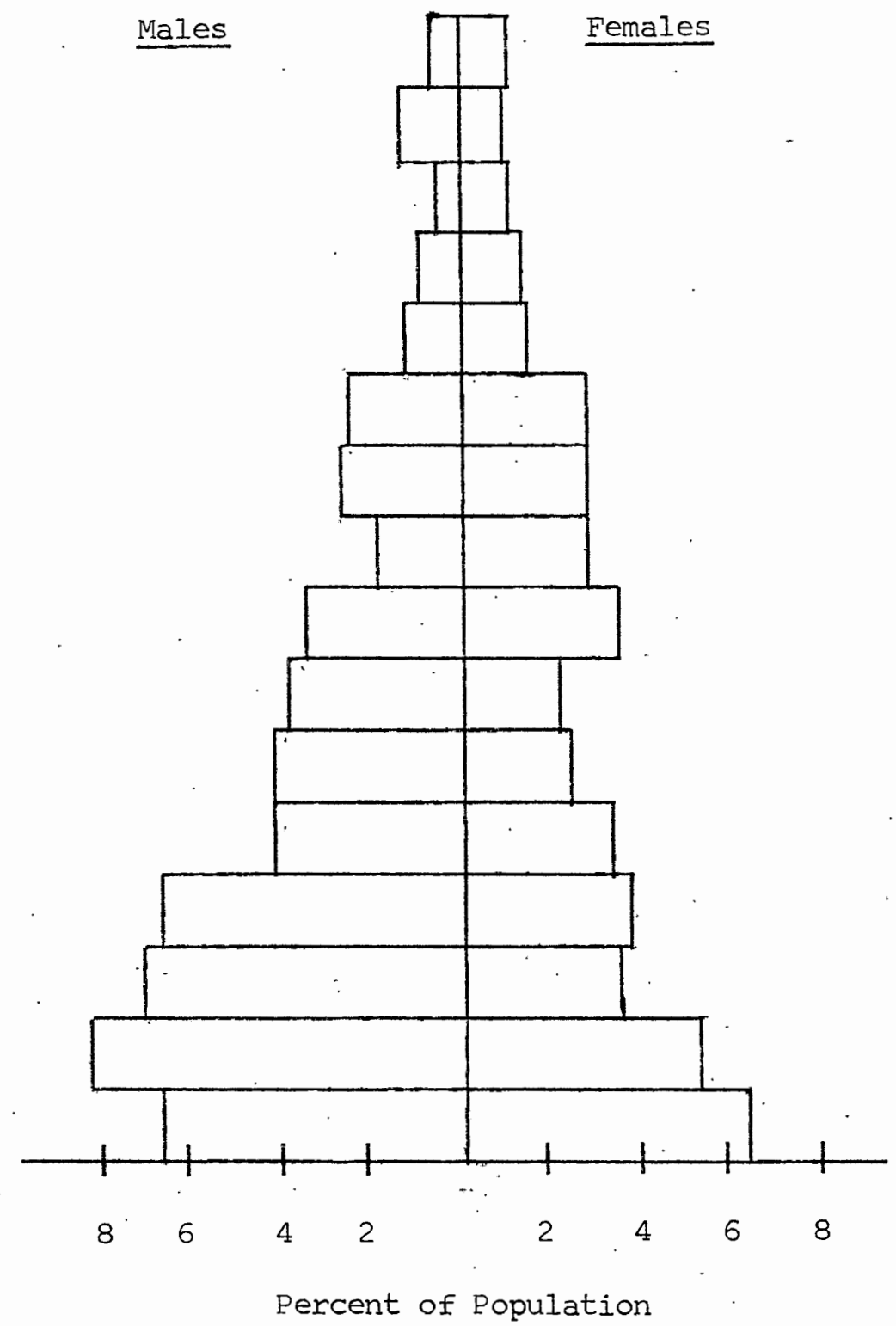

Figure 1. Population pyramid for Suba, 1958 
TABLE XII

SEX RATIO AND AGE DISTRIBUTION OF THE SUBA POPULATION, JANUARY 19.58

Age Group

\begin{tabular}{|c|c|c|c|c|c|}
\hline & & & & & \\
\hline $0-4$ & 65 & 12.72 & 32 & 33 & 96.96 \\
\hline $5-9$ & 70 & 13.69 & 41 & 29 & 141.37 \\
\hline $10-14$ & 54 & 10.56 & 35 & 19 & 184.21 \\
\hline $15-19$ & 52 & 10.17 & 32 & 20 & 160.00 \\
\hline $20-24$ & 38 & 7.43. & 20 & 18 & 111.11 \\
\hline $25-29$ & 32 & 6.26 & 20 & 12 & 166.66 \\
\hline $30-34$ & 30 & 5.87 & 19 & 11 & 172.72 \\
\hline $35-39$ & 35 & 6.84 & 17 & 18 & 94.44 \\
\hline $40-44$ & 25 & 4.89 & 10 & .15 & 66.66 \\
\hline $45-49$ & 28 & 5.47 & 13 & 15 & 86.66 \\
\hline $50-54$ & 27 & 5.28 & 12 & 15 & 80.00 \\
\hline $55-59$ & 16 & 3.13 & 7 & 9 & 77.77 \\
\hline $60-64$ & 11 & 2.15 & 4 & 7 & 57.14 \\
\hline $65-69$ & 8 & 1.56 & 2 & 6 & 33.33 \\
\hline $70-74$ & 11 & 2.15 & 6 & 5 & 120.00 \\
\hline $75+$ & 9 & 1.76 & 3 & 6 & 50.00 \\
\hline TOTALS & 511 & 100.0 & $\underline{273}$ & 238 & 114.7. \\
\hline
\end{tabular}


the provincial variations in sex ratios note that Ilocos Sur and Ilocos Norte have the two lowest sex ratios for persons ten years of age or older, 90.1 and 91,8 , respectively. Thus, these provinces run counter to national trends.

Suba itself shows the bias of the national trends, but to an even greater extent. The overall sex ratio of 114.7 can be partly explained by a greater outmigration of females from Suba, but this factor only accounts for differences among those 15 to 24 years old. Among 25, to 34. year olds another factor is a greater number of Suban females moving out of the barrio to marry and live than move into Suba to marry male residents of the barrio.

The greatest mystery of the Suba population is the cause of the wide preponderance of males over females in the 5 to 14 age range. Any forces which affect this age group, other than mortality which should tend to increase the proportion of females, should be relatively free from sexual biases except of a statistical nature. It is possible that the wide disparity is due to chance since the total number of people under 15 is below 200.

The 1960 sex ratio in the municipality of Paoay is in line with the provincial bias (Philippine Bureau of the Census 1961). The 1960 Suba population (552) shows a sex ratio of 116.5 , a continuation of the previous bias. This is the highest sex ratio found in any barrio in Paoay. 
The sex ratio of Paoay in 1970 was 88.3, while the 1970 Suba population of 338 males and 315 females had a sex ratio of 107.3 (Philippine National Census and Statistics Office .1974).

Suba is only one of three barrios in Paoay in 1960 to have a sex ratio above 100, and one of four in 1970 .

One possible explanation for the high sex ratio in Suba among those in the labor force (15 to 64 age group) might be that the Suban area, which fronts on Paoay lake (the largest body of freshwater in the Northern Philippines) offers males economic opportunities and incentives to remain, so that fewer of them migrate out relative to municipal and provincial trends. Suba and Sungadan; both near the lake, were the only two barrios to have sex ratios over 100 in both 1960 and 1970. A third barrio in the 1970 census was also near the lake. The other two barrios with high sex. ratios (one in 1960 and one in 1970) may be unique situations; one grew very slowly from 1960 to 1970 and the other barrio substantially declined in population over the same period.

The dependency ratio is a measure of the relationship of the number of people between the ages of 15 and 64 to those not in that age range. Persons 15 to 64 years of age are assumed to be the labor force, i.e. those actively contributing to the local economy, while the other persons are assumed to be economically non-productive, i.e. depen- 
dent. A dependency ratio of 100 means that the productive and non-productive portions of the population are equivalent. A lesser figure suggests a relatively smaller number of dependents, whereas a higher figure implies more dependents.

The Suban dependency ratio of 73.8 accords well with the Paoay figure of 71.7 and the Ilocos Norte ratio of 83.0 (Philippines, Bureau of the Census and Statistics 1961). These figures are al1 significantly lower than the national ratio of 93.8 (Concepcion 1966b), suggesting that the Suban, Paoay, and provincial populations are older than the Philippine population. This conclusion is indicated by the facts that the former have a lower percentage of persons under 15, a higher percentage of persons 65 or over, a lower dependency ratio, and a higher median age (22) than the Philippine population as a whole (17.1) (Philippines, Department of Commerce and Industry 1966).

Another important indicator of the growth potential of a population is the percentage of persons under 15 . A survey conducted in 1957 revealed that 45.6 percent of the Philippine population was under 15. The figure for Suba is 37 percent, which is probably representative of the Paoay and Ilocos Norte populations. A lower birth rate and/or higher death rate are indicated for the Ilocos area.

Weiss has noted (1973) that the quality of census 
data often varies and is subject to influences beyond the census-taker's control or comprehension. Exrors in the ages reported by Subans exemplify Weiss' observation. Digit preferences are striking, although these preferences are not fully apparent in figure one (page 38) due to the use of five-year age groups. There is a slight tendency to give an age in the "fertile" years (1.5-50), except for persons who are clearly old. These older persons probably tend to overestimate their real age, often because they have no idea what their real age is and since old age is associated with higher status in the community. Also, parents with children under five often report their child's age as five or over. This reporting bias may have influenced the age-specific sex ratios if males under five were more often reported to be five or over than were females. A low number of individuals in specific age groups may be due to such factors as seasonal employment. The census of Suba was taken at a time when some young persons (especially males) would be harvesting rice in other areas of the Philippines. Nevertheless, most of the irregularities in the sizes of the age groups in the Suba population can be explained by digit preferences and by the two world wars.

\section{$\underline{\text { Religion }}$}

Ilocos Norte is one of the six regions in the Philip- 
pines where the Philippine Independent Church or Aglipayan religion is strong (Wernstedt and Spencer 1967). The majority of people in Ilocos Norte, Paoay and Suba are of this faith, an offshoot of Catholicism started in 1902 by a Filipino priest, Gregorio Aglipay. This religion is stronger in Suba than in Paoay or Ilocos Norte as a whole, with 402 Suban adherents. In addition, there were 86 Catholics, the religion of the overwhelming majority of Filipinos. There were also six persons of another religion, and 17 persons for whom no religion was known.

\section{Sitio Residence}

There vere four sitios or hamlets in Suba, three of approximately equal size and a fourth about one-third that size. The smallest sitio is Libtong with 48 people. Tacnir has 137 persons. Eastern sitio, which is composed mainly of tenants, has 172 people. Central sitio has 1.54 persons. Sitios are primarily social groups, unlike the barrio which is primarily a political unit. Even though the barrio is the smallest political unit in the Philippines it often seems to lack any distinguishing social features (Romani 1965): There are differences among the sitios in terms of the economic activities that residents pursue, but none of these seem particularly significant except for:tenancy, as discussed later. 
II. VITAL STATISTICS AND MARRIAGE DATA

Fertility

A 1956 survey showed that the average Filipina between the ages of 45 and 54 who had ever been married had borne 7.22 children. As in most other countries, the number of children decreased when the mother had moṛe formal education, but the decrease was not as substantial as in some Western countries. Females with some high. school education had 5.60 children, while those with some college education had 4.13. Lower fertility for Suba than for the Philippines is indicated by Tables XIII and XIV. The average number of children per ever-married female over 44 in Suba was 5.24, considerably below the Philippine figure. Of these children, an average 3.78 were alive, with 1.46 dead. The average number of children per female over 14 was 3.09 , with 2.52. alive and 0.56 dead. of all the births for which data was available 0.64 percent were twin births, although the meagre data base does not provide a firm basis for establishing a twin rate.

The Suban data are consistent with the subsequent finding of other researchers of lower fertility in rural Luzon and the Ilocos area than for the rest of the Philippines (Flieger and Koppin 1973; Madigan and Avenceña 1964). Lorimer. (1966) has reported the results of the Philippine Statistical Survey of Households (PSSH) for 1958 as to the 


\section{TABLE XIII}

TOTAL NUMBER OF CHILDREN PER

EVER-MARRIED FEMALE BY AGE OF FEMALES

\begin{tabular}{|c|c|c|c|c|c|c|c|c|c|c|c|c|c|c|}
\hline Age & & $\mathrm{mb} \in$ & ro & & ema & les & & & & nil & Iren & & & Total \\
\hline$X=$ & 0 & & & 3 & & & & 7 & & & & 11 & .13 & \\
\hline $15-19$ & 1 & & 1 & & & & & & & & & & & 2 \\
\hline $20-24$ & 3 & 4 & 5 & 2 & 1 & & 1 & & & & & & & 16 \\
\hline $25-29$ & & 2 & 5 & 1 & & 1 & 1 & & & & & & & 10 \\
\hline $30-34$ & 1 & 1 & & 1 & 2 & 3 & 1 & 1 & & & & & & 10 \\
\hline $35-39$ & & & 4 & 5 & 1 & 4 & & & & & & & 1 & 15 \\
\hline $40-44$ & & & 1 & 1 & 2 & 3 & & 1 & & 1 & 2 & & & 11 \\
\hline $45-49$ & 2 & 1 & 1 & & & & 1. & 2 & 1 & 1 & 1 & 1 & & 11 \\
\hline $50-54$ & & 2 & 1 & 3 & & 1 & & 2 & 2 & & & & & 11 \\
\hline $55-59$ & & & & 1 & & & 1 & 2 & & & & & & \\
\hline $60-64$ & & & & 1 & 2 & . & & & 2 & & 1 & & & \\
\hline $65+$ & 5 & & 1 & & 1 & & 2 & 1 & 1 & 1 & 4 & & & 16 \\
\hline Totals & 12 & 10 & 19 & 15. & 9 & 12 & 7 & 9 & 6 & 3 & 8 & 1 & 1 & 112 \\
\hline
\end{tabular}




\section{TABLE XIV}

\section{NUMBER OF LIVING CHILDREN PER}

\section{EVER-MARRIED FEMALE BY}

AGE OF FEMALES

\begin{tabular}{|c|c|c|c|c|c|c|c|c|c|c|c|c|c|}
\hline \multirow{2}{*}{ Age } & \multirow{2}{*}{$X=$} & \multicolumn{3}{|c|}{ Number } & \multicolumn{3}{|c|}{ f Females } & \multicolumn{2}{|c|}{ with } & \multicolumn{3}{|c|}{$X$ Children } & \multirow[t]{2}{*}{ Total } \\
\hline & & 0 & 1 & 2 & 3 & 4 & 5 & 6 & 7 & 8 & 9 & 10 & \\
\hline $15-19$ & & 1 & 1 & & & & & & & & & & 2 \\
\hline $20-24$ & & 5 & 3 & 4 & 2 & 1 & & 1 & & & & & 16 \\
\hline $25-29$ & & 2. & 1 & 4 & 1 & & 2 & & & & & & 10 \\
\hline $30-34$ & & 1 & 1 & & 1 & 3 & 3 & & 1 & & & & 10 \\
\hline $35-39$ & & 1 & 1 & 3 & 5 & 2 & 3 & & & & & & 15 \\
\hline $40-44$ & & & & 1 & 1 & 6 & & 3 & & & & & 11 \\
\hline $45-49$ & & 2 & 2 & & & & 1 & 2 & 1 & 2 & & 1 & 11 \\
\hline $50-54$ & & & 2 & 3 & 1 & & 3 & 1 & 1 & & & & 11 \\
\hline $55-59$ & & & & & 1 & 1 & 1 & 1 & & & & & 4 \\
\hline $60-64$ & & & & 2 & 2 & 1 & & & 1 & & 1 & & 6 \\
\hline $65+$ & & 5 & & 2 & & & 2 & 1 & 2 & 3 & 1 & & 16 \\
\hline Totals & & 17 & 11 & 19 & 14 & 14. & 15 & 9 & 6 & 5 & 2 & 1 & 112 \\
\hline
\end{tabular}


number of children born per ever-married female. For Filipinas 25 to 29 years of age the number of children averaged 3.4, while the figure for Suban females of this age group was somewhat lower, 2.6 children. Filipinas in the 30 to 34 age group had an average 5.1 children, compared to 4.0 children for suban females. For Filipinas 35 to 44 years old the number of children was 6.3 , whereas in Suba the figure was only 4.8. These differences are significant and systematic, supporting the conclusion that fertility levels are lower in Suba and Paoay than in the nation as a whole.

The ages of suban females at their first birth is summarized in Table XV. Table XVI presents similar data

TABLE XV

AGE AT FIRST BIRTH BY AGE GROUP OF. FEMALES

Age Number of Females of $X$.Age at First Birth Totals $\mathrm{X}=15-\quad 15-19 \quad 20-24 \quad 25-29 \quad 30-34 \quad 35-39 \quad 40+$

\begin{tabular}{|c|c|c|c|c|c|c|c|c|}
\hline $15-29$ & 1 & 7 & 15 & 1 & & & & 24 \\
\hline $30-44$ & 3 & 5 & 14 & 6 & 6 & 1 & & 35 \\
\hline $45-59$ & 1 & 9 & 7 & 1 & 4 & 1 & 1 & 24 \\
\hline $60-74$ & & 7 & 4 & & 2 & & & 13 \\
\hline $75+$ & & 1 & 1 & 2 & & & & 4 \\
\hline Totals & 5 & $\underline{29}$ & 41 & 10 & 12 & 2 & 1 & 100 \\
\hline
\end{tabular}


TABLE XVI

AGE AT MOST RECEITT BIRTH BY

AGE GROUP. OF FEMALES

Age Number of Females of $X$ Age at

Totals $\mathrm{X}=15-19 \quad 20-24 \quad 25-29 \quad 30-34 \quad 35-39 \quad 40-44 \quad 45-49 \quad 50+$

\begin{tabular}{|c|c|c|c|c|c|c|c|c|}
\hline $15-29$ & 1 & 18 & 5 & & & & & \\
\hline $30-44$ & 1 & 3 & 7 & 11 & 11 & 2 & & \\
\hline $45-59$ & & 1 & 3 & 7 & 4 & 9 & & \\
\hline $60-74$ & & 1 & 1 & 1 & 4 & 2 & 3. & 1 \\
\hline $75+$ & & & & 1 & & 1 & 1 & 1 \\
\hline
\end{tabular}

Totals $2 \quad 23 \quad 16 \quad \underline{20} \quad 19 \quad \underline{14} \quad 4 \quad 2 \quad 100$

for the ages of Suban females at their most recent birth. Most females appear to start their families very soon after marriage since the distribution of ages at first birth is very similar to the provincial distribution for age at marriage. The data on age at most recent birth, especially for those 45 and over, show that a significant number of female Subans stopped having children fairly early, before age 35. It seems unlikely that this group alone could account for the lower fertility in Suba since the great majority of females have their last child after age 35. This suggests that Suban females space their children to a certain extent. The method of spacing children, if any, deserves investigation.

- It should be noted that the age of a suban female at her first and most recent birth is often an estimate. 
Estimates were required when the first or last child was dead, when all children were dead, or when the mother was dead.

There is compeling evidence that fertility levels are lower in Suba than in the nation. The national registered birth rate varies between 20 and 30 (United Nations 1959, 1964a; Lorimer 1966). Demographers who have attempted to assess the actual crude birth rate have usually developed estimates between 45 and 50, a high figure (USDA 1961; Concepcion 1966b; Flieger and Koppin 1973; Madigan and Avenceña 1964; United Nations 1971, 1973a, 1973b). The crude birth rate for Suba is 25.4. However, this figure does not include births of children who died before the census was taken. The crude birth rate is based on relatively few births, so the figure must be viewed with caution. The overall crude birth rate is probably close to 30 , still well below the national rate.

Lower fertility in Suba is also.substantiated by the fertility ratio, which is the number of children under five per thousand females between the ages of 15 and 44, inclusive. The fertility ratio in Suba is 367.6; Madigan and Avenceña (1964) noted that at that time the ratio for the Philippines was 771. This great disparity demonstrates that there are relatively fewer young children in Suba. Since the generation time in Suba is approximately 30 years a systematic spacing of births again seems 
to be indicated.

It might be possible to infer fertility and mortality levels in Suba from the differences between Scheans' 1958 census and the 1960 and 1970 censuses conducted by the Philippine government. The 1960 census showed an increase in the Suban population of 24 males and 17 females. If the increase were due solely to natural causes (births and deaths) a crude birth rate of about 50 would be indicated, clearly higher than the age structure and fertility data suggest had been true in the past. There are several possible explanations besides an increased birth rate for the increase in population. The 1958 and 1960 censuses may not have enumerated exactly the same area or there may have been some net in-migration. The 1960 Philippine census might have been slightly inflated or the Scheans census figure too low.

The 1970 census of Suba indicates an increase of 101 individuals in ten years, 41 males and 60 females. This increase approximates 13 percent over the ten-year period, and it would be consistent with an increase from 1958. to 1960 of approximately twenty individuals and a crude birth rate of approximately 25 to 30 .

It is unclear what motive Subans or the Philippine government might have to inflate census figures. Takahashi (1970) noted that the 1960 census of Kabikuran had been considerably inflated. Since the total population figures 
for the 1958 and 1960 censuses are roughly the same, accounting for natural increase, it seems likely that the 1960 census figure was not substantially inflated. Despite this conclusion, there are enough plausible causes of the different figures obtained in the two censuses to make inferences about birth and death rates unproductive.

Benedict has discussed (1972) some of the specific cultural attitudes and practices which affect fertility. He lists a series of indirect social factors, indirect because they are believed to affect fertility but the manner in which they do so is unclear. Such factors are the age at marriage, polygamy, separation and divorce, widowhood, post-partum abstinence, abstinence and menstruation, ceremonial abstinence, celibacy and the frequency of coitus. Direct social factors influencing fertility include contraception, abortion and infanticide. Little information is available on most of these subjects. Often, informants are reluctant to discuss these topics. For example, Hart (1965) found that although abortion was condemed in Caticugan, a Visayan barrio, a method of practicing it was known. The effects of the knowledge or use of this method were unclear. Hart also noted that abstinence was the only form of birth control discussed, but this was said to be "tough" for males. Most Filipino cultural attitudes and practices encourage high fertility. Conception is viewed as the normal and desired outcome of 
marriage; childlessness is pitied. On the other hand, Anderson (1972) found that Sisyanos believed that it was harder to provide well for a large family these days. The extent to which various cultural attitudes and practices influence fertility in Suba is unknown.

\section{Mortality}

Data for the age at death and the cause of death and an estimate of the year of death were coded for 119 individuals. The causes of death were recorded as related by informants, therefore the typology might be called a folk taxonomy. Nosology is listed in Tables XVII and XVIII. The principal causes of death in the Philippines are tuberculosis, pneumonia, bronchitis, and beri-beri (Philippine Information Agency 1955; Chaffee et al. 1969). Chaffee et a1. pointed out that malaria is also prevalent in many areas of the Philippines, but the Philippine Bureau of the Census and Statistics (1972) noted that Ilocos Norte is not one of those areas. The causes of death given by Subans show relatively little bias by sex, except where sex is directly related to the cause of death. Fever probably includes illnesses ranging from influenza to pneumonia. The higher number of males on which information was obtained may be due to higher male mortality rates (leaving the females to report the deaths) or to a greater tendency to remember and report the males. The data on infant 
TABLE XVII

CAUSES OF DEATH BY AGE DIED

Cause

Typhoid

Malaria

Sma1lpox

Dysentary

Bronchitis

Fever

Tuberculosis

Heart Attack

Hemorrháge

Stomach Ache

Menstrual Trouble

Weakness (01d Age)

Stillbirth

War Nerves

Appendicitis

Birth Difficulty

WorId War II

Accident

Makadalapus*

Unknown

Totals

*Spirit-caused illness

$$
\text { Age at Death }
$$

Total

$$
0-4 \quad 5-9 \quad 10-19 \quad 20-39 \quad 40-5960+
$$

$\begin{array}{rrrrrrr}1 & & 3 & 4 & 6 & 3 & 17 \\ 2 & 1 & & & 1 & & 3 \\ 1 & 1 & 1 & & 1 & & 10 \\ 2 & 1 & & & & \\ 29 & 6 & 2 & 2 & 2 & & 41 \\ 1 & 1 & & 2 & 3 & 5 \\ 1 & & 1 & & 1 & & 4 \\ & & 2 & 1 & 1 & & 2 \\ 5 & & & & & 1 & 1 \\ & & & 1 & & & 5 \\ 1 & & & 1 & 1 & & 1 \\ & 3 & 4 & 4 & & 1 & 12 \\ 1 & & 1 & . & & & 1 \\ 3 & & & & & 1 & 4 \\ \underline{54} & \underline{12} & \underline{14} & \underline{16} & \underline{17} & \underline{6} & \underline{119} \\ & & & & & & \end{array}$




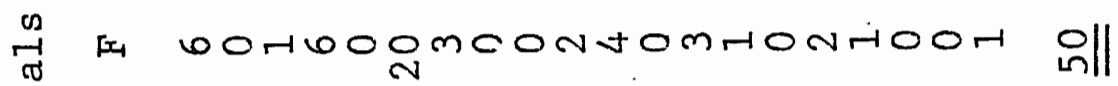

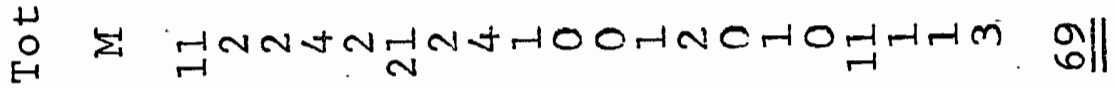

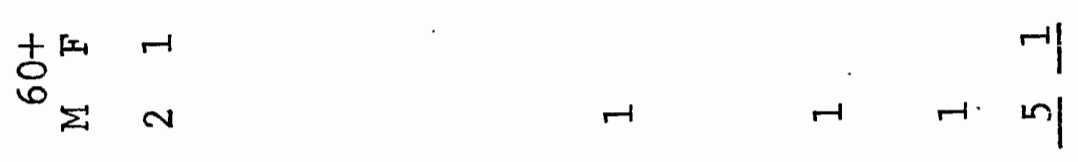

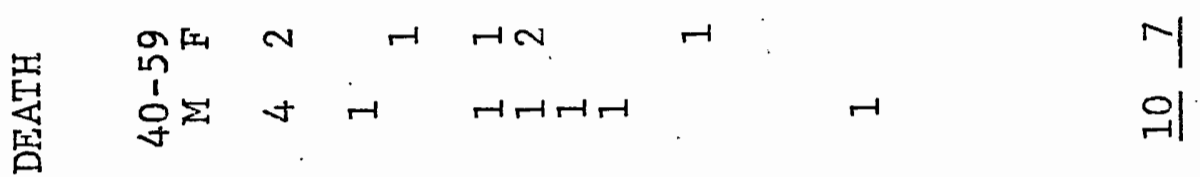

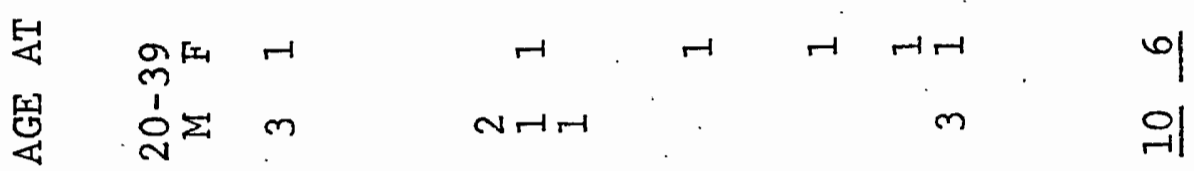

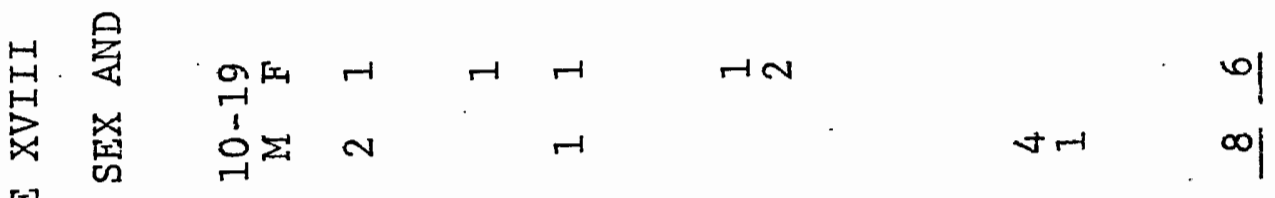

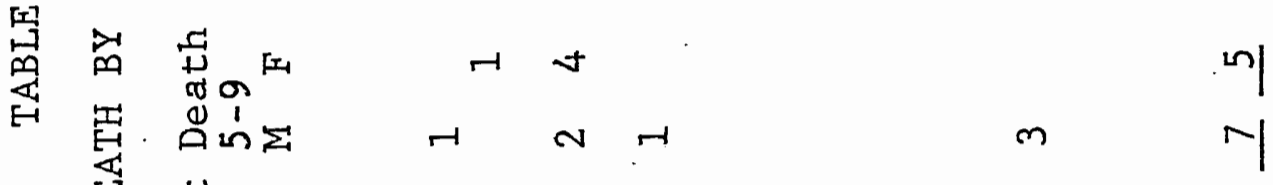

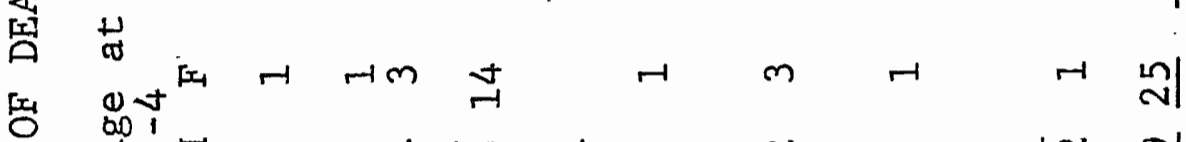

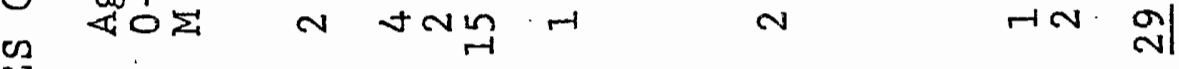

究

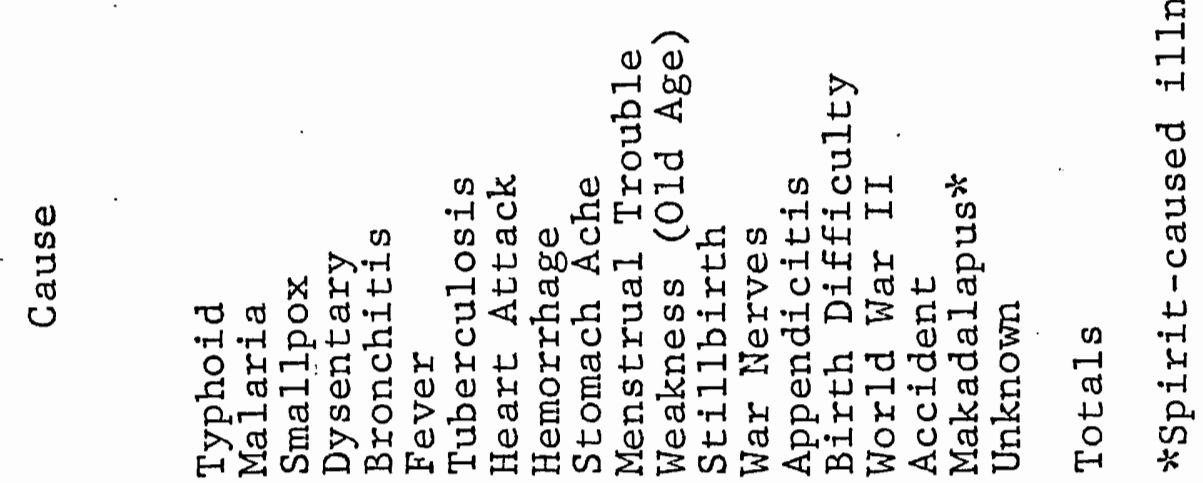


deaths seems fairly reliable since it implies slightly

higher infant mortality rates for males, a fact well

established in other areas of the world (Lorimer 1966).

Death rates and life expectancy figures as shown in

Table XIX are extremely tentative and are provided merely as a stimulus for further investigation in this area.

Estimates of these figures for the Philippines are unreliable due to a lack of information, in part as a result of an inefficient and incomplete registration system.

TABLE XIX

ESTIMATED AGE-SPECIFIC DEATH RATES IN SUBA

Age Death Rate Per Year Number Dying in 5 Years Total Male Female Total Male Female

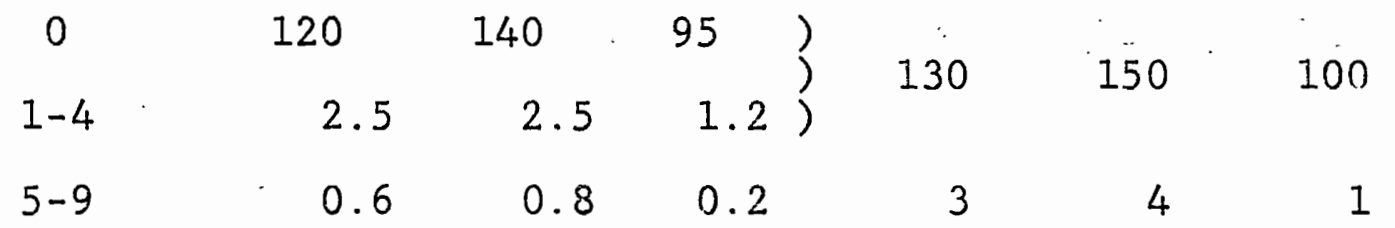

$\begin{array}{llllllll}10-19 & \cdots & 2.6 & 4.8 & 1.8 & 13 & 24 & 9\end{array}$

$\begin{array}{lllllll}20-29 & 7.2 & 12 & 4.0 & 36 & 60 & 20\end{array}$

$\begin{array}{lllllll}30-39 & 6.4 & 12 & 7.0 & 32 & 60 & 35\end{array}$

$\begin{array}{lllllll}40-49 & 19.2 & 20.4 & 18 & 96 & 102 & 90\end{array}$

$\begin{array}{lllllll}50-59 & 31.8 & 20 & 30 & 159 & 100 & 150\end{array}$

$\begin{array}{lllllll}60-69 & 38.4 & 40 & 47 & 192 & 200 & 255\end{array}$

$\begin{array}{lllllll}70+ & 59.8 & 40 & 66 & 299 & 200 & 330\end{array}$

$\begin{array}{lllllll}\text { Totals } & 11.0 & 15.0 & 8.0 \quad \underline{1000} & \underline{1000} & \underline{1000}\end{array}$ 
The death rates for Suba are essentially guesses. The data available are too deficient in quality and quantity to give any real insights into the death rate. The computer esimates of the death rate are based on deaths. within the five years next preceding the census and for the five year period before that (five to ten years before the census). The necessity to estimate the year of death introduced an extra element of uncertainty in the death rate calculations.

Average 1ife expectancy in Suba based on the tenuous death rate estimates is approximately 62 at birth and 60 at age five. For males the figures are in the neighborhood of 59 and $5 / 8$ years respectively. The average female can expect to live to be around 64 , but if she lives, at age five she can expect to live an average 61 additional years. Infant mortality is fairly high, but beyond infancy the death rates in Suba seem somewhat lower than in the nation as a whole, as evidenced by the fairly small and even decrease in the number of Subans from the younger age groups to the eldest age group.

\section{Marriage}

The Nydeggers (1966) have found Ilokano marriages to be stable, with regular intercourse and little premarital sex. Taboos and restrictions on coitus such as the postpartum taboo are usually short and insignificant. Divorce 
and separation are very rare, and since conception is desired and sterility pitied a marriage usually leads to a fairly steady stream of children.

Chandrasekaran (1966): found that a desire for children does not mean that Filipinos want a large number of children. In one survey he found that most people want to limit the number of children they will have, that some people try to limit family size despite a lack of knowledge of birth control methods, and that the rate of illegal abortion is high.

United Nations (1959) data for the Philippines showed that most males married between the ages of 20 and 29 while females generally married between 15 and 24. Concepcion (1966) noted that 4.7 percent of the brides in the Philippines are under 20, but the Philippine Bureau of the Census and Statistics (1961) figures for Ilocos Norte show that only about half of the females are married by age 25 . A higher age at marriage may be one reason for lower fertility in the Ilocos area. Concepcion also noted that in 1960 three-quarters of the females aged 15 to 44 were married. The 1960 census for Ilocos Norte showed that fifteen percent of the population had never been married by age 50 . A higher celibacy rate is another potential reason for lower fertility in Suba.

The marital status of Suba residents shown in Tables $\mathrm{XX}$ and $\mathrm{XXI}$ is consistent with the pattern prevailing in 


\section{TABLE XX}

\section{MARITAL STATUS OF SUBA RESIDENTS}

\begin{tabular}{|c|c|c|c|c|c|c|}
\hline Age & $\begin{array}{l}\text { Marital } \\
\text { Single }\end{array}$ & $\begin{array}{l}\text { Status } \\
\text { Married }\end{array}$ & Widowed & Divorced & Unkniown & Totals \\
\hline $0-9$ & 135 & & & & & 135 \\
\hline $10-14$ & 53 & 1 & & & & 54 \\
\hline $15-19$ & 49 & 3 & & & & 52 \\
\hline $20-24$ & 16 & 22 & & & & 38 \\
\hline $25-29$ & 14. & 17 & & & 1 & 32 \\
\hline $30-34$ & 7 & 23 & & & & 30 \\
\hline $35-39$ & 6 & 28 & 1 & & & 35 \\
\hline $40-44$ & 6 & 18 & 1 & & & 25 \\
\hline $45-49$ & 5 & 18 & 2 & 1 & 2 & 28 \\
\hline $50-54$ & 5 & 16 & 5 & 1 & & 27 \\
\hline $55-59$ & 5 & 10 & 1 & & & 16 \\
\hline $60-64$ & 1 & 4 & 6 & & & 11 \\
\hline $65+$ & 2 & 14 & 9 & & 3 & 28 \\
\hline Totals & 314 & 174 & $\underline{25}$ & 2 & 6 & 511 \\
\hline
\end{tabular}




\section{TABLE XXI}

\section{MARITAL STATUS BY SEX}

Age Marital Status

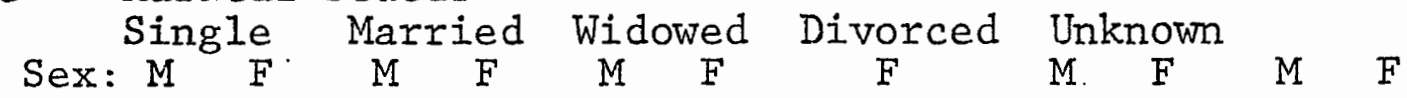
$0-9 \quad 73 \quad 62$

$73 \quad 62$

$10-14 \quad 35 \quad 18$

1

$35 \quad 19$

$\begin{array}{lll}15-19 & 32 & 17\end{array}$

3

$\begin{array}{lllll}20-24 & 13 & 3 & 7 & 15\end{array}$

$32 \quad 20$

$\begin{array}{lllll}25-29 & 12 & 2 & 7 & 10\end{array}$

1

$20 \quad 18$

$\begin{array}{lllll}30-34 & 6 & 1 & 13 & 10\end{array}$

$20 \quad 12$

$\begin{array}{lllll}35-39 & 2 & 4 & 15 & 13\end{array}$

1

$19 \quad 11$

$\begin{array}{lllll}40-44 & 2 & 4 & 8 & 10\end{array}$

1

$17 \quad 18$

$\begin{array}{rllll}45-49 & 1 & 4 & 10 & 8\end{array}$

2

1

$10 \quad 15$

50-54 $1.4 \quad 115$

$5 \quad 1$

$\begin{array}{lll}2 & 13 & 15\end{array}$

1

$12 \quad 15$

$55-59 \cdot 5 \quad 7 \quad 3 \quad 1$

7. 9

$\begin{array}{llllll}60-64 & 1 & 1 & 3 & 3 & 3\end{array}$

47

$\begin{array}{llllllll}65+ & 1 & 1 & 8 & 6 & 2 & 7\end{array}$

$311 \quad 17$

Totals $178 \quad 126 \quad 87 \quad 87 \quad 1 \quad 18 \quad 2 \quad 1 \quad 2 \quad 273 \quad 238$ 
Ilocos Norte. The census data suggest that the overwhelming majority of females in Suba get married between the ages of 20 and 24. Very few females get married before 20 . On the other hand, males start marrying in their early 20 's and by 35 most of the males who marry and start families

have already done so. It is significant that 13 of the 82 people over 49 in Suba have never been married and that 11 of these are females.

Scheans (1963, p. 225) has described the pattern of residence for newly married couples.

Residence may be neolocal, or in the vicinity of either partner's parents, depending on the place of origin of the bride and the couple's economic situation. A tabulation of residences in Barrio Suba shows that virilocality is the prevalent residence form today.

Table XXII presents a tabulation of residences for Suba.

TABLE XXII

PLACE OF ORIGIN OF SPOUSES

AT MARRIAGE BY SITIO

Origin Sitio:

Libtong Tacnir Eastern Central

Total

Wife :

Suba

Other
5

1

Husband:

Suba

Other
5

1
13

13

21

5
14

20
18

9
50

43 
The great majority of married male househeads are from Suba as are a majority of the wives. There are significantly more females from outside the barrio than males. The Nydeggers (1966) have found the same pattern in Tarong, an Ilokano barrio in Ilocos Sur province. The relative overabundance of young males and shortage of females in Suba presents a great potential for future population growth. This growth would result from males bringing in females from other barrios with few Suba females leaving, increasing the proportion of young married people in Suba relative to the current distribution and to surrounding areas.

\section{MIGRATION}

\section{Immigration}

Seventy-two of the 511 Suba residents were not born in suba. Tables XXIII and XXIV show the status of immigrants to Suba at the time of migration. Several persons moved in as nuclear family units, accounting for the immigration of children and married adults. The only other significant reasons for immigration to Suba are to marry a resident or to join relatives living in the barrio. Inmigration due to marriage is overwhelmingly female, reflecting a virilocal residence bias after marriage. Pascual has noted (1966) that immigrants to Ilocos Norte engage in a broad range of occupations; however, few are farmers. Almost all immigrants to Suba come from within 


\section{TABLE XXIII}

\section{STATUS OF PERSONS AT TIME}

OF IMMIGRATION TO SUBA

Age Status

Child Adult Single At Marriage With Family
Total Unknown

\begin{tabular}{|c|c|c|c|c|c|c|}
\hline $0-4$ & 2 & & & & & 2 \\
\hline $5-9$ & 2 & & & & & 2 \\
\hline $10-14$ & 2 & & & & & 2 \\
\hline $15-19$ & 1 & 1 & & 4 & & $\cdot 6$ \\
\hline $20-24$ & 3 & 1 & 5 & 2 & 1 & 12 \\
\hline $25-29$ & & & 5 & 3 & & 8 \\
\hline $30-34$ & 3 & & 6 & & & 9 \\
\hline $35-39$ & 1 & & 4 & & & 5 \\
\hline $40-44$ & 1 & & 5 & & & 6 \\
\hline $45-49$ & 1 & & 1 & & & 2 \\
\hline $50-54$ & & & 1 & 7 & 1 & 9 \\
\hline $55-59$ & $\cdot$ & & & 1 & & 1 \\
\hline $60-64$ & : & & 2 & & & 2 \\
\hline $65+$ & 2 & & 4 & & & 6 \\
\hline Totals & 18 & 2 & 33 & 17 & 2 & 72 \\
\hline
\end{tabular}




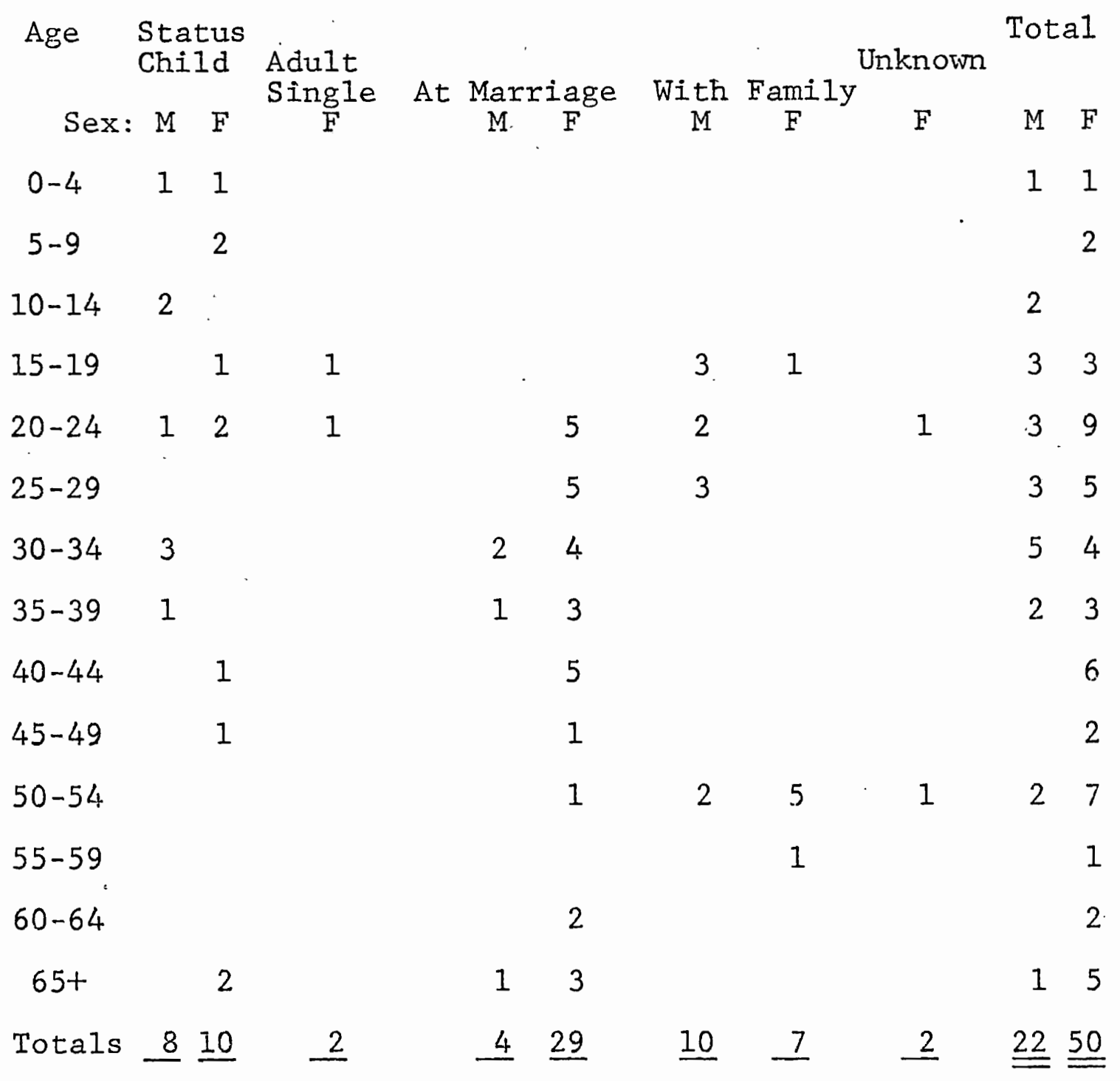


the province, as Tables XXV and XXVI show.

Accounting for out-migration (Pascual 1966) the population of Ilocos Norte increased approximately 20 percent from 1948 to 1960 compared with an increase of just over 40 percent for the Philippines. These figures again indicate lower fertility levels in the Ilocos area.

The differences in the sex of immigrants can be almost entirely explained by the virilocal residence pattern at marriage. It is interesting that immigration does not seem to be influenced by age, except for a slightly greater number of immigrants in the young adult ages of 20 to 34 . The number of neolocal immigrant married pairs and the number of young children who were immigrants suggest. that families who move into Suba generally have few if any children. Thus, these immigrants are probably young adults.

The immigrants all come from places within Ilocos Norte except for those from Hawaii and Cagayan, areas to which substantial numbers of Ilokanos have migrated. Relatively fewer of the persons 20 to 39 years of age list themselves as being from Suba, indicating a tendency on the part of older persons to falsify their place of origin or indicating greater movement into Suba than in the past. The fact that so many older people listed Suba as their place of origin is somewhat curious. Scheans (personal communication) has said that the village was first settled 
TABLE XXV

PLACE OF ORIGIN OF SUBA RESIDENTS

Origin Age

$\begin{array}{llllllll}\text { Age } & 10-19 & 20-29 & 30-39 & 40-49 & 50-59 & 60-69 & 70+\end{array}$

Tota1

$\begin{array}{llllllllll}\text { Suba } & 131 & 98 & 50 & 51 & 45 & 33 & 17 & 14 & 439\end{array}$

Baay

1 I

2

Nanguudan

1

.12

Dingras

1

1

San

Nicholas

2

$8 \quad 1$

5

$\begin{array}{ll}1 & 17\end{array}$

Calayab

22

1

1

1

7

Laoag

11

2

Nagbacalan

11

5

2

1

$1 \quad 11$

Paoay

41

1

1

3

$1 \quad 11$

Gabu

1

1

Batac

Hawaii

1

1

11

Kalayan

.

Currimao

2

1

1

Cagayan

2

3

3

2

$1 \quad 11$

Unknown

1

Totals

$135 \quad 106$

70

65

53

43

$19 \quad 20 \quad 511$ 
TABLE XXVI

PLACE OF ORIGIN OF SUBA RESIDENTS BY SEX

Origin Age

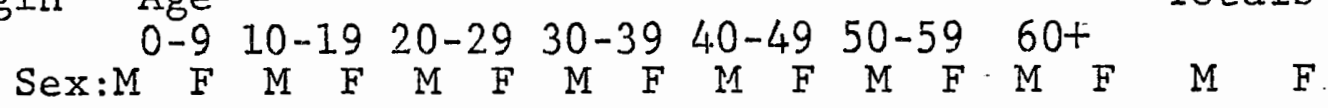
$\begin{array}{lllllllllllllllll}\text { Suba } & 72 & 59 & 62 & 36 & 34 & 16 & 29 & 22 & 23 & 22 & 17 & 16 & 14 & 17 & 251 & 188\end{array}$

Baay

Nanguudan

Dingras

San

Nicholas

Calayab

Laoag

Nagbacalan

Paoay 13

Gabu

Batac

Hawaii

Kalayan

Currimao

Cagayan

Unknown

Totals 73 6.2 67 $39 \underline{40}$ 30 $36 \underline{29}$ 23 30 19 24 $1524 \underline{273} 238$ 
between 1870 and 1900 or so. The actual date is confused due to contradictory evidence, but the fact remains that Suba was recently a pioneer village within Ilocos Norte. Thus, it seems likely that some of the older people either came with their families as children or moved their own families to Suba. However, this migration is not reflected in the data on places of origin.

Emigration

A densely settled homeland with farms of small size coupled with limited economic opportunities in other occupations have made Ilokano farmers a major source of emigrants from the Philippines (Anderson 1972; Lasker 1931; Hart 1971; Wernstedt and Simkins 1965; Pascual 1966). Anderson (1972) and Hart (1971) have both remarked that population pressure forced many individuals to look for outside jobs, but that these jobs could also become a means to acquiring land. An individual family member may emigrate to find employment or the whole family may move to an agricultural frontier. Pascual (1966, p. 342) noted:

The population pressure in the Ilocos region has forced families to seek new opportunities, primarily in agriculture, in the neighboring provinces of Isabela, Nueva Vizcaya, and the Mt. Province.

Many Filipinos emigrate expressly intending to return. For this reason, it may be inaccurate to characterize these individuals as emigrants. However, many never return and 
many more are gone for long periods of time, 20 to 40 years is not uncommon, so that substantial Filipino colonies are established overseas. Migration patterns within the Philippines are likely to reflect permanent moves (Anderson 1972). The economic aspirations of Ilokanos appear to be oriented toward land ownership.

The locations outside of the barrio where Subans have worked or are working are presented in Table XXVII: "Other" in the table means that the individual is working in another Philippine province, usually in central or northern Luzon as a migrant agricultural worker. Most Subans have never worked anywhere but in Suba or Ilocos Norte.

The figures in Table XXVII showing where Subans have worked out in the past include again those individuals who are currently working out of the barrio. However, the totals at the bottom of the table do not count these individuals twice and they correctly reflect the number of persons who have ever worked out of the barrio. Generally, males have emigrated to Hawaii. Most emigrants to Hawaii have returned to Suba and only one person was still in Hawaii at the time of the census. Work in Cagayan and other Philippine provinces is usually seasonal agricultural work. Most of the people who leave Suba seasonally to help with.planting and harvesting were still doing so. With one exception these seasonal workers are males. Emigration to 
TABLE XXVII

PAST AND PRESENT LOCATION

OF OUTSIDE EMPLOYMENT

BY AGE AND SEX

Location

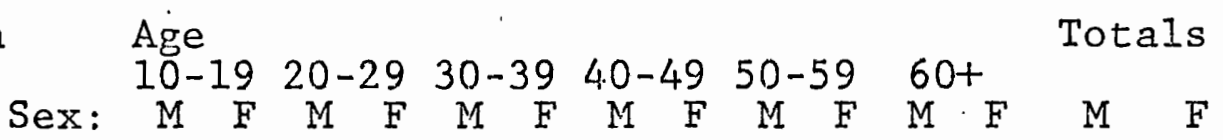

Hawaii

$\begin{array}{llrrrrrrrr}\text { Past } & 2 & 1 & 4 & 1 & 8 & 1 & 1 & 15 & 1 \\ \text { Present } & & 1 & & & & & & & 1\end{array}$

Cagayan

$\begin{array}{lllllll}\text { Past } & 3 & 5 & 1 & 8 & 1 \\ \text { Present } & 3 & 4 & 1 & 7 & 1\end{array}$

Manila

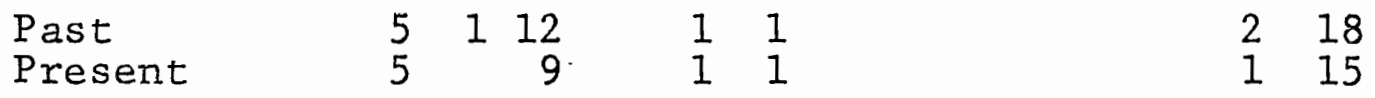

USA

Past

Present

1

1

Guam

Past

Present

1
1

1

Other

Past

Present

$\begin{array}{ll}3 & 8 \\ 2 & 2\end{array}$

$\begin{array}{ll}1 & 1 \\ 1 & 1\end{array}$

$\begin{array}{ll}1 & 1 \\ 1 & 1\end{array}$

14
7

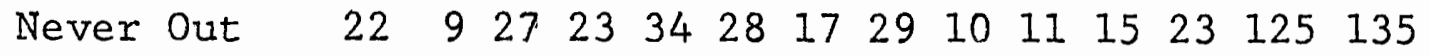

Totalst
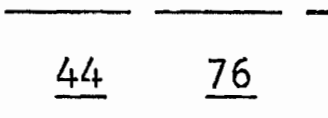

66

$\underline{53}$

$43 \quad 39 \quad 321$

*Not segregated by sex. 
the USA and to Guam has been insignificant. One housewife lives in the US, while a young carpenter works on Guam. Manila mainly attracts young females as housegirls and lavenderas, and most of these are still in Manila.

Table XXVII also reveals that international emigration for employment is a strategy no longer used by significant numbers of Subans. In the $1920^{\prime} \mathrm{s}$ and $1930^{\prime} \mathrm{s}$ a number of young men emigrated to Hawaii, but few younger men chose to do so in the $1940^{\prime} \mathrm{s}$ and $1950^{\prime} \mathrm{s}$. On the other hand, emigration to Manila is very popular among young females, indicating perhaps a trend of greater mobility of persons within the Philippines. Many young males emigrate seasonally, as a method of obtaining rice, mainly to Cagayan and central Luzon. There appears to be little permanent emigration of males from Suba.

Hart (1971) has commented that Visayans often obtain outside employment through their personal resource networks. A cousin or friend in Manila may arrange a job as a maid, which benefits both the girl and her family to whom she will send some of her earnings. This common tendency may well hold true for Suban Ilokanos as well and thus would account for some of the otherwise inexplicable biases in the data. That is, once Suban females are established in Manila as lavenderas or maids then they can aid others in obtaining similar employment.

The location of Suban emigrants and the permanency of 
their separation from the barrio are shown in Tables XXVIII and XXIX. If it was not known whether the migrant expected to return to Suba his status was determined by whether he sent any money home. Someone sending money home was determined to be a temporary emigrant, while others were judged to be permanent emigrants. The location of emigrants is biased toward international emigration since data on migration within the Philippines was usually neither elicited nor coded.

All of the males for whom information was available were permanent emigrants, usually to Hawaii or Manila. Generally, these males were in younger adult age groups. On the other hand, female emigrants split almost equally between permanent emigrants and temporary ones, although the temporary emigrants tended to be younger. AII but two of the females emigrated to Manila.

No instances of migration to places in the Philippines other than Luzon were noted. The available data on migration within the Philippines suggest primarily movements to urban areas and to agricultural frontiers.

Pascual (1966) has discovered that most people who have migrated within the Philippines are married, but his conclusion does not necessarily mean that they were married when they migrated. Unfortunately, Pascual neglected to compile statistics on the percentage of cases in which spouses came from different municipalities 


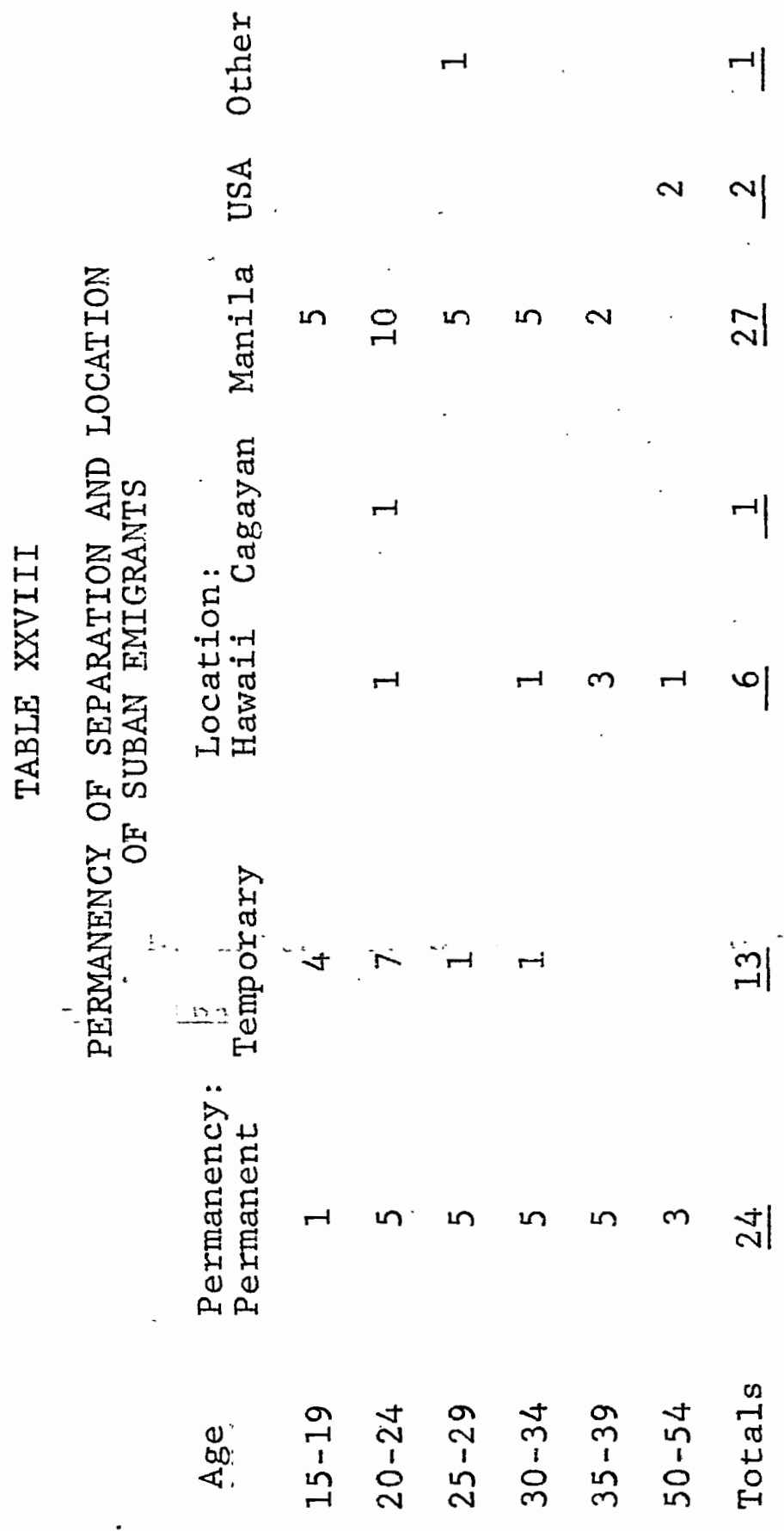




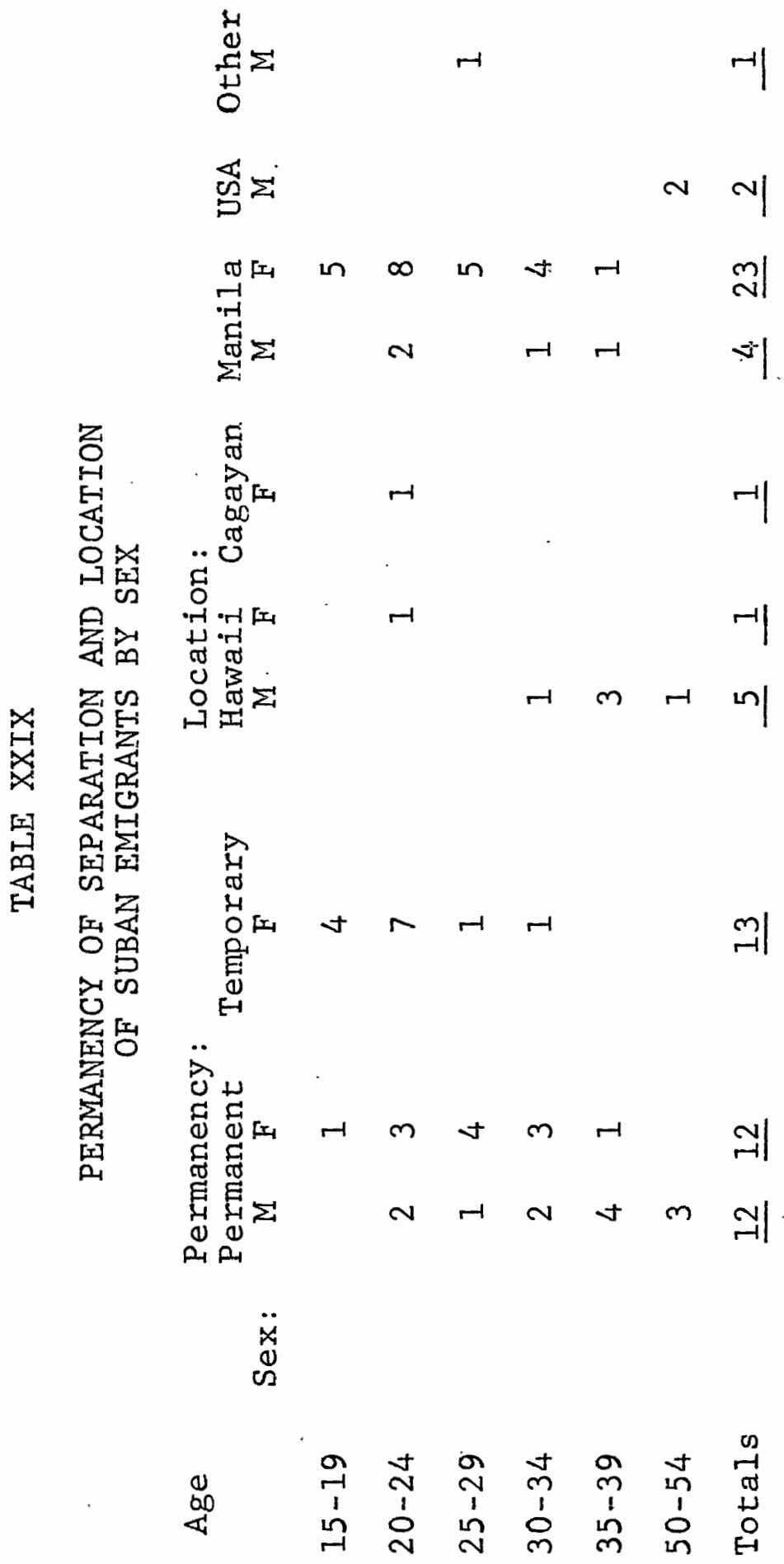


or provinces. In fact, most migrants in the Philippines, including those from Suba, are single at the time of migration. Most migrants are also females (F1ieger and Koppin 1973), due to the number of females who emigrate to become maids and to a greater number of female students than male students. Only the former factor has influenced emigration from Suba, and the Suban female is almost as likely to become a lavendera as a housegirl, although almost al1 of the female emigrants work as domestics.

Tables XXX and XXXI show the occupations of Suban emigrants. Housekeeper and housegirl are roughly the same job, but the terms were recorded as given by the Suban informants and may reflect some unknown distinction. A lavendera is a wash girl or laundress.

Only two occupations are shared by emigrants of both sexes, student and waitress or waiter. Females generally hold domestic or service jobs, while males usually perform physical labor. None of the emigrants are skilled workers, which suggests that they are not significantly more educated than those who remain in Suba. This pattern is contrary to national trends where migrants are slightly more educated than the average Filipino (Pascual 1966). The jobs generally have little to do with agriculture, a trend noticed by Anderson (1972) in Sisya, a Pangasinan barrio. In most ways, the characteristics of Suban migrants are consistent with national trends in the age, 
TABLE XXX

OCCUPATIONS OF EMIGRANTS FROM SUBA

Occupation

Housekeeper

Housegirl

Lavendera

Harvester

Laborer

Waitress

Waiter

Amah (Nanny)

Student (above 6 th grade)

Salesgirl

Armed Service

Totals
Age

$15-19 \quad 20-24 \quad 25-29 \quad 30-34 \quad 35-39 \quad 50-54$

1

1

1

1

4

3

2

1

3

1

1

13

1

1

2

1

1

1

2

1

$\begin{array}{llll}3 & 1 & 1 & 5\end{array}$

$\begin{array}{llll}3 & 1 & 1 & 5\end{array}$

$\begin{array}{llll}3 & 1 & 1 & 5\end{array}$

1

$\underline{5} \quad \underline{12}$

Total

6

4

1

7

1

1

4

$\begin{array}{lll}1 & 1 & 2\end{array}$

$12 \quad \underline{6} \quad \underline{5} \quad \underline{3} \quad \underline{\underline{3}}$ 
TABLE XXXI

OCCUPATIONS OF SUBAN EMIGRANTS BY SEX

Occupation Age $15-19$ Sex:

Housekeeper

Housegirl

Lavendera

Harvester

Laborer

Waitress

Waiter

Amah (Nanny)

Student (above 6 th grade)

Salesgirl

Armed Service

Totals
1

3

2

3

1

1

1

1.3

11

1

1

Total M. F 
sex, marital status and jobs held by migrants. Given the historical and current magnitude of migration from the Ilocos area as a whole it should be emphasized that Suba seems to experience less emigration. More people seek their opportunities in the barrio and municipality, perhaps due to the resources of the lake and the relatively young age of the barrio.

Ilokanos have been successful migrants despite frequent and extensive problems (Lasker 1931). The relative poverty of the Ilocos area seems to prompt the Ilokano migrant to undersell his labor relative to other groups (Wentworth 1941; Lava 1938). Lewis (unpublished) has also suggested that Ilokano social organization is one reason for the success of Ilokano migrants, since an open social organization based on personal resource networks gives the migrant more flexibility in responding to new opportunities and envirironments.

IV. HOUSEHOLD AND ECONOMIC DATA

Data on the size, structure and economy of Suban households were collected. Some households gave very complete, detailed and reliable information; others gave next to none.

Suban households averaged 5.15 members in size, slightly below the Philippine average (Philippines, Department of Commerce and Industry 1966). Table XXXII 
presents the size distribution of households in Suba.

The basic composition of Suban households is presented in Table XXXIII. The terms describing household composition were used in the following manner. A nuclear family consists of a married pair with or without children.

Nuclear families with other relatives usually have living in the household such as a parent of one of the spouses (who is often listed as the househead), a sibling of one of the spouses, or a distant relative such as an aunt, uncle or cousin. A joint family of three or more generations implies at least two married pairs or members of at least two distinct nuclear families, even if one of the spouses has died. The joint family differs from a nuclear family with relatives because the older family unit has remained intact save for the death of one of the parents. Unmarried persons who were the head of a household were generally spinsters... Married persons were taken as ego in the analysis of family structure except when they were distantIy related to the househead. In such a case and in all cases where there was no married pair, the househead was taken as ego.

Scheans did not gather data on the education of Subans, but some information is available from the 1960 census of Paoay. The Bureau of the Census and Statistics (1961) reported that 75.4 percent of the people in Paoay over 10 were literate, which is approximately the propor- 
TABLE XXXII

SIZE DISTRIBUTION OF SUBA HOUSEHOLDS

Size of Household

1

2

3

4

5

6

7

8

9

$10+$
Number of Households

3

10

14

16

15

13

12

8

4

4

TABLE XXXIII

FAMILY STRUCTURE OF SUBA HOUSEHOLDS

Family Type

Nuclear

Nuclear with some relatives

Nuclear with non-relatives

Joint, $3+$ lineal generations

Joint, 2+ married siblings

Unmarried person(s) with or without

relatives and non-relatives
Number of Households

61

18

2

5

1

11 
tion that had ever gone to school. This figure suggests that literacy consists of the ability to read and write one's name. The reported literacy rate for males was about ten percent higher than the rate for females.

The living conditions of most Paoay residents in 1960 ranged from poor to fair. Houses in Suba are generally constructed out of bamboo and thatch, although this information was not available for many houses. Table XXXIV summarizes the house size and construction materials for dwellings in Suba.

\section{TABLE XXXIV}

HOUSE SIZE AND CONSTRUCTION IN SUBA

$\begin{array}{lc}\text { Size and for materials } & \text { Number of Houses } \\ \text { Unknown } & 47 \\ \text { Cogon-siwali*: } & \end{array}$

Sma11

Average

Large

Wood

Total

*Bamboo and thatch construction

According to the 1960 census about half of the dwellings in Paoay were of light materials such as bamboo and thatch, about one-quarter were of strong materials such as wood and sheet metal, and another one-quarter were of mixed 
construction materials. Probably, most of the houses in Suba for which information was unavailable are of light construction and moderate size. All houses in Suba are single family dwellings as are the vast majority of buildings in Paoay. The 1960 census also revealed that a vast majority of houses in Paoay are owner-occupied, but the data for suba do not confirm this pattern since this information was often unrecorded or only incidentally noted. The Bureau of the Census and Statistics (1961) also revealed that most Paoay residents use kerosene for lighting, get their water from open wells, have pit toilets and use wood as their primary fuel. Since Scheans did not systematically collect information on these items his census cannot confirm that these patterns hold true in Suba as we11, although there is no reason to doubt that they do. Generally, residents of Paoay and Suba have relatively small investments in their living facilities, which is one indication of a fairly low level of living since house structure and facilities are roughly related to wealth (Lava 1938).

Economic Strategies Within Suba

Since the standard of living in the Ilocos area is low, the economic strategies focus on survival. Some people naturally survive better than others, but in Suba there are no definable class differences. Subsistence 
strategies in Suba revolve around four activities - farming, raising animals, fishing, and cottage industries. Households try to supplement their incomes with cash from wage work whenever possible, but local opportunities are very limited.

Land. In many cases, house ownership had to be inferred from other information on the census sheets. Table XXXV shows the economic ties between Subans and their dwellings. Persons who tenanted farmland were also assumed to be tenanting their house unless there was an indication to the contrary such as ownership of trees or a garden. Generally, tenants do not pay separately for use of the house, although the landlord may retain the right to the fruits of the trees. In some cases the name of the owner of the house was given; these owners were usually outsiders.

The available information concerning tenancy consisted of: whether the household farmed any land as tenants,

\section{TABLE XXXV}

HOUSE OWNERSHIP AMONG SUBA HOUSEHOLDS

Economic Tie to the House Number of Households

Own

Rent

Tenant

Relative's house, No Rent

Unknown 
who owned the land, and what share of the crop each party was to receive. Very little data was collected on the size of holdings or the yield per area of land. The information on overall yield of rice (rice income) is most likely to be erroneous (Scheans, personal communication). The few people that were solely landlords reported that fact. Landlords who also farmed part of their land tended not to report their holdings which were tenanted to others. However, most of the tenants farmed land for absentee landlords, although these persons were often personal acquaintances or relatives of barrio residents. Almost all of these landlords lived in Paoay.

The landholdings of Suban households by sitio is presented in Table XXXVI. The variations in landholding status by sitio are interesting. Libtong has the fewest number of households but a greater percentage of them do not farm land than in other sitios. Tacnir contains over half of the full owners and all of its residents who work land own at least part of the land they work. In contrast, the overwhelming majority of full tenants live in Eastern sitio; however, several of the households are also owners. Central sitio is harder to characterize. A large number of part tenants live in this sitio, but all other kinds of land ownership are present as well. Perhaps more significantly, every household in Central sitio works or owns land and thus relies on the land as a major subsistence 
TABLE :XXXVI

LANDHOLDING STATUS OF HOUSEHOLDS BY SITIO

Landholdings Sitio:

Total

Libtong Tacnir Eastern Central

None

Part Tenant

Ful1 Tenant

Tenant \& Landlord

Part Landlord

Landlord

Part Owner

Full Owner

Totals
3

2
5

7

2

20

1.

1

2

1

1

7

4

$\underline{38}$
12

11

3

1

4

2

2

5

28

20

25

2

5

4

12

$\underline{\underline{99}}$

activity. It should be noted that households which farm land as tenants and are also landlords usually own extremeIy fragmented parcels of land, making this arrangement useful to consolidate the land actually farmed.

Tenants predominated in the Tagalog barrio studied by Takahashi (1970). He found that most tenants had just one landlord, generally a relative. The landlord's share of the harvest was usually between 45 and 50 percent. In Suba it is common for a tenant to have more than one landlord, and although the tenant is usually not a relative of the landlord, the landlord is usually a relative of someone in the barrio. The landlord's share varies from one-half to two-thirds of the crop grown, well above the legal limit 
of 25 percent.

The basic economic orientation of Subans is to the land. When Scheans questioned Subans about the land, he received vague and often inaccurate information. Consequently, information on landholdings and income from land is the poorest of the available economic data. The available information was coded directly from the census sheets. In some cases informants gave the value of their landholdings as the assessment used for computing taxes, a figure most Subans try to minimize. Generally, the value of landholdings had to be estimated. The number of fields owned or that will be inherited also tends to be unreliable. This information was totally reliable and substantiated for only one or two households. In other cases, the number was estimated from data on landholdings, the number and amount of crops other than rice grown and tenancy. The number of fields and lats owned is a rough indicator of the fragmentation of landholdings: Tables XXXVII and XXXVIII present the distributions of the estimates for the value of 1 andholdings and the number of fields owned.

Lewis (1971) stated that the value of a hectare of wet rice land during the $1960^{\prime} \mathrm{s}$ was $\$ 12,000$ to $\$ 15,000$. Espiritu and Hunt (1964) at an earlier date gave the value of a hectare of land in Ilocos Norte as $\$ 6,000$. Even allowing for inflation and the greater value of wet rice land it can be seen that the values reported by Subans for 
TABLE XXXVII

HOUSEHOLD DISTRIBUTION OF VALUE OF LANDHOLDINGS IN PESOS

$\begin{array}{lr}\text { Value } & \text { Number of Hou } \\ 0-49 & 4 \\ 50-99 & 7 \\ 100-199 & 8 \\ 200-299 & 4 \\ 300-499 & 8 \\ 500-999 & 12 \\ 1000-1999 & 2 \\ \text { Some; amount unknown } & 17 \\ \text { TOTAL . } & 62\end{array}$

TABLE XXXVIII

NUMBER OF FIELDS OWNED BY SUBAN HOUSEHOLDS

Number of Fields Owned Number of Households

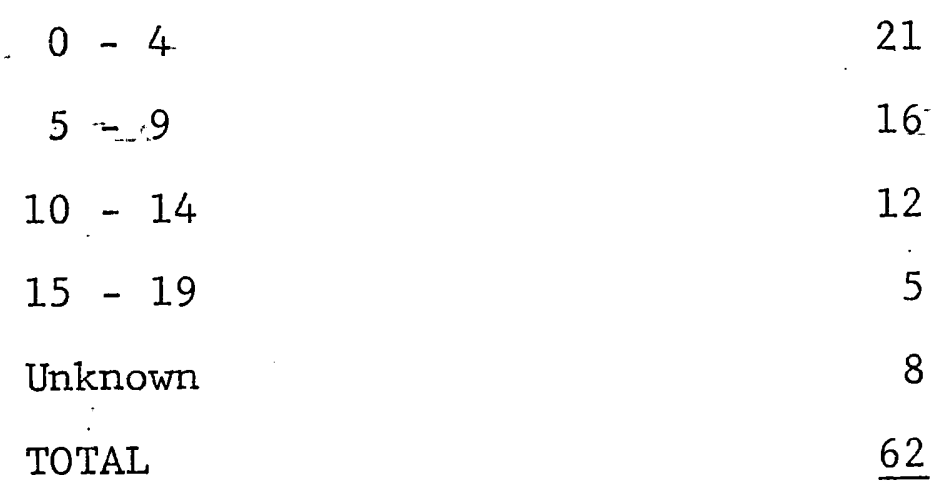


their land imply that the holdings are generally small. Geertz (1971) noted that the average holding in Java has been fairly stable for a century or more at one hectare. Anderson (1972) and others have noted that the average Filipino holding is larger than Geertz' figure. In Sisya, Anderson found the average holding to be over two hectares, but the area cultivated varied from an average of 0.94 hectares for tenants to 2.3 hectares for ownertenants. The low land values reported by Subans and the value and size of average landholdings in the Philippines and Ilocos Norte tentatively suggest that the size of the average holding in Suba is approximately one-half hectare.

Animals. Animal raising is an important economic activity in Suba for several reasons. As the Philippine Information Agency (1955) has said, the carabao is the main source of power for plowing and operating the Filipino farm. Smaller animals provide a small but steady supply of meat. Animals may also be sold for cash. Tables XXXIX and XI show the number of animals owned by households in Suba and the value of those animals.

Animal tenancy is an important local strategy where an animal owned by one person is raised by another. The two persons then either split the profit from the sale of the animal by a prearranged method, or they alternate in taking the offspring of the animal. For example, a poor family may raise a cow for a relative or neighbor. In 
TABLE XXXIX

\section{DISTRIBUTION OF THE NUMBER OF ANIMALS OWNED BY SUBAN HOUSEHOLDS}

$\begin{array}{cc}\text { Number of Animals Owned } & \text { Number of Households } \\ 0-4 & 9 \\ 5-9 & 27 \\ 10-14 & 22 \\ 15-19 & 14 \\ 20-29 & 13 \\ 30-39 & 9 \\ 40-49 & 3 \\ 50+ & 1 \\ \text { Total } & \underline{98}\end{array}$


TABLE XL

DISTRIBUTION OF VALUE IN PESOS

OF ANIMALS OWNED BY

SUBAN HOUSEHOLDS

Value of Animals Owned: Number of Households

$\begin{array}{cc}70-99 & 16 \\ 100-199 & 14 \\ 200-299 & 12 \\ 300-399 & 9 \\ 400-499 & 15 \\ 500-599 & 8 \\ 600-699 & 7 \\ 700-799 & 6 \\ 800-899 & 4 \\ 900+ & 7 \\ \text { Total } & 98\end{array}$


return, the family gets every other calf. This method enables poorer families without capital to develop investments in animals. Table XII shows the distribution of animal tenancy in Suba. As with land, animal tenants accurately reported their tenanted stock whereas animal landlords tended not to report animals raised by others. The number of subans tending someone else's animal. far exceeds the number of Subans who own animals which others tend. Like land tenure, animal tenure tends to depend on outside ownership. There may be a greater tendency to raise an animal for a relative living in a poblacion than there is to work as tenants the land of kin living in town.

\section{TABLE XLI}

ANIMAL TENANCY AMONG SUBAN HOUSEHOLDS

Animals Tenanted

None

Less than Half

More than Half

Less than Half

More than Half

A11

Some

Total
Ownership Number of Households

53

Tenant

18

Tenant

16

Owner

7

Owner

2

Tenant

1

Tenant \& Owner 1

$\underline{98}$ 
Fishing. The Philippine Information Agency (1955) has said that fishing ranks third in economic importance to the Philippines after farming and livestock raising. Next to rice the single most important element in the Filipino diet is fish. In an effort to develop and manage the fishing industry the Philippine government has sponsored the development of fish ponds. Ponds were developed in Suba but failed when the ponds broke and the fish were released into the lake (Scheans, personal communication).

The economic importance of fishing in Suba is illustrated by the investment in fishing gear and the income derived from fishing, shown in Tables XLII and XLIII, respectively. About a third of the households are not involved in fishing. Approximately another third only get plants from the lake, fish for home consumption, and do not earn any money from fishing. The remainder derives some income from fishing, forming an integral part of their economic strategy. Some households pursue fishing to the exclusion of farming, and while this approach is apparently sufficient to maintain a household it has lower prestige than owning or working land.

The split within the Suban population with respect to fishing is illustrated quantitatively by the ownership of fishing gear. Of the 99 households, 35 owned no gear, 38 owned only enough gear to provide them with fish for home use, and 36 had a substantial amount of gear. These latter 


\section{TABLE XIII}

\section{HOUSEHOLD DISTRIBUTION OF THE VALUE}

OF FISHING GEAR OWNED IN PESOS

$\begin{array}{cc}\text { Value of Gear } & \text { Number of Households } \\ 7 \quad 0-29 & 29 \\ 30-59 & 3 \\ 60-89 & 7 \\ 90-119 & 9 \\ 120-149 & 3 \\ 150-199 & 6 \\ 200-249 & 1 \\ 250-299 & 2 \\ 300-399 & 0 \\ 400+ & 7 \\ \text { Total } & 67\end{array}$




\section{TABLE XLIII}

HOUSEHOLD DISTRIBUTION OF INCOME. FROM FISHING

IN PESOS PER MONTH

Income

Home Use Only

$\$ 0-4$

$5-9$

$10-14$

$15-19$

$20-24$

$25-29$

$30-39$

$40-49$

$50+$

TOTAL
Number of Households

31

10

4

2

5

3

1

1

2

4

63 
households derived monetary income from fishing. A total of 60 households hold lot memberships, which are required by local law for garnering resources from the lake.

Another 33 households are not members. The six households for which fishing lot membership was not indicated are all assumed to be members since they all indicated some degree of involvement in fishing.

Cottage Industries. Cottage industries are an important aspect of the economic strategies of Subans, providing goods used by the household. Sometimes these activities provide an income for the household as well. Making salt, weaving, tailoring, and carpentry are the major cottage industries in Suba. Carpentry is the only one usually done by males. In the off season most males are involved with fishing or have supplementary jobs constituting an additional element in the economic strategies of households. Goods produced for the market are bartered for goods produced by other households. Barter was the only available income for some older females. The major cottage industry performed for income is salt-making. Since this activity is limited to the dry season a female who depends on salt-making must find some other means of support during the wet season.

Jobs. In all cases jobs were recorded where an occupation was given on the census sheets and if they were regularly performed for income in cash or kind. A person 
listed as performing only one occupation may engage in other activities as well. Some housekeepers, for example, also do their own weaving.

The labor force of Suba is fairly mobile and involved in diverse occupations. Table XLIV shows the place of work in January 1958 for all those normally considered residents of Suba. Over ten percent of these persons derive some income from outside the barrio. Tables XLV, XLVI, and XLVII show, respectively, the jobs held by members of the Suban labor force, by male Subans and by female Subans. The tables count some persons twice, i.e. those with two jobs, one in Suba and one outside.

The job listed for each member of the labor force was his major economic activity although many individuals engage in supplementary production of goods for home use. Subans who seemed to divide their time equally between two occupations are listed as engaged in both occupations. The vast majority of the labor force is involved in farming, fishing, and/or housekeeping. The remaining Subans are usually members of households in which there are enough other adults to conduct farming and fishing activities to free those persons to do wage work outside the barrio if they are fortunate enough to find a job.

The diversity of jobs suggests than Suban farmers are able to use their free time to engage in productive activities, contrary to the situation found among Ilokano 
TABLE XLIV

MOBILITY OF THE SUBAN IABOR FORCE

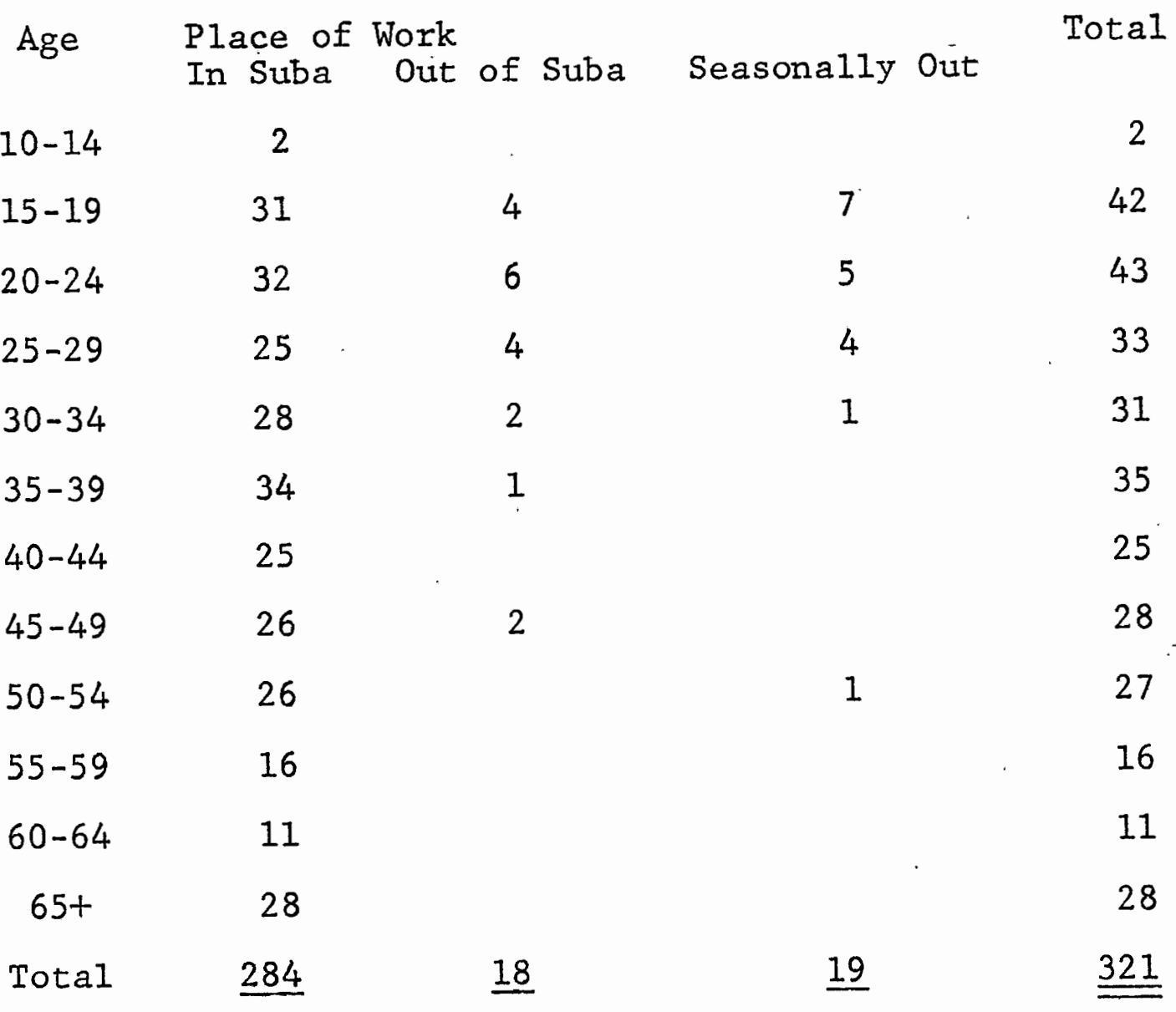




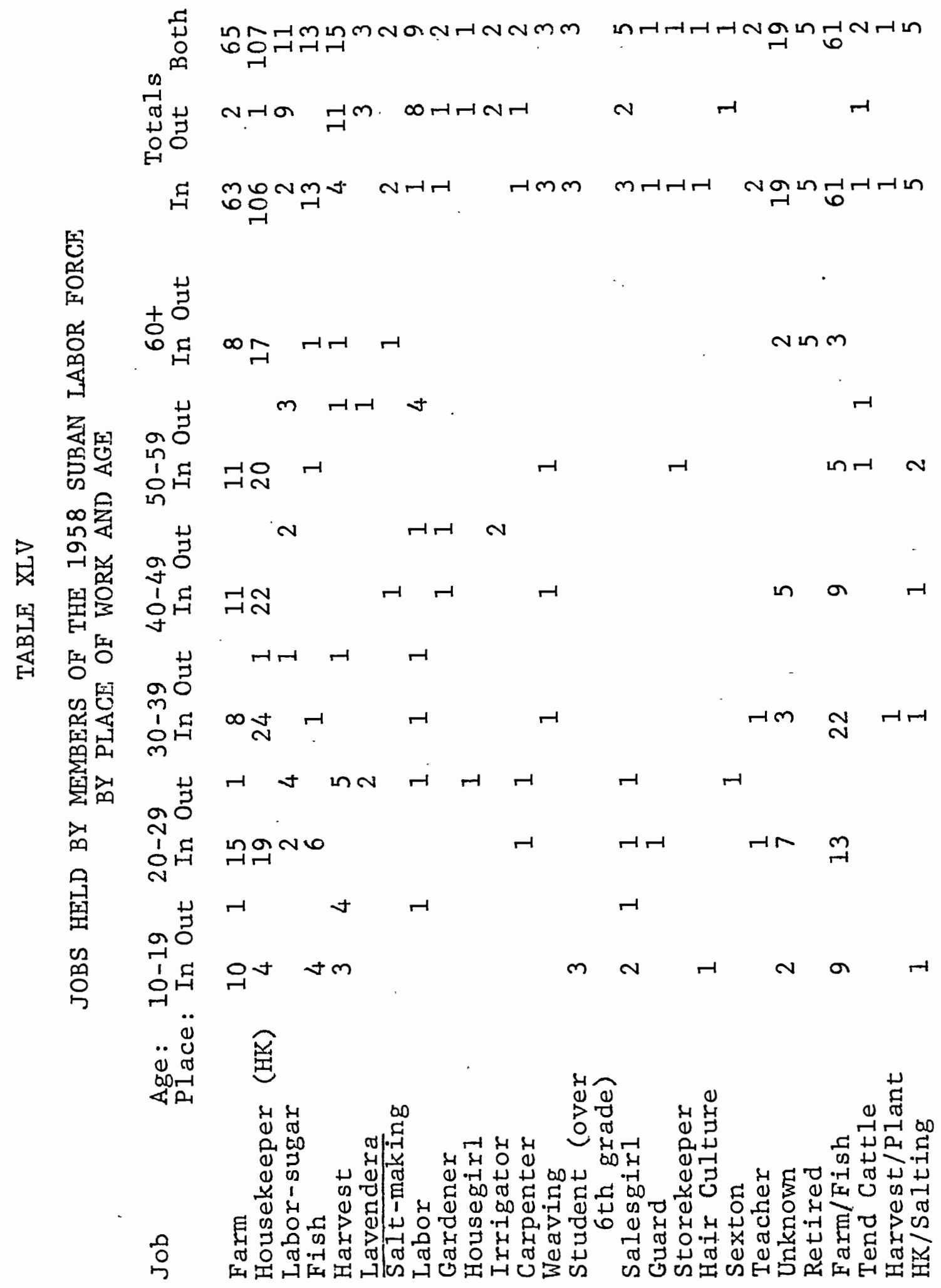




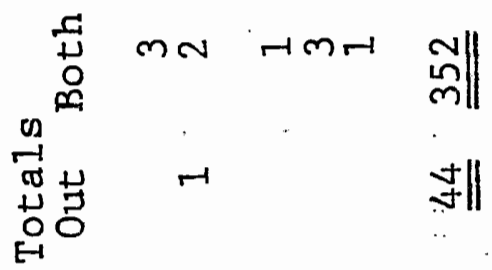

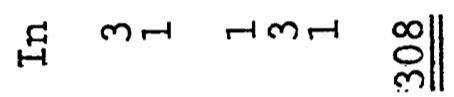

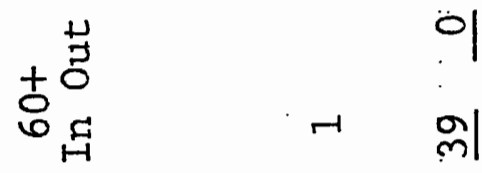

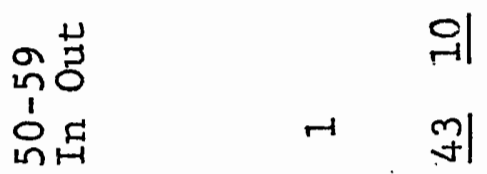

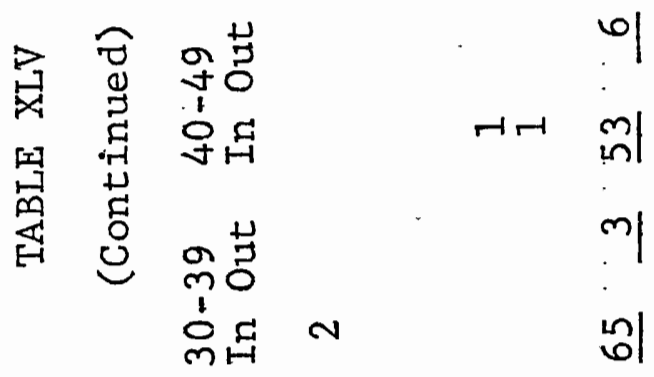

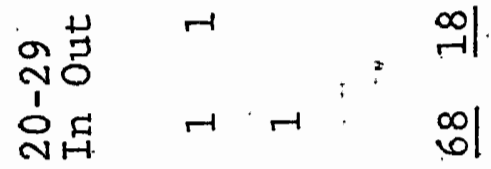

$$
\begin{aligned}
& \text { 节苨 } \\
& \text { 윰대 잉 } \\
& \text {.. } \\
& 00000000 \\
& \text { यम } \\
& \text { 펄 } \\
& \text { थ } \supset
\end{aligned}
$$

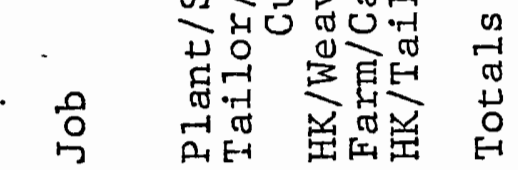




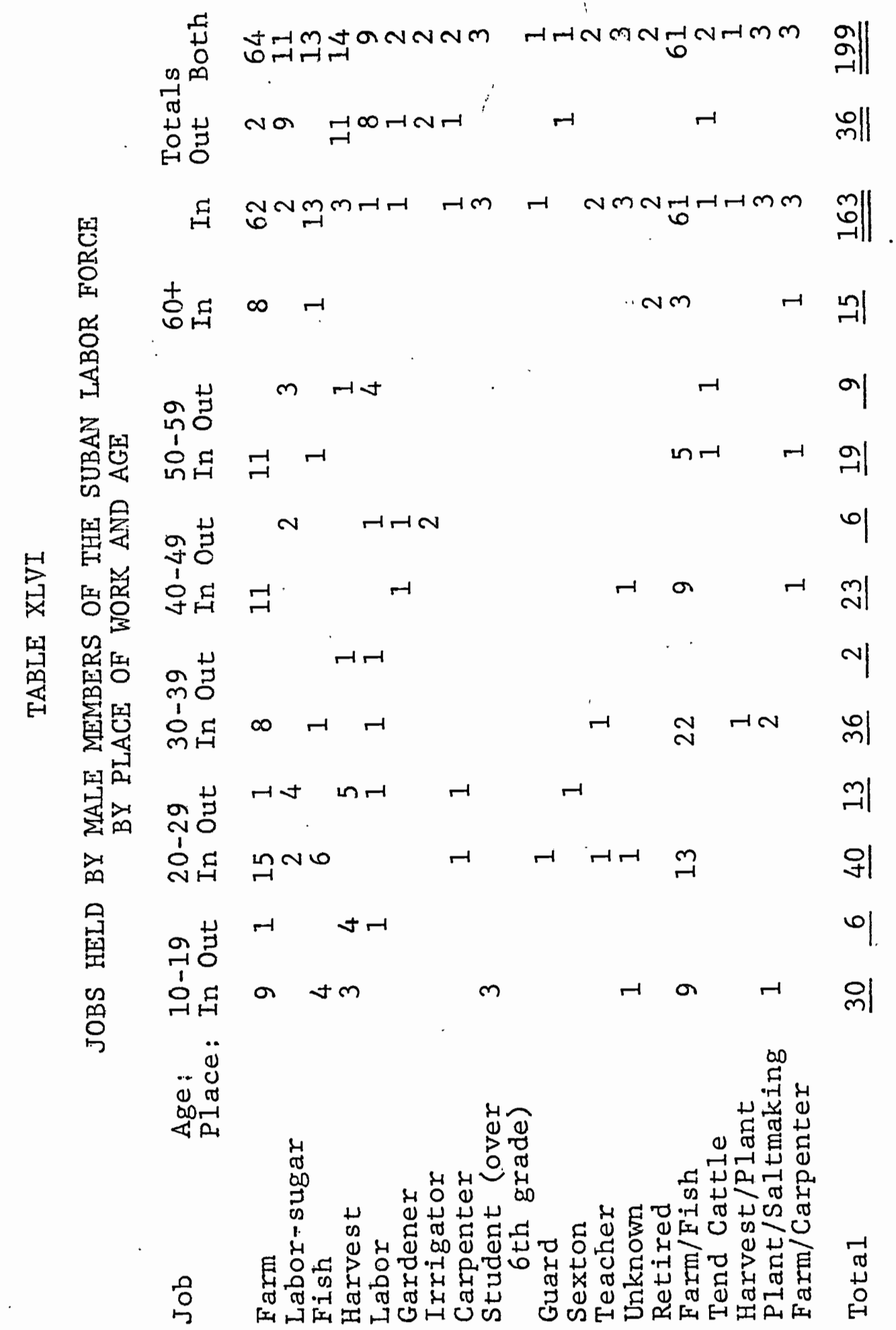




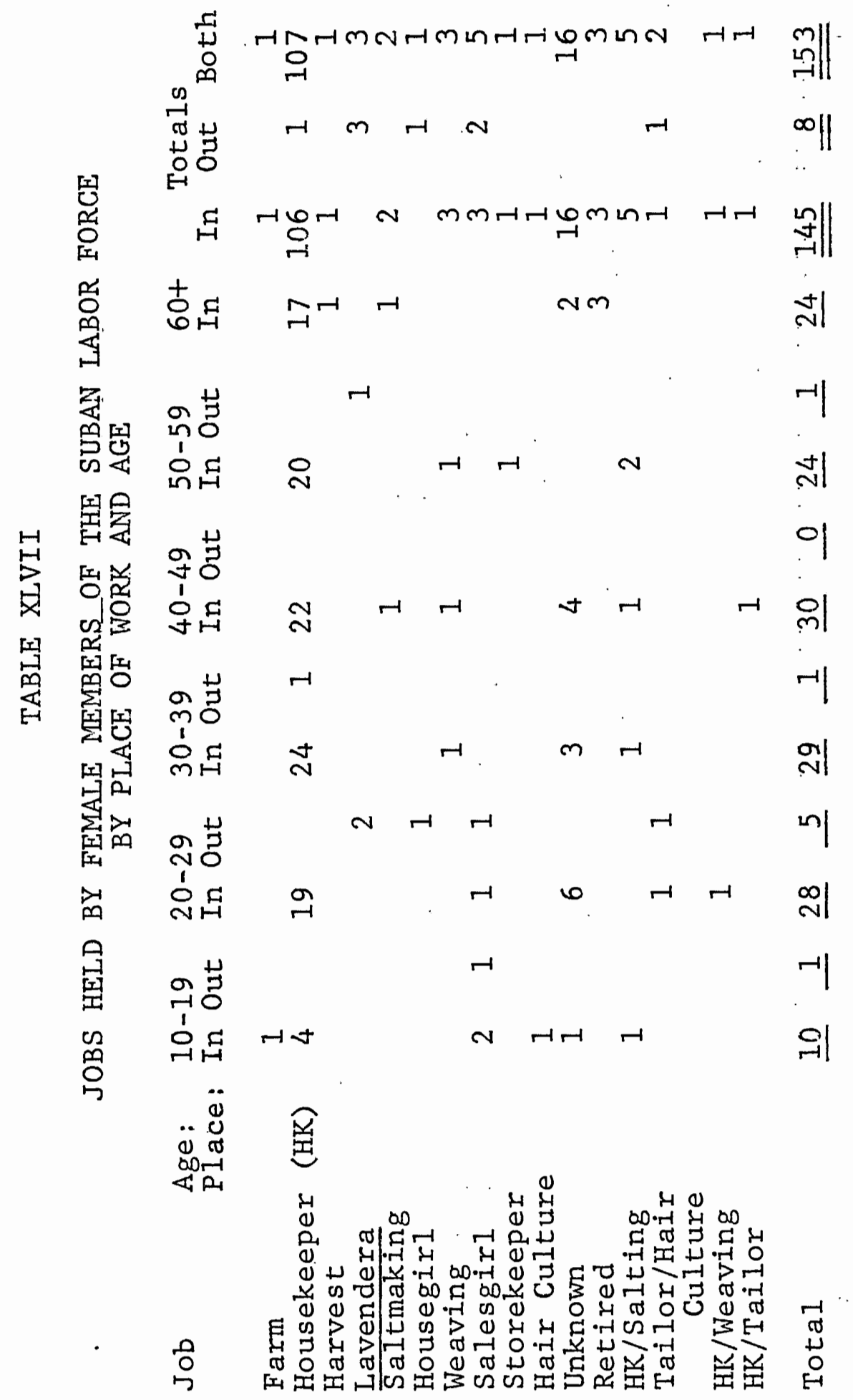


farmers by Espiritu and Hunt (1964). With the resources of the lake available it seems likely that the Suban farmer uses relatively more of his spare time in some profitable venture.

Anderson (1972) has remarked upon the high percentage of marginally employed people in Sisya, fully 22 percent of the labor force. Fewer than ten percent of the labor force of Suba (even excluding housekeepers from the labor force) could be considered marginally employed. The multiple occupational involvement Anderson found among marginally employed households in Sisya is virtually universal in Suba.

Takahashi (1970) has analyzed the jobs held by the members of a central Luzon barrio. The three major activities were transportation, shopkeeping, and buntal hat weaving, the local cottage industry. Since the data from Suba were taken some ten years before Takahashi's study, it is possible that some Subans have since become involved in transportation as the need for mobility increases. Buntal hat weaving. was the only occupation open to Kabikuran females besides housekeeping, a situation not characteristic of Suba as Table XIVII illustrates.

The wage earners are usually employed outside the barrio and send or bring their wages home. Most males who are not engaged in agriculture or fishing earn wages. Females in the barrio tend to be producing goods for barter in the market. The females outside of the barrio who are 
not seasonal agricultural workers all earn cash incomes.

Economic Indices. There are five major incomeproducing activities in Suba: farming, animal raising, fishing, barter from household industry production and wage work. Each household seeks to maximize its economic security and prestige by involvement in one or more of these activities. Its activities are directly affected by its ties to other households and by its social ambitions. Thus, economic strategies are not solely a matter of economics; however, it is necessary to view them as a matter of economics here in order to cope with the topic at all.

The diversity of economic activity is a measure concerning farming and animal raising taken directly from the census sheets. The number of kinds of animals raised was added to the number of kinds of crops grown and of fruit trees raised. Some of the supplemental crops, animals and trees raised may have provided small cash incomes, but usually these items were consumed at home. Thus, economic diversity is an indirect measure of the diversity of the diet as we11. Table XLVIII shows the distribution of the diversity of economic activity for Suban households. The average diversity was just over 14 .

To a certain extent diversity measures the involvement of the household in farming and animal raising, with a lower number indicating less involvement in those activities. The index is also a rough measure of the relative poverty 
TABLE XLVIII

DIVERSITY OF ECONOMIC ACTIVITY.

AIONG SUBAN HOUSEHOLDS

Number of kinds of crops, animals and trees raised

$\begin{array}{rr}0-4 & 7 \\ 5-9 & 15 \\ 10-14 & 25 \\ 15-19 & 32 \\ 20-24 & 16 \\ 25-29 & 3 \\ \text { Total } & 98\end{array}$

Number of Households 7

15

25

32

16

3

$\underline{98}$

of those involved in farming, especially for households with a very low diversity rating.

Geertz (1971) has noticed a trend toward diversification and away from rice monoculture in Southeast Asia. While rice monoculture is still strong in central Luzon (Lewis 1971), it has not characterized Ilocos Norte for some time, if ever. Most households are involved in raising several types of foods, cash crops (sugar cane and Virginia tobacco - though production of these was rare in 1958), and animals.

The second major economic index is income. Three types of income were measured for each household: income in rice, income from barter, and income in cash. Income from farming is measured in cavans (100 lbs.) of unhusked 
rice (palay), clearly the most important crop grown.

Income from barter is indicated by economic participation in cottage industries where the goods produced are channeled into the market. Monetary income can be from fishing, wage employment, or from relatives who send money home. Whatever the source, the monetary income per month measures the average total monthly income.

Income figures were derived directly from the census sheets with no attempt at readjustment. Income expressed in cavans of rice was assumed correct, although in many cases it was not. Income from barter was recorded if household members regularly produced cottage industry goods for the market. Monetary income was taken as recorded, or as estimated if income from fishing was implied.

Tables XIIX, L, and LI show the distribution of rice income, barter income, and money income, respectively, for households in Suba. Reported incomes in rice are generally well below the survival needs of the average family of five, with the average reported income only 3.6 cavans. Subans were probably lying systematically about their rice incomes as well as using income from other sources to buy rice or sweet potatoes.

Barter was more important than Table LI indicates. Several people produced goods for barter occasionally, but not regularly enough to consider barter a part of their income for the purposes of this table. Also, as mentioned 
RICE INCOME PER YEAR IN CAVANS OF PALAY FOR SUBAN HOUSEHOLDS

Income

0

1

2

$3-4$

$5-6$

$7-8$

$9-10$

$11-14$

Unknown

Total
Number of Households

$$
4
$$

14

31

20

14

7

4

2

3

$\underline{99}$

\section{TABLE L}

AMOUNT OF INCOME DERIVED FROM BARTER BY SUBAN HOUSEHOLDS

Income

$\mathrm{A} 11$

Part

None

Unknown

Total
Number of Households

1

6

91

1

99 


\section{TABLE LI}

\section{MONETARY INCOME IN PESOS PER MONTH FOR SUBAN HOUSEHOLDS}

$\begin{array}{lc}\text { Income } & \text { Number of Households } \\ 70-4 & 48 \\ 5-9 & 11 \\ 10-14 & 10 \\ 15-19 & 4 \\ 20-24 & 7 \\ 25-39 & 6 \\ 40-59 & 5 \\ 60-99 & 4 \\ 100+ & 2 \\ \text { Some, amount unknown } & 2 \\ \text { Total } & \underline{99}\end{array}$

earlier, even if goods produced by households are not channeled into the market this production still contributes significantly to the economic status and strategy of the household.

Cash incomes vary widely from household to household, with the majority earning very little. Most cash income comes from fishing, although outside sources are very important for some households. One spinster was supported by two sisters in Manila. Families with large cash incomes are usually fairly well off and of larger average size than other households in Suba. Generally, they have a greater 
number of productive members involved in a greater number of economic activities. Anderson. (1972) has found that the range of annual cash earnings for Sisyano households varied from $\$ 30$ to $\not 1,000$. This range is roughly the same as for Suba, except that some households in Suba apparently have no cash income.

The final economic index is a direct measure of economic strategies. A computer analysis of the economic strategies of Suban households was developed using previously coded information. A household was said to be involved in fishing if it omed substantial fishing gear. A household was involved in farming if it had any coded tenancy status other than " 0 " (not a tenant, landlord or owner). If the family owned animals worth $\$ 200$ it was involved in the economic strategy of animal raising, since this figure probably implies that one of the major animals, a cow or water buffalo, was kept. Finally, the household was said to be involved in barter if there was any income from barter, as explained earlier. All possible combinations of the four alternatives were provided for in the computer program with an "other" category for households which did not meet any of the above criteria, such as the spinster being supported by her two sisters in Manila.

This index of economic strategies may have stretched the reliability of the census information beyond the point of reasonable results, but an effort is made nevertheless 
in the hope that future work in Suba and elsewhere can improve the quality and extent of the knowledge available on the economic activities of specific households and barrios.

Table LII shows the economic strategies used by Suban households. The average strategy in Suba involves two activities. Only twelve households are not involved in farming to a significant degree. Of these, the nine households not involved in fishing are very small and/or fairly poor. Of the fifteen possible strategies, only eight are pursued, and 74 of the 99 households are involved in just three of the strategies.

Reliability of Economic Information. Chapter II discusses the method by which a scale was developed to assess the reliability of the economic information provided by Suban informants. The results are shown in Table LIII.

Based on the numerical values assigned to each level of reliability in the coding system, the average of the reliability of economic information provided by Suban informants was 2.1, or "relatively reliable." As noted in Chapter II, the standard for judging reliability is not rigorous, especially since the Subans of 1958 had more animals, better housing, and higher monetary incomes than the households Lava studied in 1935.

Households reporting some monetary income tended to obtain higher ratings of reliability. This tendency suggests that the information was more accurately relayed by 
TABLE LII

ECONOMIC STRATEGIES OF

SUBAIT HOUSEHOLDS

Strategy.

Fishing

Farming

Animal Raising

Barter

Fishing \& Farming

Farming \& Animal Raising

Farming, Barter \& Animal Raising

Farming, Fishing \& Animal Raising

Other

Total
Number of Households

3

12

2

4

7

37

3

25

3

$\underline{99}$

\section{TABLE LIII}

RELIABILITY OF ECONOMIC INFORMATION

FOR SUBAN HOUSFHOLDS

Reliability

Number of Households

Unreliable

8

Relatively Unreliable

19

Relatively Reliable

22

Reliable

48

Unknown

2

Total

$\underline{99}$ 
informants or that the conversion of money into rice income was overly generous. Greater accuracy in reporting could be a result of greater awareness of the specific amount of cash received or of lesser fear of higher taxes if the income was reported accurately.

An independent check on the assessment of the accuracy of the information on rice incomes can be made by comparing average landholdings to average yields to figure the number of cavans of palay an average family should expect to harvest. Estimates for the yield of rice in cavans of palay per hectare for the Philippines vary from 15 to 50 (Grist 1959; USDA 1961; Lava 1938; Takahashi 1970). The figure given by the Philippine Department of Commerce and Industry (1966) is used here. The Department estimates the average yearly yield to be 27 cavans of palay per hectare. Yields in the Ilocos area are lower as a result of the varieties of rice used; however, more fields are irrigated so the average yield is probably not far from the national average. Even assuming the average holding in Suba to be one-half hectare the great majority of reported incomes fall below 10-15 cavans of palay, indicating lower yields or systematic underrepresentation of rice incomes, (See Table XIIX.) Even taking into account the landlord's share the reported incomes of tenants in cavans of palay are below the expected figures.

A thorough study of field sizes, average yields and 
incomes is needed to verify the yield of Suban riceland and to judge the accuracy of the reported incomes. In the only case where the exact size of a household's landholding was known, the household reported a yield of 8 cavans from 0.33 hectare, an estimate which reinforces many of my assumptions as to field sizes and yields. These data lend credence to the conclusion that other Subans are underreporting their.rice incomes. 


\section{CHAPTER IV \\ EVALUATION AND CONCLUSION}

\section{CENSUS-TAKING}

A thorough and useful census of small populations such as that of Suba should include information on all individuals in the population and information concerning each household. A format for recording the census data is not suggested here. A separate census sheet for each individual might be the most useful way to collect the data to avoid any possible confusion. Data for the household should be collected first. The name of each individual should be listed and his relationship to the househead and other members of the household should be recorded. In addition, the age, year of birth, sex, religion, place of origin; cause of immigration, time of immigration, occupation, place of work, past places of work, past occupations, times when the individual has worked out, money the individual has sent home, marital status, and education should be collected for each individual present. For females, the name, age and year of birth for each of her children should also be recorded. For those children who have.died and for the dead spouses of household members the cause of death, year of death, place of death and age 
at death should be collected. For children no longer in Suba the place of residence, time of emigration, cause of emigration, permanence of emigration, education and marital status at the time of emigration and at the time of the census should be listed. If the census-taker is particularly interested in migration, he might also record this information concerning other relatives who have left the area. In the instances where the informant is unsure of the information given, the census-taker should note that fact. Also, wherever possible the census-taker should endeavor to cross-check the information he has obtained with available records and through other informants.

For households, the sitio of residence, number of individuals; type of family, tenancy, land owned, fields worked, income from agriculture, income from other sources (which should be listed), type of land owned, house ownership, house construction, fishing gear owned, fishing lot membership, animals owned, value of animals, animal tenancy, crops grown and goods produced for barter and household consumption should be recorded. A schedule of income, expenses, and consumption for a substantial period of time, hopefully thirty days or more, would greatly add to the reliability of the household data. However, for a census of a population engaged in different economic activities from those prevalent in Suba, the appropriate economic information must be collected and the correspond- 
ing computer program modified accordingly.

These suggestions as to the kinds of data which should be collected by a census-taker do not extend much beyond the census material recorded by Scheans. The basic objective of the suggestions as they relate to information Scheans did not gather is to establish a time perspective by recording the dates of events wherever possible. Ideally, this objective is accomplished by taking censuses at regular intervals. Therefore, it is further suggested that a census of Suba be taken in the near future attempting to utilize the format recommended here.

It is also possible and perhaps desirable to use the method proposed in this thesis to develop a form for censustaking utilizing the coding devised for computer analysis. The census-taker could record the information only in coded form. As a safeguard, however, due to the probable need to alter the codes somewhat as the census progresses and after it is finished, and to enable subsequent analysts to deal with the raw data it is suggested that all of the raw data be recorded in longhand as well.

\section{COMPUTER ANALYSIS}

The basic analysis developed in this thesis can be applied with reasonable ease to censuses of other small populations. A rudimentary knowledge of FORTRAN IV is required, such as was acquired by the author in approxi- 
mately two months. Eventually, it may be possible to have the programs in a generalized form so that the insertion of a few specific cards, along with the basic data cards, will suffice to obtain an analysis of the population.

Use of the method insures greater comparability between analyses of future censuses by eliminating any variations which would result from the use of different methods. The method also provided a reasonably accurate and thorough analysis of the Suban population, despite the lack of some desirable information and the varying quality of the available data. Thus, the method provides a technique for salvaging data from earlier censuses taken without the benefit of a standardized format or where incomplete information is available.

III. THE SUBA PATTERN

The substantive findings allow a general pattern for Suba to be outlined. $\Lambda$ Compared to other barrios in the Philippines (Lewis 1972; Takahashi 1970; Anderson 1972; Nydeggers 1966) Suba has an older population and one with lower fertility. The religion of Subans fits Ilocos Norte patterns of 1958. Scheans (personal communication) has noted that since then the distribution of religions for Suba has changed somewhat. Most notable has been the appearance of some protestants.

Sitio differences in Suba are important socially and 
to a certain extent economically, but these differences do not achieve the level of significance found in Sisya by Anderson (1972). Sisya is much larger than Suba and of composite ethnic origin; both facts may help explain the differences between the two barrios.

There is no real data on the education of Subans. There is only the indication that some persons were attending school at the time of the census. It is by no means certain that all those attending school were indicated as doing so on the census sheets.

Marital and mortality data are poor. The growth rate for Suba is therefore subject to uncertainties from both sources. The factors which affect the growth rate are even less clear as..-Bènedict aptly remarked (1972).

Except under the harshest ecological and economic conditions, human beings do not regulate their populations in relation to the food supply, but in relation to the prestige supply. (Benedict 1972, p. 88)

Prestige in Suba is closely related to economic position and strategy. The interaction of social and economic factors is complex and pervasive in Suban society. Social structure has not been thoroughly examined here, but an understanding of it is essential to comprehend Suban economics. Strategies are diverse and varied. They center on the highly prestigious working of the land, which most households supplement with other activities. An in-depth study of several specific households would be 
very useful in gaining a deeper understanding of the nature of Suban social structure and economics and their interrelationships.

The economy of Suba is fairly representative of national trends, but it contrasts sharply with those of other specific barrios. On the other hand, the social and population structure of Suba is representative of provincial trands rather than national ones. Suba exhibits most of the distinctive features of Ilokano and Filipino barrios, but it has its own distinctive features as we11.

The distinctive features of Suba include an unusally high sex ratio in a province noted for low sex ratios. Like the province, but unlike the Philippines, Suba had moderate fertility levéls. Lower fertility was indicated by a low dependency ratio, a low percentage of children under 15, a median age almost five years higher than the national average, a lower number of children per evermarried female, a low fertility ratio, a slightly higher age at marriage, a greater number of adults who never marry and a provincial growth rate roughly half that of the nation. This lower fertility implies a lower growth rate also, but a good estimate will have to wait until the completion of another census within a reasonable time. The barrio was overwhelmingly Aglipayan in religion, but this pattern may be changing.

These conclusions should not be taken too literally. 
The data are not always clear or of good quality. It is hard to estimate trends from one-census and the small number of individuals involved creates uncertainty in the accuracy of many figures. In addition, Kunstadter (1972) has illustrated the importance of time perspective in popluation studies. Of the two Thai groups he compared the Karen seem to be more successful demographically. They are expanding the area they occupy and have a high growth rate. The Lua, however, have had a fairly steady population and occupied a more or less fixed area. These factors make it seem as though the Karen are more successful, but Kunstadter noted that the area available for expansion will soon be gone. When that happens he wonders which population will prove to be more successful demographically, implying that the Lua might well be since the Karen place a heavy emphasis on high fertility.

The economy of Suba lends the impression that stability exists and that there is a fairly favorable labor to resources ratio. The economy of Suba, with more resources than the average barrio, may have an attraction for males greater than the surrounding barrios. This differential could prove to be counter-productive given the high sex ratio among younger subans. It could lead to a high growth rate, seriously impairing the ability to make a reasonable living.

Suban households are based on an economy of rice 
farming. In addition, fishing, animal raising, gardening, supplementary crops, outside jobs and cottage industries play roles in the economic structure roughly in that order of importance. The diversity of crops, animals and trees raised is typical of the Ilocos area and much higher than other areas of the Philippines. Cash incomes are low, incomes in kind are slightly higher even though many persons refused to disclose their full rice income. The wealthiest families in the barrio have what at best can be called moderate incomes. Multiple involvement in the major economic strategies is the rule. The exceptions are likely to be small and poor households or ones with high cash incomes from some source. The reliability of the information given by households was questionable. Judged by starvations levels the information was only relatively reliable. Persons with cash incomes tended to be more reliable than those without. In any event, while Subans are better off than the Ilokanos Lava studied (1938), they still generally live in poverty.

According to Pascual (1966), patterns of migration in the Philippines may be changing. Subans find it difficult to make a living wherever they go, and fewer of them are choosing to migrate. Even in the 1920's it was probably inaccurate to speak of emigration from Suba because the average Suban left with the intention of returning. Since Suba was a fairly young barrio at that time relative- 
Iy fewer of its members sought to migrate. Most of those that did go have returned, improving their economic and social position considerably. However, since most Suban migrants have no special marketable skills there is decreasing incentive to migrate. Migration has become a strategy increasingly adopted by females. The effects of the large number of young females going to Manila are unclear. Perhaps many of the remaining young males will have to wait for brides, raising the age at marriage for one or both sexes. This factor may in turn lead to a smaller number of children per ever-married female, but the percentage of females who will ever marry may rise.

There are reasons for optimism and pessimism in Suba. The population has both the potential for rapid growth and for achieving some measure of control over the rate and pattern of growth. In either case, a new census should clarify some of the factors operating on the Suba population, both ones noted here and others. Certainly, a new census would correct many errors in this thesis and confirm many suspicions.

\section{RECOMMENDATIONS}

Since the computer programs must be altered somewhat whenever a different census is coded and analyzed, the task. would be best accomplished by persons who are familiar with the programs and with census analysis. For this 
reason, the method would be most useful if an organization is used or established whose members would perform this service. Such an organization might be called the "Center for the Study of Small Populations." It is also recommended that the possibility of obtaining funds to establish and maintain such a center from independent sources such as foundations be investigated.

With respect to the substantive findings presented in Chapter III, it is recommended that another census of Suba be taken. It would be useful to have more information on the spacing of children in Suba and the means by. which this is accomplished. The fertility of urban Ilokanos deserves study, as does the study of fertility levels in other specific Ilokano and Filipino barrios. Especially important in these studies would be an attempt to detail as precisely as possible the ways in which culture influences fertility. It would be very helpful to have accurate and detailed information on the fertility and mortality levels of the Philippines as a whole, but this requires reliable information on a local level as well.

Population changes in Suba deserve investigation,. which should be revealed through a new census, including changes in the dependency ratio, the sex ratio, religion, the growth rate and life expectancy. In addition, it would be useful to investigate the factors which influence the sex ratio. of a population. 
Even though Scheans collected no data on education it would be useful to have this information at the time of a second census. Since fairly good education figures for Paoay exist from the 1960 census this data can be used, as the basis for comparisons with the new census.

A thorough economic study of the barrio would be extremely useful, including a map of the barrio, an evaluation of the size and owner of each piece of Iand, and a study of the uses of the land. Studies of the value of the types of land and the history of land transfers are also recommended after the above information has been collected. Scheans has some of this information for Suba from tax records and certificates, but these records are inadequate for a thorough study. They indicate neither the size nor type of land, indicating only the tax registration number and the assessed value of the land.

A study of the relationships between economy, technology and social structure would be a difficult yet immensely significant task. Perhaps this task might be best accomplished by a study of several of the households in Suba, ensuring that households representing all of the basic economic strategies are included. A consumption study such as the one made by Lava (1938) would provide some much needed background for assessing the actual economic status of Subans.

Migration out of Suba to other places in the Philip- 
pines also deserves investigation.

Ultimately, the goal of any census method is to process information so that comparisons among populations can be made as easily and productively as possible. In order to realize the potential usefulness of this method it should be applied to as many censuses of small populations as possible. 


\section{SOURCES CONSULTED}

Anbenoja, Macrina K. 1976. Current Fertility in the Eastern Visayas: An Application of the "Own-Children-UnderFive" Method, Philippine Quarterly of Culture and Society 4:110-129.

Anderson, James N. 1969. Buy-and-Sell Economic Personalism: Foundations for Philippine Entrepreneurship. Asian Survey 9:641-668.

1972. Social Strategies in Population Change: Village Data From Central Luzon. SEADAG Papers on Problems of Development in Southeast Asia. New York, The Asia Society.

Barclay, George W. 1958. Techniques of Population Analysis. New York, John Wiley \& Sons.

Benedict, Burton. 1972. Social Regulation of Fertility. In G.A. Harrison and A.J. Boyce, eds., The Structure of Human Populations. Oxford, Clarendon Press. pp. 73-89.

Chaffee, Frederic H., et al. 1969. Area Handbook for the Philippines. Washington; D.C., U.S. Government Printing Office.

Chandrasekaran, C. 1966. Population Programmes in ECAFE Countries. In Population Institute, Philippines, First Conference on Population, 1965, pp. 37-54. Quezon City, University of Philippines Press.

Clarke, John I. 1972. Geographical Influences upon the Size, Distribution, and Growth of Human Populations. In G.A. Harrison and A.J. Boyce, eds., The Structure of Human Populations, pp. 17-31. Oxford, Clarendon Press.

Concepcion, Mercedes B. 1966a. Demographic Factors in Philippine Development. In Population Institute, Philippines, First Conference on Population, 1965, pp. 80-84. Quezon City, University of Philippines Press.

1966b. The Population of the Philippines. In Population Institute, Philippines, First Conference on Population, 1965, pp. 185-199. Quezon City, University of Philippines Press.

Dobby, E.H.G. 1951. Southeast Asia. New York, John Wiley \& Sons. 
Eggan, Fred. 1941. Some Aspects of Culture Change in the Northern Philippines. American Anthropologist 43:1118 .

- 1954. Social Anthropology and the Method of Controlled Comparison. American Anthropologist 56:743763.

. 1960. The Sagada Igorots of Northern Luzon. In George Peter Murdock, ed., Social Structure in Southeast Asia. New York, Viking Fund Publications in Anthropology, No. 29.

Espiritu, Socorro C. and Chester L. Hunt, eds. 1964. Social Foundations of Community Development. Manila, R.M. Garcia Publishing House.

Flieger, Wilhelm and Brigida Koppin. 1973. Births, Deaths, and Migration in the Eastern Visayas, 1971-72: Results of Two Years of Sample Registration. Philippine Quarterly of Culture and Society: 1:241-273.

Fonollera, Raymundo E. 1966. Labor Intensity in Philippine Agriculture. In Population Institute, Philippines, First Conference on Population, 1965, pp. 493-496. Quezon City, University of Philippines Press.

Food and Agricultural Organization of the United Nations. 1954. Rice and Rice Diets. FAO Nutritional Studies, No. 1. Rome, Italy.

Foster, George M. 1965. Peasant Society and the Image of the Limited Good. American Anthropologist 67:293-315.

Geertz, Clifford. 1971. Agricultural Involution: The Process of Ecological Change in Indonesia. Berkeley and Los Angeles, University of California Press.

Ginsburg, Norton, ed. 1958. The Pattern of Asia. Englewood Cliffs, New Jersey, Prentice-Hall.

Grist, D.H. 1959. Rice. 3rd ed. New York, John Wiley \& Sons.

Gutierrez, Jose S. 1966. Agricultural Productivity and Population Increase: The Philippine Case. In Population

Institute, Philippines, First Conference on Population, 1965, pp. 469-492. Quezon City, University of Philippines Press.

Hanks, Lucien M. 1972. Rice and Man, Agricultural Ecology in Southeast Asia. Chicago, Aldine, Atherton. 
Hardin, Garrett, ed. 1969. Population, Evolution, and Birth Control. San Francisco, W.E. Freeman and Company.

Harris Corporation. 1977. General Specification Harris Fortran Compiler. Fort Lauderdale.

Harrison, G.A. and A.J. Boyce, eds. 1972. The Structure of Human Populations. Oxford, Clarendon Press.

Hart, Donn V. 1965. From Pregnancy Through Birth in a Bisayan Filipino Village. In Southeast Asia Birth Customs, Three Studies in Human Reproduction. New Haven, HRAF Press.

- 1971. Philippine Rural-Urban Migration: A View from Caticugan, A Bisayan Village. Behavior Science Notes $6: 103-136$.

Hauser, Philip M. 1966a. Population and Economic Development. In Population Institute, Philippines, First Conference on Population, 1965, pp. 5-31. Quezon City, University of Philippines Press.

- 1966b. Research Problems in Demography. In Population Institute, Philippines, First Conference on Population, 1965 , pp. 128-137. Quezon City, University of Philippines Press.

Henson, Mariano A. 1948. Philippine Tables of Equivalents. San Fernando, Philippines, Ing Katiwala Press.

Hooley, Richard W. 1963. Saving in the Philippines 19511960. Quezon City, University of Philippines Press.

Huke, Robert E. 1963. Shadows on the Land: An Economic Geography of the Philippines. Manila, the Bookmark.

Hunt, Chester L., et al. 1963. Sociology in the Philippine Setting, revised edition. Quezon City, Phoenix Publishing House.

Keesing, Felix M. 1962. The Ethnohistory of Northern Luzon. Stanford, California, Stanford University Press.

Kim, Yun. 1972. Net Internal Migration in the Philippines, 1960-1970. Bureau of the Census and Statistics, Journal of Philippine Statistics 23(2):ix-xxvii.

Kroeber, A.L. 1928. Peoples of the Philippines. New York, American Museum of Natural History, Handbook Series, No. 8. 
Kunstadter, Peter. 1972. Demography, Ecology, Social Structure and Settlement Patterns. In G.A.' Harrison and A.J. Boyce, eds., The Structure of Human Populations, pp. 313-35i. Oxford, Clarendon Press.

Lasker, Bruno. 1931. Filipino Immigration to Continental United States and Hawaii. Chicago, University of Chicago Press.

Lava, Horacio. 1938. Levels of Living in the Ilocos Region. Institute of Pacific Relations, Philippine Council, Study No. 1 .

Leibenstein, Harvey. 1954. A Theory of Economic-Demographic Development. Princeton, New Jersey, Princeton University Press.

Lewis, Henry T. 1971. Ilocano Rice Farmers, A Comparative Study of Two Philippine Barrios. Honolulu, University of Hawaii Press.

$?$ - Unpublished, Migration in the Philippines: The Second Wave. Unpublished paper.

Lorimer, Frank. 1954. Culture and Human Fertility. Zurich, UNESCO.

1966. Analysis and Projections of the Population of the Philippines. In Population Institute, Philippines, First Conference on Population, 1965, pp. 200314. Quezon City, University of Philippines Press.

Louden, Robert K.. and George Ledin, Jr. 1972. Programming the IBM 1130. 2d ed. Englewood Cliffs, New Jersey, Prentice-HaII.

Luna, Telesforo W., Jr. 1966. The Land and Natural Resources of the Philippines. In Population Institute, Philippines, First Conference on Population, 1965, pp. 161184. Quezon City, University of Philippines Press.

Madigan, Francis C. and Rosalio 0. Avenceña. 1964. Philippine Fertility and Mortality with Special Reference to the North Mindinao Region: A Critique of Recent Estimates. Part I: The Philippines in General. Philippine Sociological Review 12:35-42.

Maring, Ester G. and Joel M. Maring. 1973. Historical and Cultural Dictionary of the Philippines. Metuchen, New Jersey, The Scarecrow Press. 
Moerman, Michael. 1968. Agricultural Change and Peasant Choice in a Thai Village. Berkeley and Los Angeles, University of California Press.

Nydegger, William F. and Corinne Nydegger. 1966. Tarong: An Ilocos Barrio in the Philippines. Volume VI of Beatrice B. Whiting, ed., Six Cultures - Studies in Child Rearing. New York, John Wiley \& Sons.

Pascual, Elvira M. 1966. Internal Migration in the Philippines. In Population Institute, Philippines, First Conference on Population, 1965, pp. 315-353. Quezon City, University of Philippines Press.

Phelan, John L. 1959. The Hispanization of the Philippines. Madison, Wisconsin, University of Wisconsin Press.

Philippine Delegation. 1965. Status of Manpower and Educational Planning in the Philippines. Philippine Journal of Public Administration $9: 128-144$.

Philippine Information Agency. 1955. The Philippines, a Handbook of Information. Manila.

Philippines, Bureau of the Census and Statistics. 1961. Census of the Philippines 1960, Volume I, Population and Housing. Report by Province, Nos. $21 \& 22$ (Ilocos Norte \& Ilocos Sur).

- 1972. Vital and Travel Statistics. Journal of Philippine Statistics 23(2):1-19.

Philippines, National Census and Statistics Office. 1974. 1970 Census of Population and Housing, Final Report, Volume I, Ilocos Norte.

- 19.75. Population Dimension of Planning III, Population Projections of Cities and Municipalities in the Philippines 1970-2000.

Philippines, Department of Commerce and Industry, 1966. The Philippines, A Handbook of Economic Facts and General Information. Research and Economic Division.

Philippines Free Press 49(5). (Saturday, February 1, 1958).

Population Institute, Philippines. 1966. First Conference on Population, 1965. Quezon City, University of Philippines Press.

Pratt, William F. 1966. Illustrative Projections of School Enrollment. In Population Institute, Philippines, 
First Conference on Population, 1965, pp. 389-422. Quezon City, University of Philippines Press.

Reyes, Wilfredo I. 1966. Philippine Population Growth and Health Development. In Population Institute, Philippines, First Conference on Population, 1965, pp. 423468. Quezon City, University of Philippines Press.

Rogers, Everett M. 1969. Modernization Among Peasant, The Impact of Communication. Chicago, Holt, Rinehart and Winston.

Romani, John H. 1956. The Philippine Barrio. The Far Eastern Quarterly 15:229-237.

Scheans, Daniel J. 1963. Suban Society. Philippine Sociological Review 11:216-235. 394-398.

1964. The Apayao of Ilocos Norte. Ethnology 11:

. 1965. The Ilocano: Marriage and the Land. Philippine Sociological Review 13:57-62.

. 1966. Anak Ti Digos, Ilokano Name Changing and Ritual Kinship. Philippine Sociological Review 14:8285 .

SEADAG Reports. 1972. Ad Hoc Population Seminar. Report of SEADAG Meeting, June 5-7, 1972, Washington, D.C.

Seng, You Poh. 1966. Some Aspects of the Determinants of Population Growth. In Population Institute, Philippines, First Conference on Population, 1965, pp. 5569. Quezon City, University of Philippines Press.

Simkins, Paul D. and Frederick L. Wernstedt. 1963. Growth and Internal Migrations of the Philippine Population, 1948 to 1960. Journal of Tropical Geography 17:197202.

Spencer, J.E. 1954. Land and People in the Philippines. Berkeley and Los Angeles, University of California Press.

Stycos, J. Mayone. 1955. Family and Fertility in Puerto Rico. New York, Columbia University Press.

- 1969. Problems of Fertility Control in Underdeveloped Areas. In Garrett Hardin, ed. Population, Evolution, and Birth Control pp. 316-334. San Francisco; W.E. Freeman. 
Takahashi, Akira. 1970. Land and Peasants in Central Luzon, Socio-Economic Structure of a Philippine Village. Honolulu, East-West Center Press.

Turnbu11, Colin M. 1972. Demography of Smal1-Scale Societies. In G.A. Harrison and A.J. Boyce, eds., The Structure of Human Populations, pp. 283-312. Oxford, Clarendon Press.

United Nations. 1950. The Philippines. In Economic Development in Selected Countries, Plans, Programmes, and Agencies, Volume II, pp. 143-180. New York, Department of Economic Affairs. New York.

1959. Demographic Yearbook 1958. Tenth Issue, - 1964a. Demographic Yearbook 1963. Fifteenth Issue. New York.

- 1964b. Report of the Asian Population Conference and Selected Papers. New York, Economic Commission for Asia and the Far East.

- 1967. Proceedings of the World Population Conference, Belgrade, 30 August-10 September 1965. New York, Department of Economic and Social Affairs.

. 1971. Demographic Yearbook 1970. Twenty-second Issue. New York.

- 1973a. Demographic Yearbook 1972. Twenty-fourth Issue. New York.

- 1973b. Statistical Yearbook 1972. Twenty-fourth Issue. New York.

United States, Bureau of the Census, 1905. Census of the Philippine Islands. Volume I. Washington, D.C., U.S . Government Printing Office.

United States, Department of Agriculture. 1961. The Philippines, Long-Term Projection of Supply of and Demand for Selected Agricultural Products. ERS-Foreign-34.

Vandoverbergh, Morice. 1956. Iloko-English Dictionary. Baguio, Philippines, Catholic School Press.

Weiss, Kenneth M. 1973. Demographic Models for Anthropology. Memoirs of the Society for American Archeology, No. 27; Issued as American Antiquity, 38(2,2). 
Wentworth, Edna Clark. 1941. Filipino Plantation Workers in Hawaii. Institute of Pacific Relations, American Council, Studies of the Pacific, No. 7.

Wernstedt, Frederick L. and Paul D. Simkins. 1965. Migrations and the Settlement of Mindinao. Journal of Asian Studies 25:83-103.

Wernstedt, Frederick L. and.J.E. Spencer. 1967. The Philippine Island World, A Physical, Cultural, and Regional Geography. Berkeley and Los Angeles, University of California Press. 
APPENDIX A

FORM OF CENSUS DATA SHEETS 


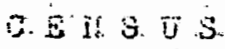

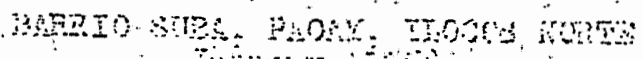

(9.9)

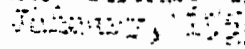

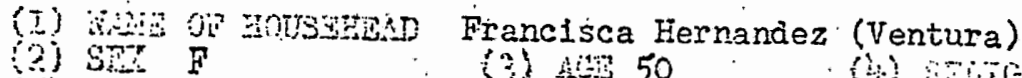

(i) Dinte $\mathrm{E}$

(3) 1950

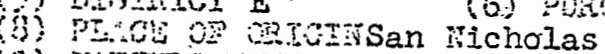

(1) $1 \mathrm{Nat} 70$ Dario

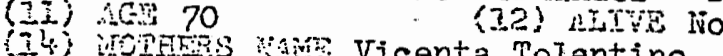

Hernandez - San Micholas

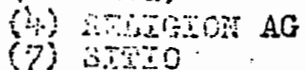

A. At? Yes

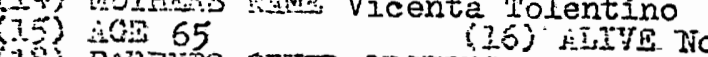

(18) PAPEMT ORES sporsis

(39) $\mathrm{HAS}$ (20) $\mathrm{ACE}$

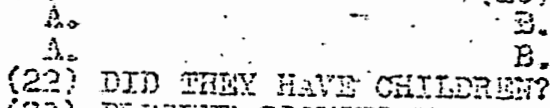

A) AEE (2I) ORETH

(23) cul old age

(23) PADSFit SPOTSE

(24) $0 \mathrm{~B} 45$ sous Mas Santiago Ventura COD Typhoid

(27) (25) ORIGIIS. Nich. (26) MAP TED BEFORP

Min

\section{* $* \mathrm{I} / \mathrm{H}$}

I. Mariano $V$.

2. Istrella V.

3:- Samso V.

*. Alberto $V$.

*5: Anacleto $v$.

6.

8.

90.

(23) Ompe STCU3is None
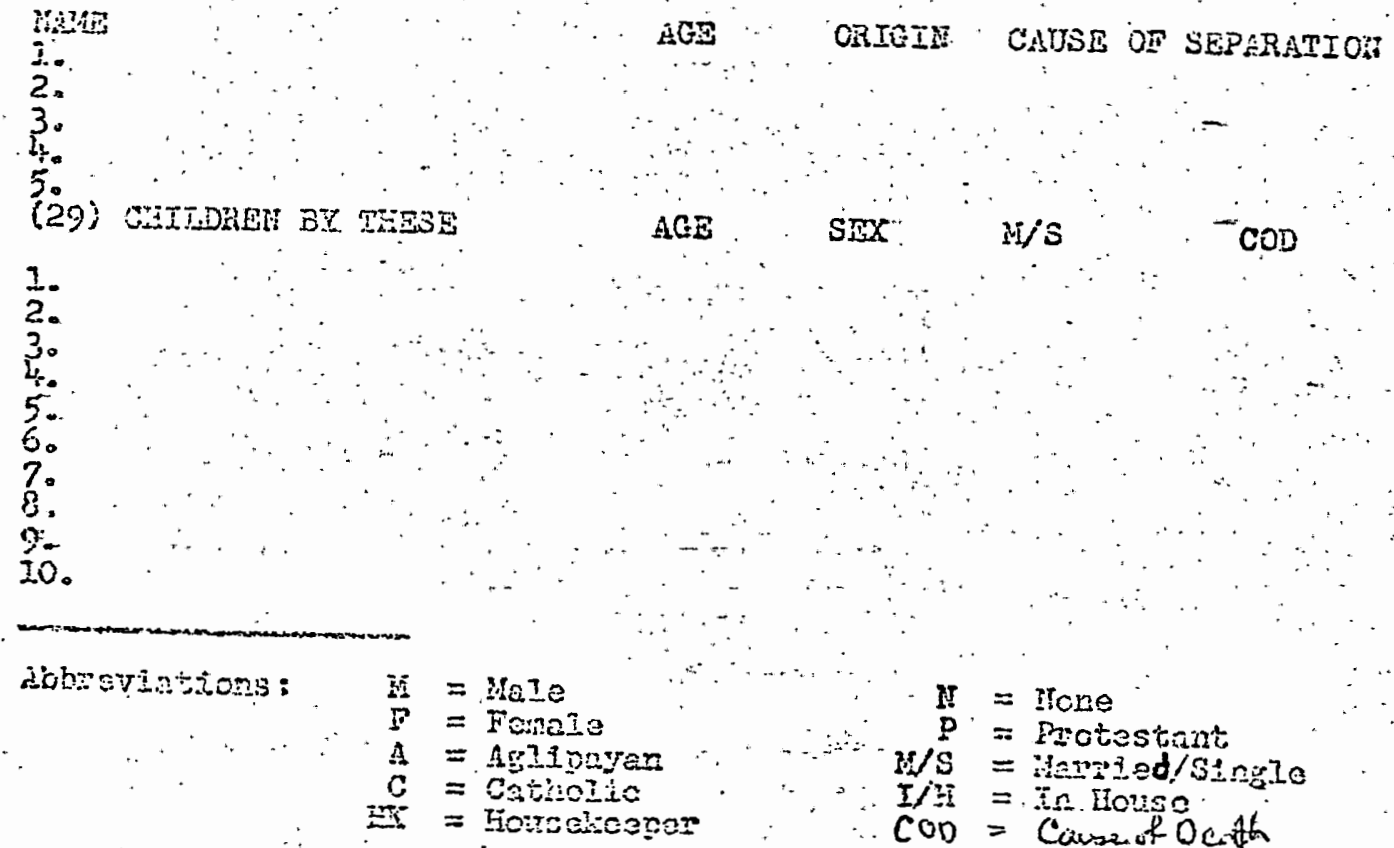

$A G S$

$\operatorname{Six}$

H/s

COD

$\begin{array}{ll}M & S \\ E & M \\ M & S \\ M & S\end{array}$

FWMALES. 
$2:$

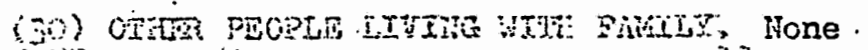

\section{:}

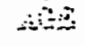

$x$

27

99

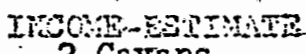

2 Cavans

(3i) OCOt? A2tois

A. FOUST HES HK

B. SFOUSE

C. OMDEns Sons - Iaborers

D.

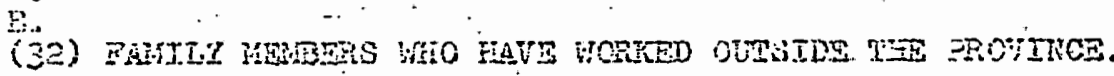

Sises

I. Alberto

2. inacieto

HiFig:

Tarlac

Tarlac

3

5.

(33) invos

S. Irriff. Rice

B. Unirrig. Fice

G. Dasture

B. Fopest

.. Pising Lot Member

AHONHT VALISE

House lot is

Euselio Tolentino's 3 ,

Tone

$1957-58$
$5=0$

1500 a veak

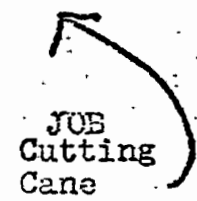

(35) CHOPS

Ho, of Pieids

inarlect

(36) Trass Etc.

UTIPS MARKET

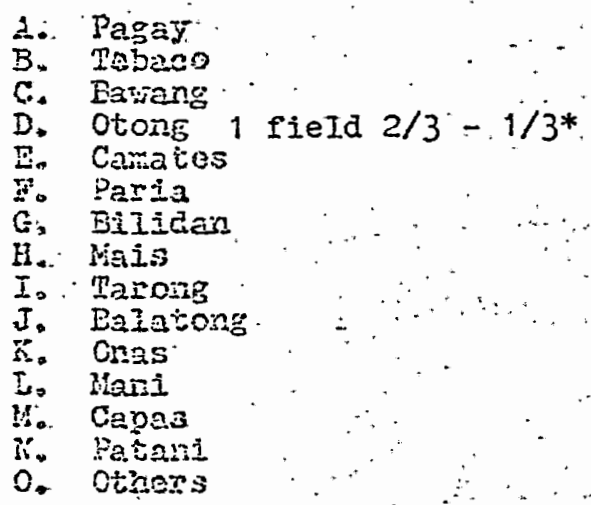

A. papza 1

B. Saita

C. Tias

D. Feciess 4

Ex. Maña

F. Coimeto

G. jegues

H., Buca

I.: Dalcair

J: Karmay

Ti. Gaúbana

I. Capasanglay

H. Otiners

IIJSBIS?

VAIIS

(37) AHINit:S

A. Tuen:

E. Daca 1 male - orm

C. Daboy 1 - own

+o. Calsine -

Iir jungk 4 hens, 1 rooster, 20 chicks

P. Dato

G. Turtri -

I. Aso

*Exsebio Tolentino 


\section{APPENDIX B \\ CODING SYSTEM FOR CENSUS \\ DATA CARDS}

The following system contains the key used to code the census data cards. The column number refers to the column on the data card in which the information described in the category was recorded.

$\begin{array}{lll}\text { Column } & \text { Category } & \text { Codes } \\ 1-2 & \text { Household Number } & 01-99 \\ 3-5 & \text { Individual Number } & 001-999 \\ 7 & \text { Sex } & \text { Male }=0 \\ & & \text { Female }=1 \\ 8 & \text { Life Condition } & \text { Alive }=0 \\ & & \text { Dead }=1 \\ 9-10 & \text { Age } & \text { Oo-98 } \\ & & \text { All over } 98=99 \\ 11 & \text { Religion } & \text { Aglipayan }=0 \\ & & \text { Protestant }=1 \\ 12-14 & \text { Year Born } & \text { Catholic }=2 \\ & & \text { Other }=3\end{array}$


Column Category

16

$17-18$

19

Whereabouts

20.

Sitio
Place of Origin$$
\text { Baay }
$$

Nanguudan

Dingras

San Nicholas

Calayab

Laoag

Nagbacalan

Paoay

Gabu

Batac

Hawaii

Kalayan

Balacad

Currimao

Unknown

Cagayan

In home

Not in home $=1$

In Province

$=0$

Out of Province $=1$ 
Column Category

21

22

23

$24-25$

Occupation when

worked out (if

another when home

26

Where work out

Where worked out

When migrated in
As Be

Cagayan $=1$

Manila $=2$

USA $=3$

Guam $=4$

Other $=5$

Codes

Seasonally out $=2$

Hawaii $=0$
Cagayan $=1$
Manila $=2$
USA $=3$
Guam $=4$
Other $=5$

Same codes as column 21

Never out $=6$

As child $=0$

Before marriage (as $=1$ single person)

At marriage $\quad=2$

After marriage (as $=3$ or with family)

After family grown $=4$

Unknown $=5$

Use code for 51-52 
Column

27

28

29

$30-31$

$32-33$

34 36-37

$38-39$

40-41 Nosology
Category

No. of times

married

No. of living

children

No. of dead

children

Age at first

birth

Age at most

recent birth
Codes

1-9

10 or more $=0$

$1-9$

10 or more $=0$

$1-9$

10 or more $=0$

00-98

Cannot be estimated $=99$

00-98

Cannot be estimated $=99$

No. of twin births $0-9$

Age at death

00-98

Over $98=99$

Year of death

Begin with $1859=00$

End with $1958=99$

Typhoid

$=00$

Malaria

$=01$

Burtong (smallpox) = 02

Leprosy

$=03$

Dysentary

$=04$

Bronchitis

$=05$

Influenza

$=06$

Tuberculosis

$=07$

Heart Attack

$=08$

Hemorrhage

$=09$ 


\section{Column Category}

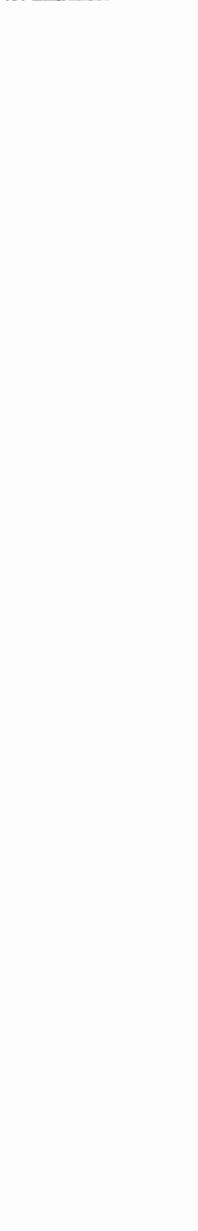

45

Status in House
Codes

\begin{tabular}{ll} 
Stomach Ache & $=11$ \\
Menstrual Trouble & $=12$ \\
Weakness & $=13$ \\
Stillbirth & $=14$ \\
War Nerves & $=15$ \\
Coughing & $=16$ \\
Appendicitis & $=17$ \\
Birth Difficulty & $=18$ \\
Headache & $=19$ \\
World War II & $=20$ \\
Accident & $=21$ \\
Drowning & $=22$ \\
Makadalapus (spirit- & \\
\multicolumn{1}{c}{ caused) } & $=23$ \\
Unknown & $=24$
\end{tabular}

Present in house

$=0$

In house, absent

$=1$

Present, non-relative $=2$.

Dead spouse of househead $=3$

Dead child of someone in

$$
\text { house }=4
$$

Relative not in house or province expected to support household $=5$ 
Column Category

47 Total Living in 1-9

House

48-49 Family Type
Codes

Emigrant child, not due to marriage $\quad=6$

Simple (nuclear) $=00$

00 with ascendant relatives:

$$
\begin{array}{ll}
\text { of husband } & =01 \\
\text { of wife } & =02
\end{array}
$$

00 with siblings:

$$
\begin{array}{ll}
\text { of husband } & =03 \\
\text { of wife } & =04
\end{array}
$$

00 with 1 distant relative $=05$

00 with 2 or more distant

$$
\text { relatives }=06
$$

00 with non-relatives $\quad=07$

00 with other relatives

$$
\text { and non-relatives }=08
$$

Joint (3 lineal genera- ,

$$
\text { tions) }=09
$$

Joint with 2 or more

$$
\text { married siblings } \quad=10
$$

Unmarried persons $\quad=11$

11 with relatives $\quad=12$

11 with relatives and non-

$$
\text { relatives }=13
$$


Column Category

51-52 Occupation
Codes

01 and 02

$=14$

03 and 04

$=15$

05 and 06

$=16$

01 or 02 and 03 or 04

$=17$

01 or 02 and 05 or 06

$=18$

03 or 04 and 05 or $06^{\circ}=19$

Farmer

$=00$

Housekeeper

$=01$

Laborer (sugar)

$=02$

Fishing

$=03$

Harvester

$=04$

Lavandera

$=05$

Salting

$=06$

Rice Planting

$=07$

Laborer

$=08$

Gardener

$=09$

Housegir1

$=10$

Waitress

$=11$

Tailor

$=12$

Irrigator

$=13$

Waiter

$=14$

Amah (Nanny)

$=15$

Carpenter

$=16$

Armed Services

$=17$

Weaving 
Column Category

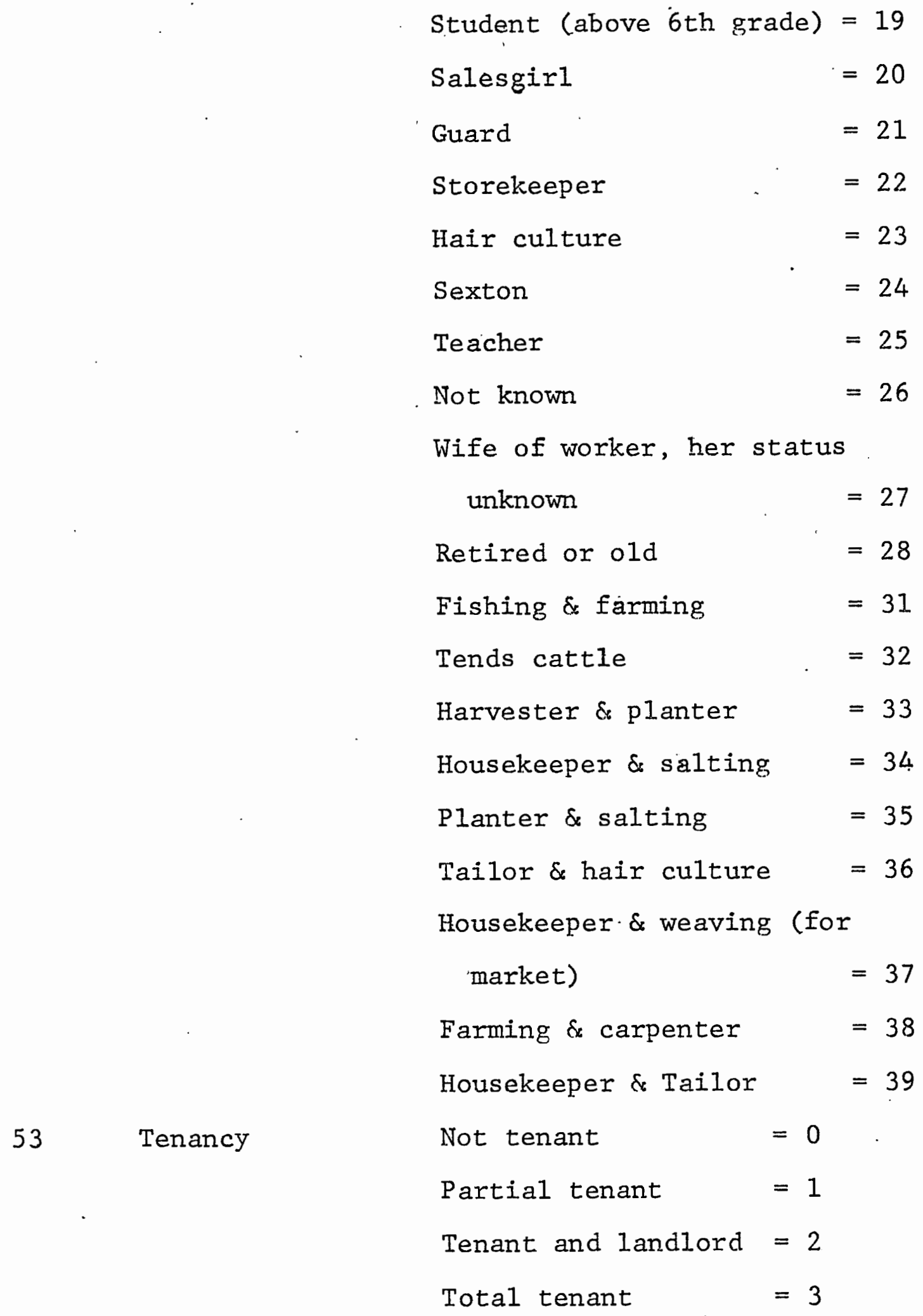


Column Category

54

56

57

58 .

$$
\begin{aligned}
& \text { Value of Fishing } 0-29=0 \\
& \text { Gear in Pesos } 30-59=1
\end{aligned}
$$

Fishing Gear

Owned

Type of House

Structure

$\begin{array}{ll}\text { Partial landlord } & =4 \\ \text { Total landlord } & =5 \\ \text { Part owner } & =6 \\ \text { Owner } & =7\end{array}$

Unknown

Cogon-siwali:

Wooden

$\begin{array}{ll}\text { small } & =1 \\ \text { average } & =2 \\ \text { large } & =3 \\ & =4\end{array}$

None $\quad=0$

Some $\quad=1$

Substantial $=2$

Income from Fish- Home use $=0$

$\begin{array}{lll}\text { ing in Pesos } & 0-4 & =1 \\ \text { per month } & 5-9 & =2 \\ & 10-14 & =3 \\ 15-19 & =4 \\ 20-24 & =5 \\ 25-29 & =6 \\ 30-39 & =7 \\ 40-49 & =8 \\ & \text { Over } 49 & =9\end{array}$


Column

59

61

62
Category

Fishing lot

membership

No $\quad=1$

Unknown $=2$

Codes

Yes $=0$

$$
\begin{array}{ll}
60-89 & =2 \\
90-119 & =3 \\
120-149 & =4 \\
150-199 & =5 \\
200-249 & =6 \\
250-299 & =7 \\
300-399 & =8 \\
\text { Over } 399 & =9
\end{array}
$$

Some, amount unknown $=0$

holdings in

$0-49$

$=1$

Pesos

$50-99$

$=2$

100-199

$=3$

200-299

$=4$

$300-499$

$=5$

500-999

$=6$

1000-1999

$=7$

2000-3999

$=8$

4000 and over

$=9$

Own

$=0$

Rent

$=1$

Tenant

$=2$

Unknown

$=3$ 
Column

$63-64$

66

$67-68$

69
Category

\section{Codes}

Relative's (no charge) $=4$

No. of Fields \& 00-98

Lots Owned (or Unknown $=99$

worked if can

expect to inherit)

Value of animials $0-99=0$

in Pesos

$$
\begin{aligned}
& 100-199=1 \\
& 200-299=2 \\
& 300-399=3 \\
& 400-499=4 \\
& 500-599=5 \\
& 600-699=6 \\
& 700-799=7 \\
& 800-899=8 \\
& \text { Over } 899=9
\end{aligned}
$$

No. of animals 00-98

Unknown $=99$

None

$=0$

Part, non-owner, under $1 / 2=1$

Part, non-owner, over $1 / 2=2$

Part, owner, under $1 / 2=3$

Part, owner, over $1 / 2=4$
A11
$=5$
Owner and non-owner
$=6$ 
Column Category $\underline{\text { Codes }}$

71-72 Diversity of Eco- 00-98

nomic activity Unknown $=99$

(no. of kinds of

trees, crops \&

animals raised)

73-74 Income in no. of 00-98

Cavans Unknown $=99$

75 Barter Activity. Yes, all income $=0$

Yes, part income $=1$

None $\quad=2$

Unknown $\quad=3$

76 Monetary income Some, amount unknown $=0$

in Pesos per $0-4=1$

Month

$5-9$

$=2$

$10-14$

$=3$

$15-19$

$=4$

$20-24$

$=5$

$25-39$

$=6$

$40-59$

$=7$

$60-99$

$=8$

Over 99

$=9$

77

Reliability of

Unreliable

$=0$

Economic Information

Relatively unreliable $=1$

Relatively reliable $=2$

Reliable

$=3$ 
Column Category
Codes

Unknown $=4$ 


\section{APPENDIX C}

\section{INFORMATION CODED FOR INDIVIDUALS}

Appendix C contains a printout of columns one through fifty-two for each of the 667 Suban census data cards . 
010010021093620100530211

0100210180939

0100300000957

0100401000

$0100401 \quad 956 \quad 01$

020051055090230000

0200601900

0200700390918

$02008 \quad 10350322$

.0200910350922

0201010040953

02011100209553000

$0201201 \quad 94200$

02013101309443000

02014001109463000

0301510500907

$0301601 \quad 905$

0301700170940

$04018 \quad 00400917$

0401910350722

$0402001 \quad 952$

$0402101 \quad 953$

0502210570900

0502300440913

0602410530904

$\begin{array}{llll}06025 & 01 & 934\end{array}$

0602601935

0602700180939

$05028 \quad 10150942$

0602900130944

0603010110946

0503110090948

0603210200937

0703300500907

0703410400917

0703500180939

0703600160941

0703710140943

$07038 \div 1945$

0903900320925

$08040 \quad 10330924$

0804100120945

0804200060951

0804310000957

$0904401 \quad 95400$

$090451065089210000 \quad 6^{218} \quad 28360$

$0904501 \quad 890 \quad 00$

0904710400917100006

09048101809391000

09049.10080949 .1000

10050105009071070063

$\begin{array}{llllll}10051 & 0.1 & 905 & 07 & 3\end{array}$

100520016094110702553
111116180

0

$005607 \quad 4$

0080901

$454700 \quad 3$

11

212120240

11231330 0

0

$004207 \quad 4$

$0 \quad 01$

01

21323330

0020018

$1 \quad 384320 \quad 3$

11

11230310 3

$01 \quad 04$

0020000

0101

015301

005301

4

0011101

0080031

01

01

104420

094420

4

4

01

31

01

01

01

01

$5 \quad 05$

0050032

0101

$01: 00$

01,19

01

004518

4

0050033

01.34

01

01

01

4

0041200

5040093

0

01

06

01

01

0031234

212120340

$1 \quad 505510^{\cdots} 3$

0

01

04 


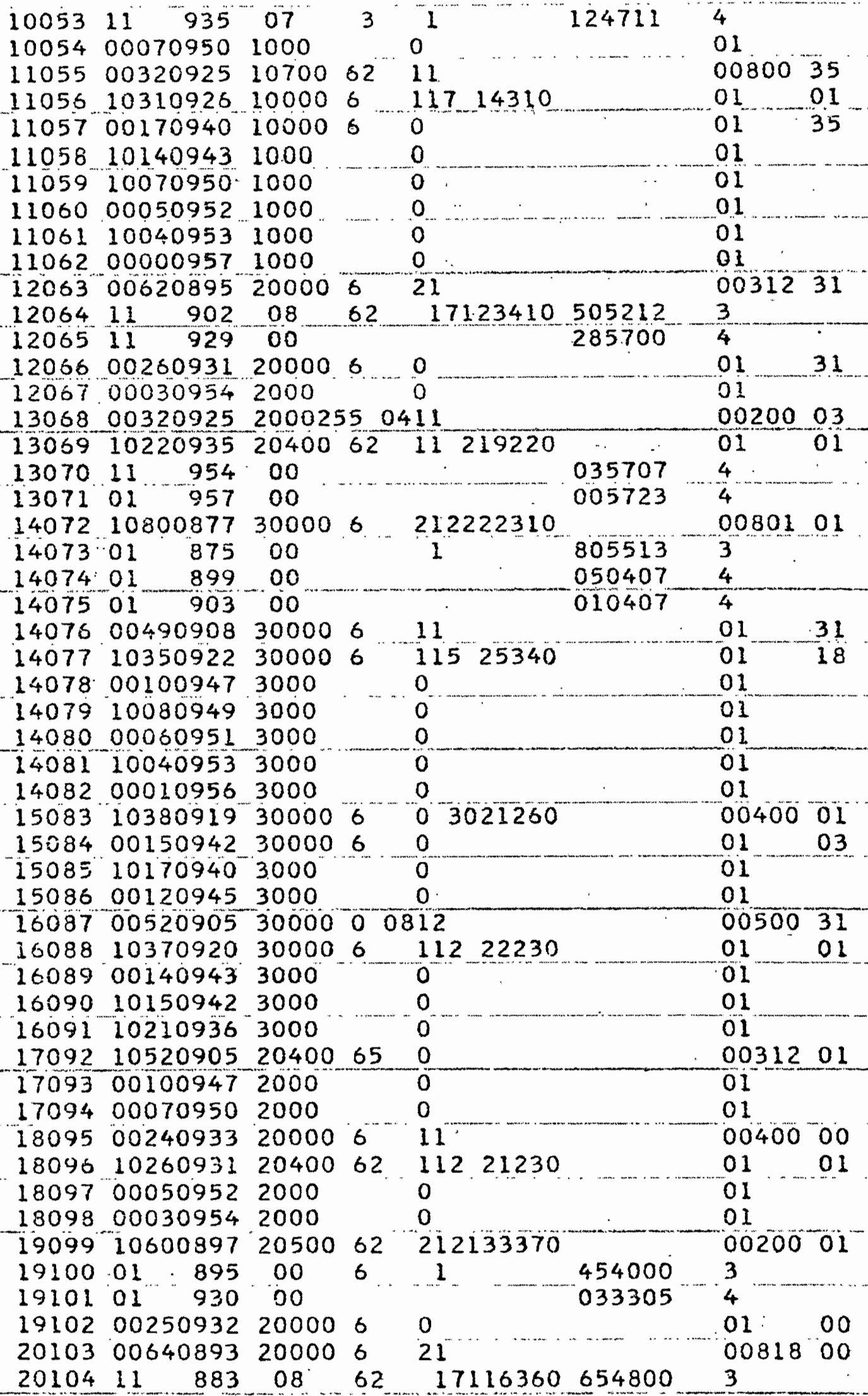


$2010510532899200006^{\cdots} 0$

$2010511 \quad 916 \quad 00$

20107007028872000060

$\begin{array}{llllll}20108 & 00302927 \quad 20000 & 6 & \text { II }\end{array}$

201090019293820000 s 0

2011010252932200006

$20111001429432000 \quad 0$

$20112000029572000 \ldots \ldots$

$2011300502907001130^{\cdots}$

$21114 \quad 00310926 \quad 20000 \quad 6 \quad 11$

$21115 \quad 102809292030062 \quad 11224250$

$\begin{array}{llll}21116 & 11 & 953 \quad 00\end{array}$

2111701.95400

$22118 \quad 00312926 \quad 20400 \quad 60 \quad 11$

$2211910242933200006 \quad 11317220$

$22120 \quad 10072950 \quad 2000$

22121000529522000

22122100229552000 0

1124240

152.

2312300480909200006

$23124 \quad 10450912200006$

2312500240933200006

0

0

$2312600190938200006 \quad 0$

23127001709402000

$\begin{array}{lll}23128 & 00140943 \quad 2000\end{array}$

23129001109462000

23130000809492000

241310047091010000

11

11621370

005407
005407

(100470

$24132 \quad 10330924 \quad 10500 \quad 62 \quad 114 \quad 25310$

24133100809491000

$2413400060951 \quad 1000$

24135000409531000

0

24136000209551000

2413700340923100006

$25138 \quad 00700887$

$251391183700^{\circ}$

251401190900

$2514111-90600$

$\begin{array}{llll}2514201 & 905 & 00\end{array}$

$2514311 \quad 904 \quad 00$

0

-

01

01

01

$01 \quad 00$

$01 \quad 31$

$01-26$

$01 \quad 27$

01

01

6 o8

$00200 \quad 00$

01 01

25144104509120000

2514510650892000006

25146001309440000

0

0080000

25147000409530000

$0 \quad 01$

$01 \quad 01$

$01 \quad 00$

$01 \quad 00$

01

01

01

01

0070300

$01 \quad 01$

01

01

01

0100

0050928

$2514800470910 \quad 001122 \quad 11$

$2614900280929000006 \cdots 11$

26150102809290000020511126260

$26151^{2} 0195500$

12

$271520038091930000 \quad 6 \quad 11$

$27153 \quad 1042091530000 \quad 6 \cdots \cdots \cdots 114125390$

$\begin{array}{ll}402708 & 3 \\ 031207 & 4 \\ 061207 & 4 \\ 071209 & 4 \\ 081207 & 4\end{array}$

11132320

27154001709403000060

$271.55 \quad 10140943 \quad 3000$

12

0

0

3

4

4

4

0101

$01 \quad 01$

01

01

1109

$00200 \% 00$

$01 \quad 01$

$27156 \quad 001009473000$

0

0

0070231

$01 \quad 01$

$01 \quad 31$

01

01 
$27157000509523000 \quad 0$

$\begin{array}{lllll}27158 & 01 & 954 & 00\end{array}$

2715910750882300006

2816000360921300006

2816110350922300006

$2816200070950 \quad 3000$

2816320050952.3000

28164000209553000

2916500440913300006

$29166 \quad 10380919300006$

$2916711 \quad 94200$

$2916800120945 \quad 3000$

29169101009473000

$29170 \quad 100609513000$

$29171 \quad 100309543000$

$3017200500907 \quad 30000$

301731045091230000 .

$\begin{array}{llll}30174 & 01 & 928 & 00\end{array}$

$3017500250932300006 \% 0$

$\begin{array}{lllll}30176 & 01 & 937 & 00\end{array}$

3017710150942001122

$30178 \quad 00170940 \quad 300006$

30179101009473000

$30180 \quad 10660891-30000$

$31181 \quad 10500907300006$

$\begin{array}{llll}31182 & 01 & 902 & 00\end{array}$

311831035092230000 क

3118400330924300006

$3218510300927 \quad 001133$

$31186 \quad 10280929 \quad 001122$

$\begin{array}{lllllll}3118701 & 93200\end{array}$

$3118800210936 \quad 300006$

$3118901 \quad 938$

$32190 \quad 10700887300006$

$\begin{array}{llllll}3219101 & 882 & 00 & 6\end{array}$

$32192 \quad 10550902 \quad 300006$

3219310430914300006

$32194 \quad 10390918 \quad 3001122$

$\begin{array}{lllllllllll}32195 & 01 & 921 & 00\end{array}$

$\begin{array}{llll}32196 & 01 & 924 & 00\end{array}$

32197103009273001122

3219800280929300006

$3219910250932 \quad 3000122$

3220000230934300006

3320100532904200006

$33202 \quad 104329142080062$

$3320300192938^{2} 200006$

$\begin{array}{llll}3320411 & 940 \quad 00\end{array}$

33205001629412000

33206001229452000

$\begin{array}{llll}33207 & 11 & 947 & 00\end{array}$

$3320811 \quad 949 \quad 00$

0

0

0

0

0

4

0
0

025607

21

11

11328330

11

114123350

0

$01 \quad 28$

0050031

0102

01

01

01

0060031

$01 \quad 01$

$\begin{array}{lll}1141233507 & 4 \\ 0 & 01\end{array}$

$0 \quad 01$

0 01

13

0060300

115216350 01:01

$0 \quad 144200 \quad \frac{4}{01} 00$

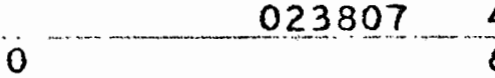

$\frac{4}{6}$

0

01

10

215215320

01

0101 $1 \quad 464800 \quad 3$
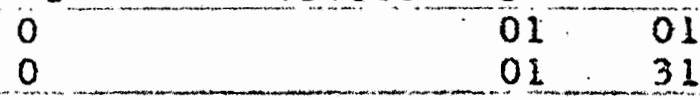

11

$11 \cdot 01$

0

$053707^{4}$

0

$6 \quad 11$

218215470

$1 \quad 705224$

0

0

$214207 \quad 6$

$204408 \quad 4$
-

$\begin{array}{lll}0 & 01 & 31\end{array}$

01

31

4

0050001

3

$01-01$

$01 \quad 18$

$6 \quad 01$

$\begin{array}{lll}0 & 11 & 36\end{array}$

$\begin{array}{lll}0 & 01 & 31\end{array}$

$11 \quad 0050000$

$114324350 \quad 01 \quad 01$

0100

$004014 \quad 4$

0

01

0

01

$004714^{-1}$

$004914 \quad 4$ 
$34209002909280080063 " 11$

$\begin{array}{lllllll}34210 & 10290928 & 00000 & 6 & 115.21290\end{array}$

$34211 \quad 10080949$

3421210060951

3421300040953

3421410020955

3421500000957

$34216 \quad 10190938$

3421700200937

35218

3521911910

3522000200937

3522100180939

$\begin{array}{lll}35222 & 11 & 941\end{array}$

3622300452912

$36224 \quad 10392918$

3622500272930

35226

36227

37228

37229

37230

3723110120945

3823200900867

3823310850872

3823411905

3823500540903100006 . 0

$\begin{array}{lll}38236 & 11 & 911\end{array}$

3823700230934

3923800550902

3923910400917

39240

39241

39242

39243

40244

40245

40246

40247

40248

40249

40250

40251

40252

40253

40254

41255

41256

41257

4125811

41259

41260

$0080 \quad 0 \quad 0$

$0080 \quad 0$

008000

$0000 \quad 0$

00800610

$10000 \quad 0 \quad 1321$

$1001122 \quad 0$

1000060

00

1000001311

1070062

001155

1000

0

0

0

1000060

100006

1000

1000 (

$100006 \quad 11$

00

1000060

$10000 \quad 0 \quad 0213$

0

1000

1000

0

1000

0

.........

0

$100006 \quad 11$

100006

001122

0

0012110

1000

0

0

11

0

0

0
$0080 \quad 0 \quad 0$

$08 \quad 62 \quad 12127310354515$

034407

11312260

$1070062 \quad 118229500$

$100006 \quad 11432380$

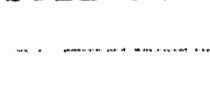

(……

010607

152607

$1050062 \quad 115 \quad 13180$

11319220
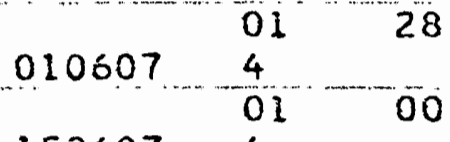

4

0100

0060000

01

01

01

01

01

0090938

$01 \quad 01$

0101

$6 \quad 05$

$5 \quad 04$

01

01

$01^{0} 0$

01

01

01

0070000

0101

$5 \quad 15$

0345114

01

01 
$4126110090948 \quad 1000 \quad 0$

$41262.000809491000 \quad \ldots$

$\begin{array}{llll}41263 & 01 & 952 & 00\end{array}$

41264000309541000

$422650035092210000 \% \quad 11$

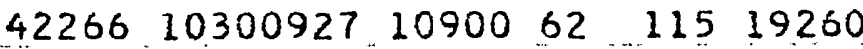

42267001109461000

$42268 \quad 100909481000$

42269000709501000

4227000050952.1000

42271000409531000

$432720056090110000 \quad 0 \quad 0211$

$432731054090310000 \% \quad 112117400$ $43274 \quad 01 \quad 920 \quad 00$

43275001409431000

$43270 \quad 0026093110000$

4327710240933

$43278 \quad 10030954$

4327910000957

$44280 \quad 00500907$

4428110350922

4428200200937

4423310180939

$44284 \quad 00120945$

$44285 \quad 10090948$

44286,10010956

4528700480909

$45288 \quad 10460911$

4528910250932

$45290 \quad 10240933$

100006

1000

1000

0

0

0

01

$005205^{\cdots}{ }_{4}^{01}$

01

4529110180939

$100006 \quad 12$

$1 1 2 \longdiv { 2 1 2 4 0 }$

0070000

$01 \cdot 01$

01

01

01

01

01

0070600

$01 \quad 34$

4529210150942

4529310120945

$45294 \quad 10090948$

4529500070950

$\begin{array}{lllll}10800 & 62 & 115 & 15340\end{array}$

$244420-\frac{4}{0}$

1000060

1000

0

1000

0

0

1000

1000

$100006 \quad 11$

01

01

01

01

$00700 \quad 38$

$01 \quad 01$

01

01

01

01

01

100006

001122

001122

001122

$110 \quad 18390$

0060000

100006

1000

5

0

0

0

1000

0

5

$5 \quad 10$

$5-10$

$01 \quad 34$

$4629600630894 \quad 100006 \quad 11$

4629710620895

$4629801 \quad 927$

46299 oi 930

$\begin{array}{llll}46300 & 11 & 931 & 00\end{array}$

463011193300

$4630200180939100006 \quad 0$

$\begin{array}{lllllllll}47303 & 00360921 & 10000 & 6 & 11\end{array}$

$47304 \quad 10340923$

47305001509421000

$\begin{array}{llll}47306 & 01 & 945 & 00\end{array}$

47307001009471000

0

01

01

$0-01$

$4730800070950 \quad 1000$

114417480

0030500

0101

47309100109561000

4831000420915200006

4831110400917200006

$48312 \quad 100609512000$

$\begin{array}{ll}174420 & 4 \\ 154520 & 4 \\ 134412 & 4 \\ 033604 & 4\end{array}$

$01 \quad 00$

0060000

0101

01

0

$014604 \quad 4$

01

01

01

11

11234360

$00400 \quad 00$

$01 \quad 39$

0

01 
$48313100409532000 \quad 0 \quad 01$ 49314002229352000050211

$\begin{array}{llllll}49315 & 102029372040062 & 11120200\end{array}$

0030031

$49316 \quad 100029572000 \quad 0$

0101

$5031700750882200006 \quad 21$

01

$50318 \quad 11 \quad 888 \quad 00$

\section{6}

0060500

5031900380919200006

$50320 \quad 00350922 \quad 20000 \quad 6 \quad 11$

50321003009272000060

$5032210550902 \quad 20000 \quad 6 \quad 0$

$5032310200937215006 \quad 1$

$\begin{array}{lllll}51324 & 10650892 \quad 20000 & 6 & 215220400\end{array}$

51325.01 .89000

110131

$11 \quad 01 \ldots 31$

$51326 \quad 1038091920000 \quad 6 \quad 0$

513270191200

$1473702 \quad 3$

$\begin{array}{lllll}51328 & 00420915 & 20000 \quad 6 & 0\end{array}$

$5132911 \quad 91700$

071902

$01 \quad 31$

$\begin{array}{lllll}51330 & 00380919 & 001122 & 1\end{array}$

51331103309242000060

51332.002509322000060

$5233300500907200006 \quad 11$

$52334 \quad 10280929 \quad 20500 \quad 62 \cdot 113 \quad 21280$

$52335000709502000 \quad 0$

$5233610010956 \quad 2000 \quad 0$

01

$5233700000957 \cdot 2000$

O

$01 \quad 01$

$\begin{array}{llllll}52338 & 10200937 & 20500 & 61 & 0\end{array}$

$5333910630894200006 \quad 219118371$

$021902 \quad 4$

$01 \quad 01$

$00500 \quad 01$

$\begin{array}{llll}53340 & 01 & 892 & 00\end{array}$

533411199200

$01 \quad 26$

4

$01 \quad 26$

$\begin{array}{lllll}5334200320925 & 200006 & 0\end{array}$

5334300300927200006

$1 \quad 635500 \quad 3$

$5334400280929200006 \quad 1$

$5334500260931200006 \ldots$

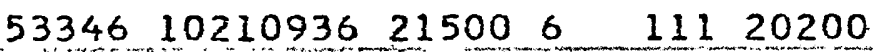

53347100109562000

0

$\begin{array}{llllll}54348 & 00340923 & 20000 & 6 & 11\end{array}$

54349102209352040062 iा 120200

$\begin{array}{llll}54350 & 01 & 955 & 00\end{array}$

$5535100330924200006 \quad 11$

$\begin{array}{llllll}55352 \quad 10240933 \quad 20400 \quad 62 & 114 & 17220\end{array}$

55353100709502000

55354000509522000

55355100409532000

$55356 \cdot 100209552000$

$56357003559221160062 \quad 11$

$\begin{array}{lllllll}56358 & 10335924 & 10000 & 6 & 115 & 25330\end{array}$

56359000659511000

193712

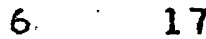

$01-01$

$01 \quad 00$

0060400

$01 \quad 01$

01

01

01

0101

0071701

56360000559521000

56361100359541000

56362000059571000

5736310630894200006

$\begin{array}{llll}57364 & 01 & 882 & 01\end{array}$

0

$\frac{3}{4}$

$01 \quad 31$

$01 \quad 31$

0131

$01 \quad 31$

$01 \quad 27$

01 -

0020031

$01 \quad 01$

4

0060031

0101

01

$\begin{array}{ll}0 & 01 \\ 0 & 01\end{array}$

01

0060035

0101

01

01

01

01

0021204

212222330 51

$604520 \quad 3$ 


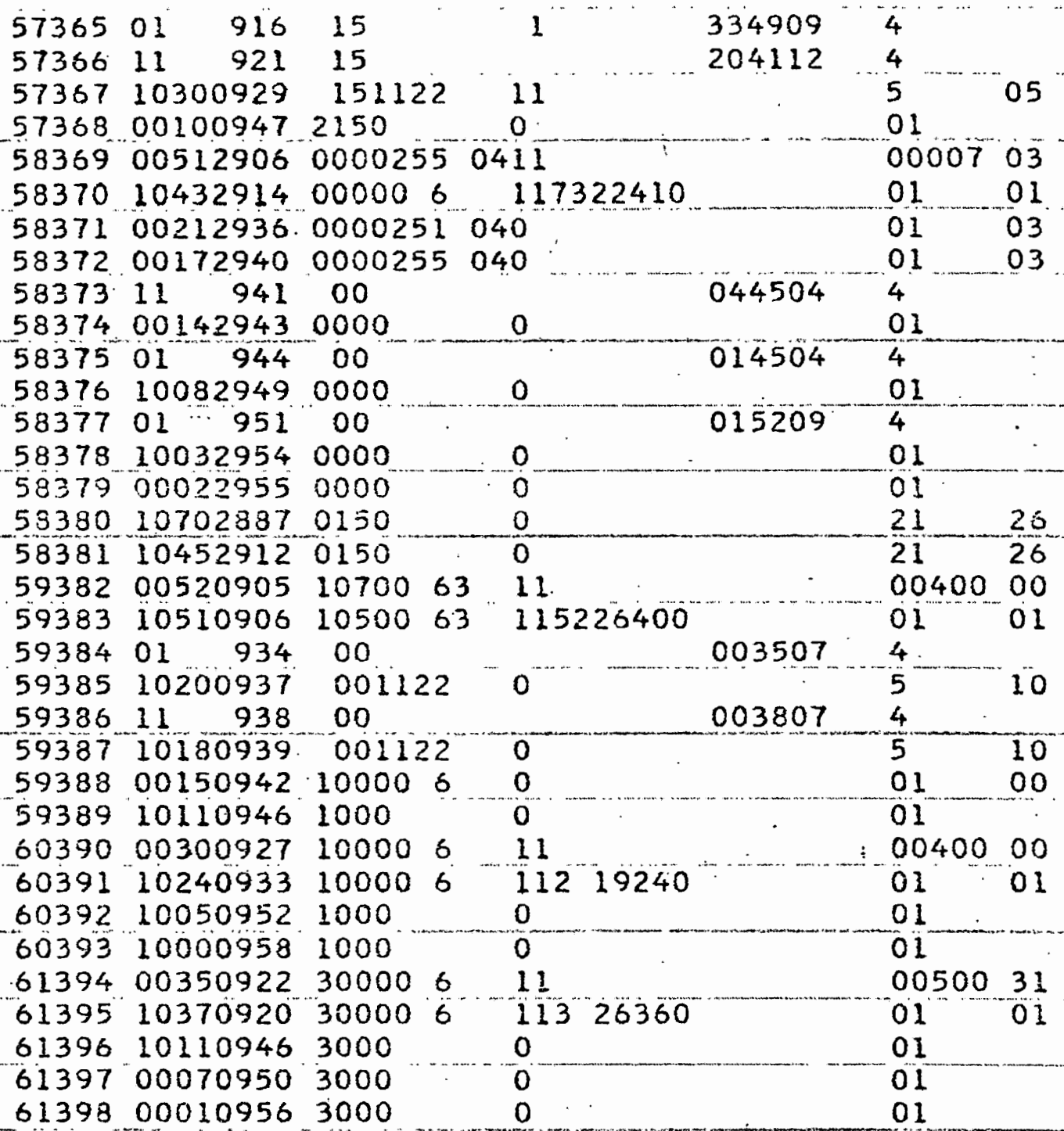

$62399107028873100062 \quad 21218220 \quad 0020001$ $\begin{array}{lllllll}62400 & 01 & 885 & 06 & 2 & 1 & 554007\end{array}$ $6240100522905001100 \quad 0 \quad \cdots \quad 68$ $\begin{array}{llllll}62402 & 10482909300006 & 311124270 & 01 & 01\end{array}$ $6240310212936001100 \quad 0 \quad 6019$ $6340400612896000006 \quad 21 \quad 00700 \quad 03$ $6340511 \quad 90400 \quad 16123390404404$ $\begin{array}{llll}63406 & 01 & 927 & 00\end{array}$ 63407002829290000211.040 $113821 \quad 4$

63408002629310000211040 63409002529320000211040 $63410 \quad 002329340000215040$ 63411001729400000211040 $63412.00142943000006 \quad 0$ $64413005109062040063 \ldots 11$ $64414 \quad 1058089920400 \quad 63 \quad 114333400$ $64415002509322040063 \quad 11$ $64416 \quad 10230934 \quad 0411223 \quad 0$ 


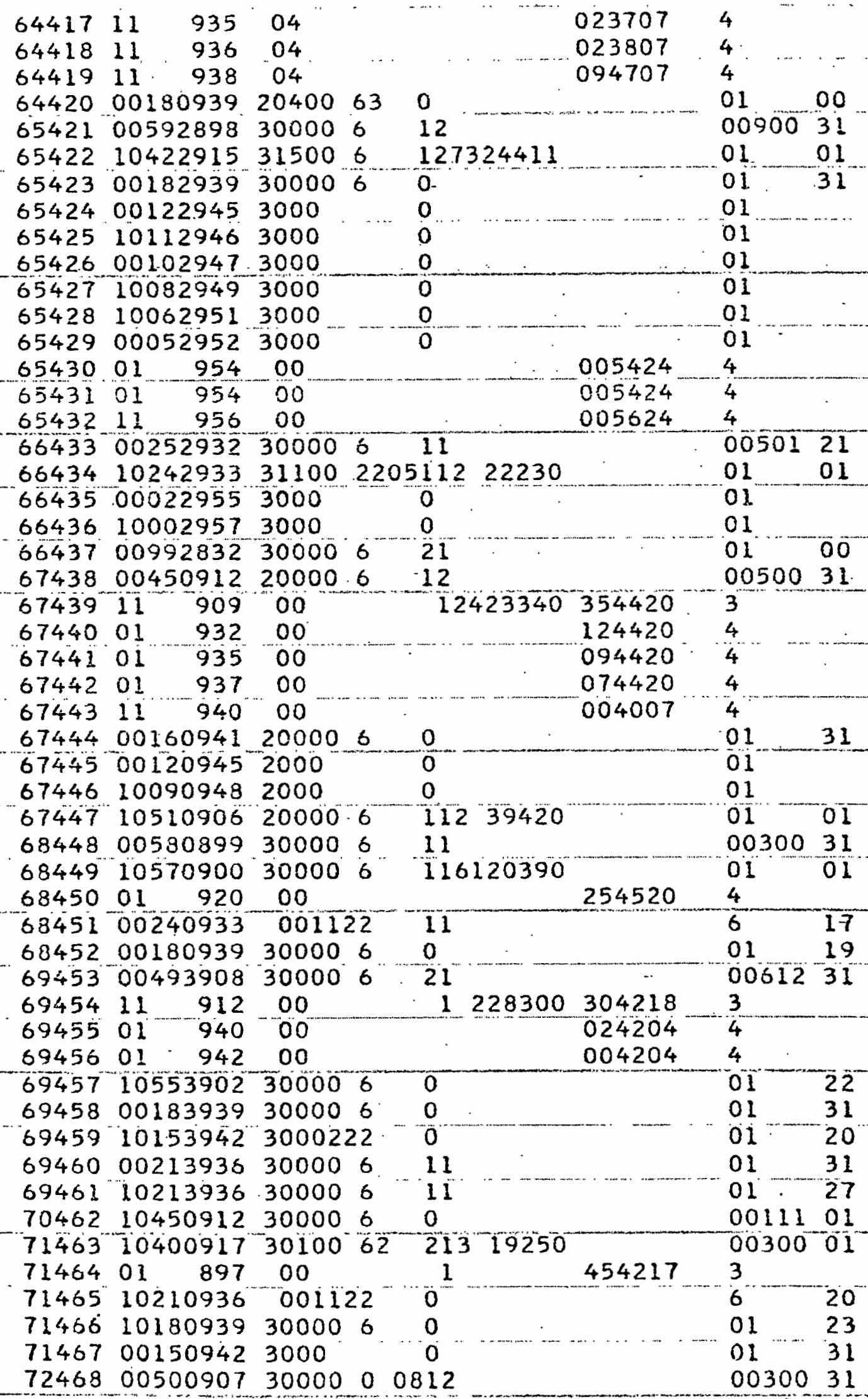


$7246910542903 \quad 31200 \quad 030511143430$

$\begin{array}{llllll}72470 & 00110946 & 3110 & 0 & 0\end{array}$

$\begin{array}{llllll}73471 & 00352922 & 30000 & 6 & 11\end{array}$

$\begin{array}{llllll}73472 & 10282929 & 30700 & 62 & 115118270\end{array}$

$7347311 \quad 94700$

73474000829493000

7347500052951.3000

$73476 \quad 10042953 \quad 3000$

$73477 \quad 100329543000$

73478000029573000

744790045291230000

$74480 \quad 10402917 \quad 30000$

744810020293730000

$\begin{array}{llll}74482 & 11 & 938 & 00\end{array}$

7448300182939300025080

$74484 \quad 10142943 \cdot 3000$

744850035292231500

7548600700887300006

7548710650892300006

7548800330924300006

$7548911 \cdot 930 \quad 00$

$75490 \quad 10240933 \quad 30000$

7549100140943300006

$\begin{array}{lllll}76492 & 10502907 & 30600 \quad 62 \ldots 317113300\end{array}$

$7649301 \quad 92700$

7649400262931300002244

7649500222935300006

$7649600202937 \quad 30000 \cdot 6 \quad 11$

76497102029373000021011120200

$76498 \quad 000029573000$

7649910182939300006

$77500 \quad 00440913300006$

7750110360921300006

$7750200120945 \quad 3000$

77503000909483000

77504000709503000

77505000009573000

785060041091630000

$78507 \quad 10240933300006$

$7850800040953 \quad 3000$

78509000009573000

$79510 \quad 0074088330000$

795111072088530000

$79512 \quad 1050090730000$

$\begin{array}{llll}79513 & 01 & 909^{\prime} 00\end{array}$

$7951501 \quad 91400$

$79516 \quad 0032092530000$

$79517 \quad 10290928 \quad 3001122$

$\begin{array}{llll}79518 & 01 & 930 & 00\end{array}$

$7951910140943 \quad 3000$

$79520 \quad 10300927300006$
004700

0101

01

0070031

$01 \quad 01$

4

01

01

01

01

01

0060731

0101

$01 \quad 31$

4

$01 \quad 31$

01

$21-25$

0050500

11

115121410

$01 \quad 01$

11

$01 \quad 31$

0

01

$00710 \quad 01$ $224907 \quad 4$

0131

$01 \quad 31$

$01 \quad 31$

$01 \quad 27$

01

0127

0060031

$11424350 \quad 0060031$

0

0

01

0

01

01

0 01

110040031

$11220240 \quad 01 \quad 01$

$0 \quad 01$

0001

11

0000931

117322450

$01 \quad 01$

$01 \quad 01$

4

$01 \quad 01$

11

284200

4

0131

$11 \quad 20$

$124200 \ldots 4$

$0 \quad 01$

11324300 
$79521 \quad 100609513000 \quad 0$

7952200040953

7952300000958

8052400380919

8052510400917

$80526 \quad 10080949$

8052710070950

8052800050952

8052910010956

8053010180939

8153110800877

$\begin{array}{llll}81532 & 01 & 875\end{array}$

8153310520905

81534.10500907

8153510480919

$\begin{array}{lllll}81536 & 01 \quad 914 & 00\end{array}$

81537003009273000060

$\begin{array}{lllll}82538 & 00575900 & 20000 & 6 & 11\end{array}$

$825391070588720200 \quad 62 \quad 11633550$

8254000195938

8254110155942

8354200590898

8354310560901

8354400370920

8354500350922

8354600300928

$83.54701 \quad 930$

$83548 \quad 10070950$

8454900470910

8455010470910

8455110180939

8455200150942

$8455301 \quad 945$

8455400090948

8455500090948

8455600050952

8555710340923

8555800360921

8555900120945

8556010020956

8656100530904

8656210450912

8656310220935

8656411937

8656510180939

8656600160941

8656711944

$8656800100947 \quad 1000$

8656901 ' $948^{\prime \prime} 00$

$86570 \quad 000709501000$

86571000609511000

86572100209551000

$001100 \quad 11$

00

0

0012110

00 $001122-0$

00

1000060

0

0
001

01

01

0070531

$01 \quad 01$

01

01

01

01

$11 \quad 01$

0050001

3

$\begin{array}{ll}01 & 01 \\ 01 & 01 \\ 01 & 01\end{array}$

$001407 \quad 4$

0131

0040031

$01 \quad 01$

0131

$01 \quad 20$

0030500

$01 \quad 01$

$6 \quad 08$

$6 \quad 08$

003007

$6 \quad 19$

01

0060000

0101

$5 \quad 01$

004514

$11 \quad 04$

01

01

01

0030001

1108

$01 \quad 19$

01

0080000

$\begin{array}{llll}100006 & 118321430 & 01 & 01\end{array}$

$5 \quad 05$

$003707 \quad 4$

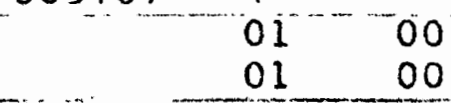

$014507-4$

01

004807

01

01

01 
$87573 \quad 10530904200006 \quad 21131310$

$\begin{array}{llllllll}8757.4 & 01 & 901 & 06 & 2 & 1 & \ldots & 545\end{array}$

$8757510220935001122 \quad 0$

$88576 \quad 0036092120000 \quad 6 \quad 11$

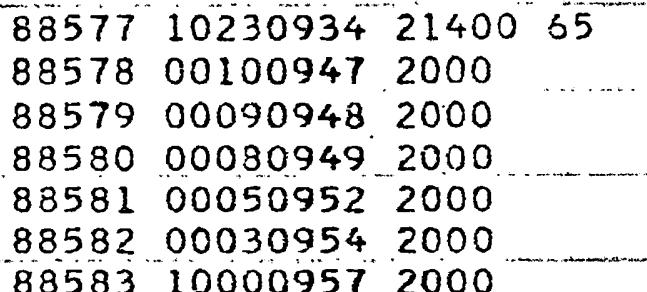

$\begin{array}{lllll}88583 & 10000957 & 2000 & 0 \\ 89584 & 00352922 & 20000 & 6 & 11\end{array}$

89585102529322140062

$89586 \quad 100429532000$

89587100129562000

$90538 \quad 00652892 \quad 20000$

$9058910602897200006 \quad 113119250$

$90590 \quad 11 \quad 916 \quad 00$

9059110372920

9159200680889

9159310470910 $20000 \cdot 6-0$

$91594 \quad 11 \quad 894$

$9159511 \quad 915$

9159600350922

9159.700320925

$9159801 \quad 926$

$9159911 \quad 931$

07

$91600 \quad 11 \quad 932 \quad 00$

$9160100200937000006^{0}$

$9160211 \quad 926 \quad 00$

916031193400

91604101409430000

92605002959280001144

$92606 \quad 10315926$

9260700145943

9260800095948

9260900075950

9261010055952

$9261110155942000006 \quad 11$

$93612007008872040062 \quad 11$

$9361310600897200006 \quad 117115350$

$\begin{array}{llll}93614 & 01 & 912 & 00\end{array}$

$936151042091520000 \% 0$

9361600350922200006

9361710320925

001122

$93618 \quad 10270930$

001122

9361910250932

001122

$93620 \quad 10950862200006$

9362110650892200006

9362210470910200006

9362310450912200006

.93624100509522000

0

0

0

0011101

161

5455083

5

0080031

0101

01

01

01

01

01

01

0040031

$01 \quad 01$

01

01

$00300 \quad 31$

4

0101

$00405 \quad 38$

01 ol

$18228380 \quad 595300-3$
$1-305500-3$

$11 \quad 608$

$0 \quad 6 \quad 08$

$255100 \quad 4$

$174800-4$

$073904 \quad 4$

$01 \quad 00$

$002607-4$

1101

$11-1070516$

$11417260 \quad 01 \quad 01$

0 01

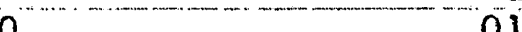

01

10101

0091900

$01 \quad 01$

$001307 \quad 4$

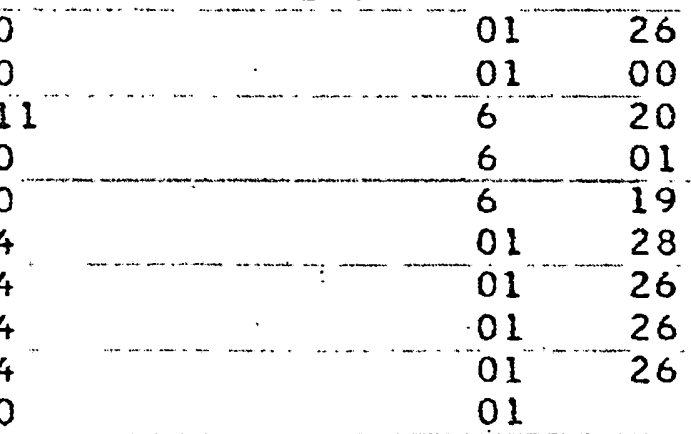


9462500440913200006

9462610390918200006

94627000209552000

9562800400917200006

$9562910370920 \quad 200006$

9563000300927215006

95631000109562000

$\begin{array}{lllll}95632 & 01 & 957 & 00\end{array}$

96663005509022000000811

$96634 \quad 10450912 \quad 20800 \quad 62 \quad 118 \quad 23410$

9663500270930200006

96636002209352000060

96637002109362000060

$9663800190938200006 \quad 0$

96639101809392000

$95040 \quad 10170940 \quad 2000$

96541101509422000

96642101309442000

96643000409532000

9764400350922

9764510280929

9764600070950

9764700050951

$98648 \quad 00700887$

$98649 \cdot 10750882$

$98650 \quad 00500907$

9865101010

9865200450912

9865310420915

9865411919

9865510300927

9865610290928

9865710270930

$98658 \quad 10140943$

9865900120945

9866000120945

98661 00120945 2000

98662100609512000

9866310050952.2000

$99664 \quad 10500907$

9966501905

9966600250932

9966700220935
11

$113 \quad 32370$

0

0

111136370

11

0

0

0

0

0

0

005707.4

0030000

$01 \ldots 01$

01

0051200

$01 \quad 01$

$01 \quad 00$

01

0000000

$01 \quad 01$

$01 \quad 25$

$01 \quad 00$

01.00

$01 \quad 00$

01

01

01

01

al

0040031

$01 \quad 01$

01

01

0000900

0101

$6 \quad 08$

$01 \quad 31$

$01 \quad 01$

4

$6 \quad 11$

$01 \quad 27$

$6 \quad 20$

01

01

01

01

01

01

0030001

3

$01 \quad 02$

$01-02$ 


\section{APPENDIX D}

\section{INFORMATION CODED FOR HOUSEHOLDS}

Appendix $D$ contains a printout of columns fiftythree through seventy-seven for each of the ninety-nine census data cards with information on Suban househoids. 
$\begin{array}{llllll}30 & 1000 \quad 1300 \quad 2041 & 0803212\end{array}$

$112640 \quad 2003 \quad 3170 \quad 1502263$

$01001100 \quad 1042 \quad 0301210$

$\begin{array}{llll}32 & 0 & 1 & 200 \quad 2090 \quad 1602212\end{array}$

$\begin{array}{lllllllllll}23 & 0 & 1 & 100 & 0050 & 0401212\end{array}$

$\begin{array}{llllll}30 & 2200 & 200 & 5201 & 2302221\end{array}$

$01 \quad 1000 \quad 04995192 \quad 0613213$

$\begin{array}{lllllll}01 & 0 & 1 & 100 & 0052 & 0601111\end{array}$

$00011000 \quad 1076 \quad 1402122$

0100140000150204043

0101140001020705111

$\begin{array}{lllll}30 & 2310 & 000 & 2040 & 0902233\end{array}$

$\begin{array}{llllll}00 & 2540 & 100 & 00 & 0001253\end{array}$

$73 \quad 2200 \quad 3013 \quad 4090 \quad 1602221$

$142540 \quad 0099 \quad 4100 \quad 2102253$

$\begin{array}{lllll}40 \quad 1 & 0 & 0099 & 0070 & 9999204\end{array}$

6301210100541000273

$\begin{array}{llllll}61 & 0 & 1 & 409 & 4160 & 1502211\end{array}$

70000000913101502212

43000501173012605211

$600 \quad 160126380 \quad 1304213$

$\begin{array}{llllll}30 & 2010 & 200 & 3151 & 1902210\end{array}$

1001601892712210212

$13013006 \quad 6330 \quad 1607213$

$\begin{array}{lllllllllll}00 & 0 & 1 & 100 & 2051 & 0900232\end{array}$

$30011200 \quad 4231 \quad 1002211$

$102310 \quad 00045190 \quad 1602232$

$112100 \quad 0001 \quad 6200 \quad 1301210$

$442530 \quad 10074070 \quad 1702253$

$10 \quad 1420 \quad 4006 \quad 3101 \quad 2001243$

$10 " 1540200271001902253$

$\begin{array}{llllll}72 & 2950 & 5007 & 9140 & 2403283\end{array}$

$301002 \quad 0085110 \quad 2402211$

$\begin{array}{llllll}60 & 2970 & 101 & 0221 & 0400293\end{array}$

701000500831321602212

$74 \quad 1000 \quad 6013 \quad 3080 \quad 1706213$

$70 \quad 1000 \quad 609920631404212$

$\begin{array}{lllll}10 & 1000 & 0099 & 3091 & 1302211\end{array}$

$\begin{array}{llllll}72 & 0 & 1 & 6016 & 8330 \quad 1706212\end{array}$

$10 \quad 1000 \quad 3003 \quad 0122 \quad 0804210$

$70 \quad 10001012 \quad 4140 \quad 1408263$

$70 \quad 1000 \quad 3005.1151 \quad 1102211$

$141000 \quad 50024083 \quad 1209113$

$12 \quad 1000 \quad 2002 \quad 3051 \quad 1302211$

$101000 \quad 40034060 \quad 1402133$

$\begin{array}{llllll}74 & 0 & 1 & 6011 & 2093 & 1506213\end{array}$

$600012005 \quad 3111 \quad 1705211$

$\begin{array}{lllllll}60 & 0 & 1 & 0409 & 4180 & 2105213\end{array}$

$\begin{array}{lllllll}31 & 1200 & 200 & 0072 & 0505223\end{array}$

$\begin{array}{lllll}33 & 1000 & 200 & 5141 & 2208212\end{array}$

$\begin{array}{llllll}33 & 0 & 1 & 200 & 9261 & 1603311\end{array}$

$\begin{array}{llllll}31 & 0 & 1 & 200 \quad 4090 \quad 1802210\end{array}$ 
$7329802005 \quad 8110 \quad 1704283$

$60 \quad 2200 \quad 0499 \quad 1050 \quad 1002223$

$612312 \quad 0404 \quad 1222 \quad 1403233$

50001319900420402210

$0101100 \quad 100420701211$

$002750 \quad 100 \quad 01121004263$

101000600251101307223

$610 \quad 1 \quad 2405 \quad 22321603211$

$112202 \quad 200.7190 .1501221$

54.0 1 0.004.11901102263

$032990 \quad 10012100606283$

$300: 1 \quad 200 \quad 4340.1702223$

7025306004924011703253

$62 \quad 2192 \quad 009910301299283$

$10231042018170 \quad 2008233$

$20 \quad 1000.0002 \quad 2040 \quad 1204202$

432990501252531506273

$510 \quad 1300100500801212$

$412320 \quad 5007 \quad 4190 \quad 0802273$

$74 \quad 2960 \quad 7005 \quad 6210 \quad 1805273$

$301000 \quad 20071001704211$

$10 \quad 2990 \quad 4014 \quad 7110 \quad 2004293$

122750501010932003263

$\begin{array}{llllll}30 & 2542 & 200 & 4431 & 1002253\end{array}$

$1223100402 \quad 3140 \quad 1504233$

$1010001004 \quad 10401002210$

$70 \begin{array}{lllllll}7280 & 7015 & 7360 & 2209222\end{array}$

$6223100005 \quad 51701502232$

$332420 \quad 0004103 \quad 1703243$

$\begin{array}{lllll}30 & 2422 & 200 & 2163 & 2702243\end{array}$

741000601361501108113

$\begin{array}{lllllll}74 & 1000 & 6010 & 4331 & 1306212\end{array}$

$54^{\circ} 01500200340406213$

$73 \quad 1000 \quad 6010.8120 \quad 1408212$

00011.10000700700253

$312310 \quad 200 \quad 0082 \quad 1101231$

$312310 \quad 200 \cdot 1062 \cdot 1601232$

$302210 \quad 200-1052 \cdots 1501222$

300120021421501222

$332100 \quad 200 \quad 9650 \quad 2604211$

$300 \quad 1 \quad 20064812005213$

$\begin{array}{llllll}630 & 1 & 0418 & 9390 & 2114213\end{array}$

$7001 \% 601594102110212$

$30 \quad 1000 \quad 000 \quad 20701999214$

$331000 \quad 200 \quad 6110 \quad 2203210$

$30 \quad 1000 \quad 200 \quad 2270-0602263$ 